\title{
España en la Universidad de Bolonia: vida académica y comunidad nacional (siglos XIII-XIV) $^{*}$
}

\author{
Pascual TAMBurRI Bariain**
}

\begin{abstract}
RESUMEN
Ha primado, en el estudio de las Universidades medievales, el atractivo de la historia institucional sobre el indudable interés de la vida, inquietudes y perspectivas de los estudiantes mismos. Bolonia posee unas fuentes documentales notariales, los regisros fiscales de los Memoriali, $y$ otros testimonios igualmente preciosos, que permiten trazar un panorama de la presencia española en la gran Universidad italiana a lo largo del primer tercio del siglo XIV. El objeto

de la investigación es la vida, las actividades y la organización interná de la comunidad estudiantil española en Bolonia, y el papel de los jóvenes escolares, principalmente juristas, en
\end{abstract}

ABSTRACT

Much effort has been devoted to the study of the transmission of the Roman Law in the Western Middle Ages. Even if that work has proved extremely useful, the subject of the study have often been the ideas, and the political and legal institutions thus forgetting the people that made their extension possible. With the precious private documentation contained in the bolognese Memoriali, helped by additional information offered by the local criminal court acts, here is analysed the Spanish presence in the first Italian University in the first thirty years of the 14th century. The object of this research is the life, activities and organisation of

* Este trabajo está dedicado al Dr. D. Pedro Rodríguez-Ponga que, en 1935, siendo colegial en Bolonia, se interesó por la presencia española en aquella Universidad antes de la fundación albornociana. Las páginas que siguen son, al tiempo que el resultado lejano de su esfuerzo y de los estudios de los Profs.Dres. D. Antonio Pérez Martín y D. Antonio García y García, una parte de la tesis doctoral del Autor, inspirada, dirigida y en realidad hecha posible por el Prof.Dr. D. Antonio I. Pini.

** Doctor en Historia por la Universidad de Bolonia. 
la evolución del Estudio y de la ciudad. La conclusión esencial del trabajo es que las relaciones intelectuales entre Italia y España durante este período se basaron más en la presencia de estudiantes que en la de maestros ( $a$ diferencia del siglo anterior) o que en los vínculos institucionales (como en la época posterior), dando como resultado una convivencia panhispánica imposible en otros contextos. the Spaniards in Bologne, and the role of those young jurists in the municipal and University evolution. The main conclusion of the work is that the intellectual link between Italy and Spain over that period was based on the continuous affluence of students that never ceased completely.

\section{INTRODUCCIÓN}

La polémica sobre la identidad jurídica y cultural común de España ha durado más de un siglo. Antes de la unidad política e institucional, y sin negar la importancia circunstancialmente fundamental del intercambio con los vecinos-enemigos musulmanes, los reinos hispánicos eran parte de pleno derecho del ámbito europeo occidental de raíz cristiana y romana. Uno de los pilares de esa pertenencia fue, sin discusión, el Derecho común y su difusión a través de la red universitaria a partir del siglo XII ${ }^{1}$.

Los problemas de identidad cultural fueron comunes a todos los reinos hispánicos en la plenitud de la Edad Media, según A. García y García. Unidas por un proyecto expansivo compartido, las formaciones políticas peninsulares, en torno a 1150 se encontraron frente a su propia inserción en la Christianitas europea. En este contexto, el Derecho común, el Derecho romano clásico se convirtió en un instrumento privilegiado de homogeneización y de homologación al resto del Continente. Tanto en materia civil como en materia institucional, estos dos procesos implicaban necesariamente la recepción del depósito jurídico boloñés, amén de la renovación del Derecho canónico, dos tendencias que sólo la Universidad podía satisfacer. Así surgió la multiplicidad característica del Derecho español premoderno: al Derecho tradicional se unió primero el real, generado por los poderes públicos y, a continuación el común, cuya vigencia en España fue limitada, pero que poseyó una influencia nunca olvidada ${ }^{2}$.

\footnotetext{
F. Tomás y Valiente, Manual de Historia del Derecho español, Madrid, 1990, págs. 200 y ss. F. TOMÁs Y VALIENTE, Manual, pág. 204.
} 
Ante estas necesidades, los monarcas favorecieron pronto la presencia española en los Estudios, primero incentivando la tendencia natural a acudir a los extrapeninsulares, y después realizando fundaciones directas, que recogieron la experiencia de los numerosos estudiantes y maestros antes dispersos en el extranjero. Especialmente, los reyes Trastámara se sirvieron para su proyecto unitario y autoritario del Derecho romano, cuando los cuatro espacios políticos estaban ya sólidamente en manos de hombres formados en el romanismo jurídico.

No siempre se ha recordado suficientemente, sin embargo, que este proceso es anterior al siglo XIV, en el que culmina, e incluso al interés oficial por las Universidades (por lo demás innegablemente temprano). Los españoles empezaron a acudir a los Estudios extranjeros por iniciativa propia y por puro afán de saber, mucho antes de que aquellos conocimientos tuviesen directas consecuencias profesionales. España, que no había olvidado su propio romanismo jurídico, recuperó así el derecho culto. La fuente, como dijo en su momento Rafael Gibert, fue Bolonia, desde donde partió esa recepción, creando "...portadores del derecho común hacia las cortes, los tribunales y las curias eclesiásticas...».

Ya se ha descrito adecuadamente la importancia de la presencia española en Bolonia, decisiva sí para España, pero también para el Estudio boloñés. Sin embargo, han primado los análisis cualitativos sobre la transmisión del saber jurídico, su contenido y sus principales figuras, dejando con frecuencia de lado un hecho esencial, como es el peso numérico de los estudiantes españoles en Bolonia a lo largo de buena parte del período medieval. Particularmente el último tercio del siglo xIII y la primera mitad del XIV, en la época de Giovanni d'Andrea (1270-1348), Bártolo (13131357) y Baldo (1327-1400), pese a la existencia de fundaciones universitarias en la Península, vieron cómo los españoles acudían en contingentes apreciables a la Universidad italiana. Allí, no sólo contribuyeron a la completa transmisión del saber romanista, sino que marcaron el carácter y el funcionamiento de un Estudio cuyo rasgo original había sido el poder estudiantil. Tal vez durante esta época los maestros españoles, o al menos los más conocidos, prefiriesen concentrarse en su lugar de origen, pero los escolares mantuvieron la libertad de elección que era propia de la Universidad medieval.

Las cuestiones pendientes de un estudio detenido, en este sentido, son muchas y variadas. Es preciso, ante todo, valorar con precisión, en lo posible, el peso demográfico español en Bolonia, tanto en términos absolutos como relativos. Además, se debe ponderar la influencia de esa presencia en España (estudios y transmisión de ideas) y en Bolonia (vida 
universitaria). Por último, aspecto no siempre recordado, las formas institucionales de ese contacto hispano-boloñés carecen todavía de un análisis global: posición de los hispani en las nationes, formas de apoyo mútuo en la comunidad española, precedentes y orígenes del Colegio de España.

El obstáculo principal para esta tarea está en relación con la escasez de fuentes y con los problemas metodológicos para su uso. Los documentos universitarios boloñeses muestran la formación de una elite medieval, prácticamente desconocida hasta nuestro siglo, pero no se conservan en cantidad más que desde finales del siglo XIV. Pese a su prestigio intelectual, las referencias documentales a la vida de los españoles en Bolonia antes de esa fecha son siempre indirectas y carentes de una ordenación apropiada. Sólo en los últimos cincuenta años se ha propuesto un esquema para el aprovechamiento sistemático de la documentación boloñesa, pública y privada, en la reconstrucción de la historia universitaria de las diversas comunidades nacionales.

Un problema que este proyecto plantea es el enorme volumen documental. Así, en el presente trabajo, a través de treinta y dos años a caballo entre el siglo XIII y el XIV, se pretende, por una parte, proponer unas conclusiones provisionales sobre el cuestionario abierto en historia universitaria y en Historia del Derecho, pero, por otra, perfeccionar un esquema metodológico aplicable en investigaciones más extensas. Desde el punto de vista boloñés, como desde el español, estas páginas no pueden considerarse sino una primera aproximación a la doble vertiente de este tipo de análisis, que para Jacques Verger han de versar, por un lado, sobre el contenido de las enseñanzas universitarias, especialmente jurídicas, y por otro sobre la historia de la institución universitaria en sí; la misma idea, en definitiva, de Sven Stelling-Michaud, que distinguió para la Universidad un papel «ideológico» y una función «formativo-profesional». Igualmente cierto es que, en el caso que nos ocupa, se trata de dos realidades inseparables, de consecuencias fundamentales para la posterior evolución de España y de la Universidad que durante nueve siglos ha formado a una parte tan significativa de los juristas españoles.

\section{HISTORIOGRAFIA PRECEDENTE}

A pesar de límites evidentes, los estudios precientíficos sobre la Universidad de Boionia tienen la rara virtud de poderse consultar todavía con 
provecho ${ }^{3}$. Algunos de aquellos trabajos, exhaustivos y en general documentados con abundancia, han hecho posible el estudio moderno de la trayectoria de la Universidad a través de los siglos. Incluso los trabajos más positivistas, dada la importancia de la documentación como problema central de este campo histórico, conservan hoy algo de su valor ${ }^{4}$. Una obra magna y adelantada a su tiempo, el Chartularium Studii Bononiensis ${ }^{5}$, partió del acierto de intentar sustituir una documentación propiamente universitaria, que no existe o se ha perdido para los siglos XIII y XIV, con la documentación notarial. Fue en esto precursora de toda una escuela, cuya vocación fue lograr la edición integral de las fuentes existentes ${ }^{6}$. La

3 M. SARTI y M. FATTORINI, De claris Archigymnasii Bononiensis Professoribus a saeculo XI usque ad saeculum XIV. Iterum ediderunt Caesar Albicinius () et Carolus Malagola.Tomus I, Bononiae, 1888-1896, pág. XXXVI-675, y M. SARTI y M. FATTORINI, De claris Archigymnasii Bononiensis Professoribus a saeculo XI usque ad saeculum XIV. Iterum ediderunt Caesar Albicinius () et Carolus Malagola. Tomus II, Bononiae, 1888-1896, pág. 386. S. MAZzETTI, Alcune aggiunte e correzioni alle opere dell'Alidosi, del Cavazza, del Sarti, del Fantuzzi e del Tiraboschi, per quella parte soltanto che tratta de' professori dell'Università di Bologna, Bologna, 1848, pág. 94, S. MAZZETTI, Memorie storiche sopra l'Università e l'Istituto delle Scienze di Bologna e sopra gli stabillmenti e i corpi scientifici alla medesima addetti., Bologna, 1840, y S. MAZZETTI, Repertorio di tutti $i$ Professori antichi e moderni della famosa Università e del celebre Istituto delle Scienze dr̈Bologna, con in fine alcune aggiunte e correzioni alle opere dell'Alidosi, del Cavazza, del Sarti, del Fantuzzi, e del Tiraboschi, Bologna, 1848, págs. 2-379. G.N. Alıoosi PAsquaLI, Li dottori bolognesi di Teologia, Filosofia e d'Arti liberali dall'anno 1000 per tutto Marzo del 1623, Bologna, 1623, pág. 226, G.N.P. ALIDOSI, Li dottori bolognesi di legge canonica e civile dal principio di essi per tutto l'anno 1619, Bologna, 1620, y G.N.P. ALIDOSI, Li dottori forestieri che in Bologna hanno letto Teologia, Filosofia, Medicina e Arti con li rettori dello Studio dell'anno 1000 per tutto Maggio 1623, Bologna, 1623. U. DALLARI, I rotuli dei lettori legisti e artisti dello Studio bolognese dal 1348 al 1799, a cura del dott., Bologna, 1888-1924, 4 vol.

4 A. SORBELLI, L'opera dell'Istituto per la Storia dell'Università di Bologna (1907-1941), «Studi e Memorie per la Storia dell'Università di Bologna”, 15, Bologna, 1942, págs. 179-198.

5 S. STELLING-MICHAUD, La storia delle Università nel medioevo e nel Rinascimento: stato degli studi e prospettive di ricerca, en G. AANALDI, Le origini dell'Università, Bologna, 1976, pág. 204, nota 227. Chartularium Studii Bononiensis. Documenti per la storia dell'Università di Bologna dalle origini sino al secolo XV. Bologna, 1921-1937, en cuyos 13 primeros volúmenes se recogieron los documentos correspondientes a los Memoriali de 1265, 1266, 1267, 1268, 1269 (en parte) y 1286 (G. ZACCAGNINI, y L. Colini-BalDESCHI). En 1981 se retomó la iniciativa, con los documentos de 1270: L. Ferrara, y G. Tamba, Chartularium Studii Bononiensis. Documenti per la storia dell'Università di Bologna dalle origini fino al secolo XV, v. XIV, Bologna, 1981, pág. 328; a continuación, L. Ferrara, G. TAMBA y M. ZaGHIN1, Chartularium Studii Bononiensis. Documenti, v. xv, Bologna, 1988, pág. 148, y L. FerRARA, G. TAMBA y M. ZAGHINI, Chartularium Studii Bononiensis. Documenti, v. XVbis, Bologna, 1988, pág. 127. La segunda época del proyecto no ha incorporado cambios metodológicos, prosiguiéndose con la publicación íntegra de los documentos, frente a las propuestas de limitarse a simples regestos.

6 G. ZACCAGNINI, Per la storia letteraria del Duecento. Notizie bibliografiche ed appunti dagli archivi bolognesi, I: Grammatici e dettatori a Bologna, "ull libro e la stampa. Bullettino ufficiale della Società Bibliografica Italiana», 1913, págs. 228 y ss.; G. ZACCAGNinI, Appunti di varia erudizione per la storia dello Studio di Bologna, Bologna, 1942; G. ZACCAGNINI, II costo dei libri allo Studio di Bologna, «Studi e memorie per la storia dell'Università di Bologna", 15, Bologna, 1942, págs. 33-36. G. OrlandelLI, // libro a Bologna dal 1300 al 1330. Documenti. Con uno studio su il contratto di 
documentación boloñesa auténticamente universitaria empieza a fines del XIV, y antes, desde 1270, los Memoriali agilizan como veremos a continuación el recurso a los protocolos notariales ${ }^{7}$. Inspirado en el Chartularium y en las mismas fuentes, el suizo Sven Stelling-Michaud propuso que el estudio de esta documentación se completase de acuerdo a criterios más ágiles y modernos, valiéndose de un esquema de tipo prosopográfico, que la amplitud cronológica y la riqueza informativa del registro permiten ${ }^{8}$.

El renovado interés por la historia universitaria, en especial por la formación de los juristas de toda Europa en Bolonia, ha adoptado nuevos enfoques. A partir de S. Stelling-Michaud, en el caso que nos ocupa, la vida de escolares y maestros se considera una parte esencial de la historia del Estudio ${ }^{9}$. El suizo fue, de hecho, el primero en mostrar una aplicación práctica de las posibilidades de las nuevas tendencias, lo que sirvió para fijar un cuestionario aplicable a todos los estudios sobre la Bolonia universitaria premoderna: origen de la presencia de los distintos grupos de ultramontanos, movilidad de scholares, distinción entre Studium y Universitates, organización institucional, relaciones con los poderes externos y actividad económica, por ejemplo ${ }^{10}$. Aunque sin renunciar nunca a la centralidad de la documentación notarial —especialmente entre los siglos

scrittura nella dottrina notarile bolognese, Bologna, 1959. G. TAMBA, In margine all'edizione del $X I V$ volume del Chartularium Studii Bononiensis, "Atti e memorie della Deputazione di Storia Patria per le Province di Romagna», n.s., XXXIII, 1982, págs. 151-167.

7 S. StElling-Michaud, Plan de recherche pour l'etablissement d'un Corpus des étudiants européens (juristes, médecins, théologiens) ayant étudié à Bologne de 1270 à 1500, «Bollettino storico-bibliografico subalpino», LIV, 1956, págs. 191-195. Sigue siendo válido su estudio de los estudiantes del área helvética, con conclusiones que en parte pueden ser generales: $S$. STELLING-MICHAUD, L'Université de Bologne et la pénétration des droits romain et canonique en Suisse aux XIIIe et XIV siècles, Genève, 1955, y S. STELLING-MıCHAUD, L'Université de Bologne et la Suisse à l'époque de la première reception du Droit Romain, «Studi e memorie per la storia dell'Università di Bologna", 1, Bologna, 1956.

8 G.P. BRIzzI, Matricole ed effettivi. aspetti della presenza studentesca a Bologna fra Cinque e Seicento, en G.P. BRIZZI y A.I. PINI, Studenti e Università degli studenti a Bologna dal XIII al XIX secolo, “Studi e memorie per la storia dell'Università di Bologna», n.s., VIl, Bologna, 1988, págs. 236.

9 A.l. PINI, «Discere turba volens». Studenti e vita studentesca a Bologna dalle origini dello Studio alla metà del Trecento, en G.P. BRIzZI y A.I. PINI, Studenti, págs. 45-136. A. DE BENEDICTIS, La fine dell'autonomia studentesca tra autorità e disciplinamento, ibidem, págs. 193-224; R. GRECI, L'associazionismo degli studenti dalle origini alla fine del XIV secolo, ibídem, págs. 13-44; A.L. TROMBETTI BudRIESI, L'esame di laurea presso lo Studio bolognese. Laureati in diritto civile nel secolo XV, ibídem, págs. 137-192.

10 J. VERGER, S. Stelling-Michaud and the History of Universities, "History of Universities", 8, Oxford, 1989, págs. 201-210. S. STELLING-MiCHAUD, La storia, págs. 153-215, también en S. STELLING-MICHAUD, L'histoire des Universités au Moyen Âge et à la Renaissance au cours des vingtcinq dernières années, «Rapports du XI Congrès International des Sciences Historiques», 1, Stockhoim, 1960. 
XIII y XIV-, Stelling-Michaud y quienes se han inspirado en su obra han aceptado el uso de fuentes de distinta naturaleza ${ }^{11}$, especialmente judicial. Un proyecto ambicioso, basado en el modelo helvético, se propuso hace un cuarto de siglo; a pesar de las aportaciones, ya citadas, de A. Pérez Martín y A. García y García, todo está por hacer en lo tocante a España. No se trata ya de una publicación íntegra de las fuentes disponibles: falta incluso un estudio preliminar de las mismas. Tiene razón J. Verger ${ }^{12}$ cuando subraya, al tiempo, la importancia del modelo de Stelling-Michaud y la imposibilidad de seguirlo sin importantes adaptaciones que reduzcan lo ambicioso de sus objetivos.

España ha seguido a distancia la evolución de la historiografía boloñesa desde 1888. Por una parte, ha sido universalmente resaltada la importancia de Bolonia en la recepción española del Derecho común y en la formación de intelectuales. Escasearon, por otra, las contribuciones monográficas: G.M. Brocá y J.M. Miret y Sans se detuvieron sobre los escolares catalanes, en unos estudios entonces innovadores que lamentablemente no fueron proseguidos ${ }^{13}$. Albano Sorbelli careció, a diferencia de otros países, de datos sobre los españoles, que siempre han sido liquidados con observaciones generales y extrapolaciones muy discutibles, ajenas al rigor documental y cuantitativo ${ }^{14}$. Sólo tardíamente, D. Marcelino Martín de Castro intentó ocuparse de la presencia española en Bolonia aplicando una metodología más moderna, con una intuición no siempre errada. Por influencia de los profesores Orlandelli y StellingMichaud, y contando con los fondos del Archivo del Colegio de España además de los del Archivio di Stato, trató de reunir datos sobre todos los

11 S. Stelling-Michaud, La storia, pág. 202. S. Stelling-Michaud, Plan de recherche, pág. 192. Habría que analizar su contacto con la prosopografía y la renovación de la metodología histórica. Un modelo de lo que habría de ser el Corpus se encuntra en S. y S. STELLING-MICHAUD, LeS juristes suisses à Bologne (1255-1330). Notices biographiques et regestes des actes bolonais, Genève, 1960.

12 J. Verger, S.Stelling-Michaud, pág. 204.

13 J. Beneyto PÉrez, La tradición española en Bolonia, "Revista de Archivos, Bibliotecas y Museos», 50, Madrid, 1929, págs. 187-184, con un interés retomado más tarde en J. BENEYTO PÉrez, El Cardenal Albornoz, Canciller de Castilla y Caudillo de España, Madrid, 1950, 350 pág. y en J. Beneyto PÉREz, La Universidad de Bolonia y la cultura española, «Studi e memorie per la storia dell'Università di Bologna», n.s., I, Bologna, 1956, págs. 589-602. G.M. BrocÁ, Juristes i jurisconsults catalans dels segles XI, XII $i$ XIII, fonts dels seus coneixements y trascendencia que exerciren, "Anuari de l'Institut d'Estudis Catalans", 2, Barcelona, 1908, págs. 429-440, y G.M. BrocÁ, Juristes $i$ jurisconsults catalans dels segles XIV-XVII, "Anuari de l'Institut d'Estudis Catalans", 3, Barcelona, 1909-10, págs. 483-515. Además, J. MIRET y SANS, Escolars catalans al estudi de Bolonia en la XII"a centuria, "Boletín de la Academia de Buenas Letras de Barcelona», 8, Barcelona, 1915, págs. 137-155.

14 A. SORBELLI, Bibliografia e cultura iberica in Bologna. La «Casa degli spagnuoli», "L'Archiginnasio», 30, Bologna, 1935, pág. 362. 
españoles presentes en Bolonia, relacionados o no con el Colegio. Por desgracia, sus trabajos no han sido ni concluidos ni suficientemente divulgados. Para él, la abundante presencia española en Bolonia en los siglos XIII y XIV, y sus vicisitudes, explicaba la fundación posterior del Colegio; su trabajo, aunque no siempre rigurosamente científico, tuvo un indudable mérito anticipador ${ }^{15}$.

El proyecto de S. Stelling-Michaud llegó tardíamente a España, de la mano de R. Gibert y A. García y García ${ }^{16}$, y se orientó a los documentos notariales de 1265 a 1350 . Desde un principio los primeros treinta años del XIV, ya estudiados en lo relativo a Italia por G. Orlandelli, parecieron los más interesantes ${ }^{17}$; sin embargo, no se han llegado a publicar hasta ahora los resultados. Dedicado intensamente al estudio de la relación hispano-boloñesa, el profesor García y García, junto a sus trabajos dedicados a Laurentius Hispanus, Juan de Dios, S. Raimundo de Peñafort o Fernando Álvarez de Albornoz, por ejemplo, ha producido la única aproximación española a esta fuente ${ }^{18}$. Sus investigaciones, que se complementan con las que el Colegio de España ha incentivado constantemente sobre sus propios orígenes, como las de A. Pérez Martín ya citadas y a un artículo de base méramente bibliográfica de $\mathrm{C}$. Mesini ${ }^{19}$, serán en las páginas que siguen nuestra constante referencia. Por lo demás, casi todo está por hacer.

15 E. Verdera y Tuells, Prólogo, «Studia Albornotiana», XI, «El Cardenal Albornoz y el Colegio de España", I, Bolonia, 1972, págs. 14-15. M. MARTín DE CAStro, Españoles, portugueses e iberoamericanos en Bolonia, 1. 1353-1499, s.e., Madrid, 1977, 335 págs.

16 A. García y García, Escolares ibéricos en Bolonia, 1300-1330, en A. García y GarCíA, Derecho Común en España. Los juristas y sus obras, Murcia, 1991, pág. 21, con referencia a su participación en el proyecto de Stellig-Michaud y Cencetti. Ya antes, en relación con R. Gibert, había trabajado en torno a la introducción del Derecho boloñés en España A. GaRcía y Garcia, La penetración del Derecho clásico medieval en España, «Anuario de Historia del Derecho Español», 36, Madrid, 1966, págs. 575-592. Sobre la participación española en el abortado Corpus, vid. A. PÉREz MARTin, "I "Corpus Scholarium Bononiensium", «Bollettino Informativo dell'Istituto Giuridico Spagnolo in Roma», 17, Roma, 1969, págs. 711.

17 G. Orlandelli, II libro a Bologna, y A. García y García, Escolares

18 A. García y García, El Studium bononiense y la Península lbérica, en A. García y Garcia, Iglesia, Sociedad y Derecho, Salamanca, 1985, págs. 45-64; A. GARCiA Y GARCíA, En torno al Derecho romano en la España medieval, en A. GarcíA Y GARcía, Iglesia, págs. 65-76; A. GARCíA Y García, Escolares, págs. 21-45; A. García Y GARcía, Investigación y estudio del Derecho común medieval en España, in Atti del Convegno "I glossatori", Milano, 1973; A. García Y García, La canonística ibérica medieval posterior al Decreto de Graciano, «Repertorio de Historia de las Ciencias eclesiásticas en España», 1, Salamanca, 1967, págs. 397-434.

19 C. MesINi, Gli spagnoli a Bologna prima della fondazione del Collegio di Egidio di Albornoz (1364-1369), «Studia Albornotiana», XII, «El cardenal Albornoz y el Colegio de España», II, Bolonia, 1973, págs. 41-71. 


\section{ANÁLISIS DE LA DOCUMENTACIÓN}

Las matrículas generales, fundamento de la historia de otras instituciones universitarias, no existen en el período medieval del Estudio boloñés ${ }^{20}$. Los escolares obtenían la admisión a las nationes que constituian las Universitates (italianos citramontanos y extraitalianos ultramontanos, dentro de cada grupo de civilistas, canonistas, artistas y médicos) y sólo las nationes poseían registros de miembros. Sólo los boloñeses permanecían fuera del sistema de Universitates y nationes, y eran inscritos en un liber. seu matricula specialis. Lamentablemente, faltan las matrículas de las nationes hispánicas anteriores al siglo $\mathrm{xV}$, lo que implica que toda investigación debe basarse en fuentes sustitutivas.

La primera opción sería la constituída por otra documentación universitaria, preferentemente administrativa; una vez más, Bolonia ha perdido casi todos sus fondos anteriores a los últimos años del siglo XIV ${ }^{21}$. Así, los estatutos de las Universitates, de las nationes y de los colegios; las actas de los rectores, de las Universitates y de las nationes, especialmente detalladas en el caso de la colación de grados: Libri secreti del Colegio de doctores civilistas (desde 1337), y Acta de los Colegios de médicos y de artistas ${ }^{22}$; la

20 El mejor panorama general sobre la documentación universitaria en J. PAQUET, Les matricules universitaires (Typologie des Sources du Moyen Áge Occidental, 65), Turnhout, 1992, en especial págs. 14 y ss. R. GRECl, L'associazionismo, pág. 16. C. MALAGolA, Statuti delle Università e dei collegi dello Studio di Bologna, Bologna, 1888, pág. 128, y, sobre las reglas estatutarias relativas a la inscripción de los estudiantes, H. DENIFLE, Die Statuten der Juristen-Universität Bologna vom Jahre 1317-1347, und deren Verhältnis zur jenen Paduas, Perugias, Florenz, "Archiv für Literatur- und Kirchengeschichte des Mittelalters», 3, 1887, págs. 359 y ss. G.P. Brizzl, Matricole ed effettivi. Aspetti della presenza studentesca a Bologna fra cinque e seicento, en G.P. Brizzı, y A.I. PINI, Studenti, págs. 230-233. Vid. et. H. RASHDALL, The Universities of Europe in the Middle Ages by the late -, Oxford, 1936, vol. 3, págs. 325 y ss. P. KIBRE, The nations in the mediaeval Universities, Cambrige (Mass.), 1948 y, sobre el caso boloñés, A. SoRBELLI, La «nazione" nelle antiche Università italiane e straniere, «Studi e memorie per la storia dell'Università di Bologna», 15, 1943, págs. 91-132; P. Colliva, Statuta nationis germanicae Universitatis Bononiae, 1292-1750, "Acta Germanica. Quaderni dell'Associazione italo-Tedesca», Bologna, 1975.

21 G. CENCETTI, Inventari e regesti del fondi più importanti conservati nel $R$ Archivio di Stato di Bologna, "Notizie degli Archivi di Stato», I, Roma, 1941, págs. 49-54; G. CENCETTI, Gli Archivi dello Studio Bolognese, Bologna, 1933 (1938); G. CENCETTI, I precedenti storici dell'archivio notarile in Bologna, en G. CENCETTI, Scritti Archivistici, Roma, 1970, págs. 300-312. Archivio di Stato di Bologna, en Guida generale degli Archivi di Stato Italiani, Roma, 1981, I, pág. 579. Un modelo válido en A.F. VERDE, Lo Studio fiorentino (1473-1503). Ricerche e documenti, III, 1 , Pistoia, 1977, pág. XXI; J. PAQUET, Les matricules, pág. 24.

22 A. SORBELLI, Liber secretus iuris caesarei dell'Università di Bologna, I: 1378-1420, Bologna, 1938; A. SORBELLI, Liber secretus iuris caesarei dell'Università di Bologna, II: 1421-1450, Bologna, 1942; C. PIANA, Liber secretus iuris caesarei dell'Università di Bologna, III: 1451-1500, Milano, 1984. Los artistas desde 1481: Archivio di Stato di Bologna [en lo sucesivo A.S.B.], Archivi dello Studio, a partir del n. 121. Civilistas desde 1483; A.S.B., Archivi dello Studio, a partir del n. 26. Canonistas desde 1431 ; A.S.B., Archivi dello Studio, a partir del n. 18. 
contabilidad; $y$, entre otras, finalmente, la literatura universitaria, en la que aparecen maestros y estudiantes desconocidos de otro modo ${ }^{23}$. Desde mediados del XIV, además, las propias autoridades municipales, cada vez más presentes en la vida universitaria, elaboraban cada año su lista de maestros (rotuli) ${ }^{24}$. En cualquier caso, estas fuentes o no existen o no son útiles antes de 1350 aproximadamente.

Los fondos de archivo no universitarios, por su parte, plantean un notable problema de desorden y de excesiva prolijidad. En Bolonia, es sobre todo documentación municipal, sin olvidar algunos documentos pontificios e imperiales de gran importancia. Maestros y escolares, antes que en los rotuli, aparecen a menudo en el Registro Grosso, en los Libri partitorum, en los archivos de cofradías benáficas e instituciones religiosas como $\mathrm{S}$. María de la Mascarella ${ }^{25} \mathrm{y}$, sobre todo, en las Carte di Corredo del tribunal municipal del Podestà.

Ya S. Stelling-Michaud se detuvo en las Carte di Corredo y en las Accusationes, para completar y matizar las informaciones, cuantitativamente mucho más importantes, de los documentos privados. Las Carte di Corredo son actas de las declaraciones de denunciantes y testigos ante el tribunal que, en los siglos XIII y XIV, era competente en las causas que afectasen a ultramontanos. Su volumen impone un uso sólo cualitativo y subsidiario, ya que no constituye una muestra significativa de la población estudiantil ${ }^{26}$. Junto a otras series de códices procesales, la de las Carte di Corredo ${ }^{27}$ está formada por 458 carpetas, con documentos de 1241 a 1512. Es una documentación de naturaleza muy variada, entre la que destacan tres carpetas dedicadas en exclusiva a los asuntos de maestros y

23 C. PIANA, Nuovi documenti sull'Università di Bologna e sul Collegio di Spagna, I, Bolonia, 1976, págs. 109-136, por ejemplo, sobre el final del siglo XV.

24 U. DALLARI, I rotuli dei letiori legisti e artisti dello Studio bolognese dal 1348 al 1799 , a cura del dott.--, Bologna, 1888-1924, 4 volúmenes; G. ZAOLl, Di alcuni rrotuli» dello Studio della prima metà del secolo XV, «Studi e memorie per la storia dell'Università di Bologna», 3, Bologna, 1912, págs. 193-249

25 G. Orlandell, Maestri e scolari nelle "carte di corredo" del podestà di Bologna, "Atti dell'Accademia delle Scienze dell'lstituto di Bologna. Classe di Scienze Sociali. Rendiconti», 74, 1985-1986, págs. 19-33; G. ZaCCAGNini, La vita dei maestri e degli scolari nello Studio di Bologna nei secoli XII e XIV, «Archivum Romanicum", 5, Genève, 1926; S. STELLING-MICHaud, Les juristes suisses à Bologne (1255-1320). Notices biographiques et regestes des actes bolonais, Genève, 1960.

26 S. Stelling-Michaud, L'Université, 1955, pág. 9. G. Orlandelli, Maestri e scolari, págs. 19-33. G. ZacCAGNINI, La vita, pág. 239. Eł trabajo de S. Stelling-Michaud se centró, obviamente, en los suizos. W. Montorsi, Curia del Podestà, Giudici "ad maleficia». Libri inquisitionum et testium. Parte prima (1242-1350, Bologna, 1993, pág. I.

27 A.R. BAMBi, Curia del Podestà, Giudici ad maleficia, Carte di Corredo, Bologna, 1986, pág. I. 
España en la Universidad de Bolonia: vida académica y comunidad nacional...

estudiantes hasta 1330 (la número 35, con documentos de 1301 a 1317, y la 65 , de 1318 a 1348).

Porque, en definitiva, son los documentos privados los más significativos para trazar la línea evolutiva del Estudio y de los españoles dentro de él. Bolonia conserva una serie completa de documentos notariales de los siglos medievales, susceptible de un despojo de este tipo, lo que no es usual entre las viejas ciudades universitarias; los documentos privados reflejan la vida y suponen una cierta forma de sondeo de la población estudiantil española. El único problema de esta fuente, que ofrece cientos de actas y potencialmente miles de nombres, es su excesiva abundancia y extensión ${ }^{28}$. Sin embargo, una institución peculiarmente boloñesa favorece el acceso a estos datos. Desde 1265 existía la obligación de registrar, en una dependencia municipal (el registro de los Memoriali, ya mencionado), todos los actos jurídicos documentados que implicasen una transmisión patrimonial de valor superior a veinte libras boloñesas. Todas las compraventas, alquileres, préstamos, dotes y capitulaciones matrimoniales, donaciones y testamentos, entre otros, debían someterse a ese trámite, que implicaba una moderada tasa municipal, proporcional al valor ${ }^{29}$. Los llamados «Memoriali» (Libri memorialium o Memorialia Communis), son códices documentales formados por tres oficinas (Cambio, Gabella y Scarania) para los documentos urbanos y de la comarca, divididos por semestres - aunque la disposición en códices responde, dentro de cada año, a razones sólo materiales, de cantidad de entradas. Sin comparecer ante uno de los notarios de estas dependencias administrativas el documento correspondiente era nulo de pleno derecho. Como prueba del trámite y garantía permanente de la autenticidad del documento, quedaba testimonio sucintamente del nombre de los actores, el objeto y naturaleza del contrato, su valor, los nombres de los testigos y la fecha. Aparte de la nulidad, el incumplimiento de la obligación implicaba una multa de cien libras.

Los Memoriali, de todas formas, contienen un resumen bastante extenso del documento, con todos los datos útiles para una investigación

28 Sobre los notarios boloñeses, M. BERTRAM, Bologneser Testamente, "Quellen und Forschungen aus italienischen Archiven und Bibliotheken", 71, 1991, y G. FASOLI, I notai nella vita cittadina bolognese (sec. XI-XV), en Notariato medievale bolognese. Atti di un convegno, Roma, 1977 , págs. $121-142$.

29 S. Stelling-Michaud, L'Université, pág. 8. W. Cesarint-SForZa, Sull'officio dei «Memoriali», «L'Archiginnasio", 9, Bologna, 1914, págs. 379-392. L. ContINELLI, Introduzione, in L'Archivio dell'Ufficio dei Memoriali. Inventario, Vol. I Memoriali, 1265-1436, Tomo I, 1265-1333, «Universitatis Bononiensis Monumenta», IV, Bologna, 1988, págs. IX-XL. V. Franchini, L'instituto dei «Memoriali» in Bologna nel secolo XIII, "L'Archiginnasio", 9, Bologna, 1914, págs. 95-106. G. TAMBA, I Memoriali del Comune di Bologna nel secolo XII. Note di diplomatica, «Rassegna degli Archivi di Stato», 47, Roma, 1987, págs. 235-290. 
prosopográfica (nombres, condición y grados académicos, lugares de origen y residencia, datos patrimoniales, afinidades personales) pero generando un volumen enorme de registros: de 1265 a 1333 son 181 códices ${ }^{30}$, que además se acumulan hacia final del período porque, al no modificarse el límite de veinte libras, la inflación produjo un incremento exponencial de documentos registrados. Como efecto positivo, resulta que en las tres primeras décadas del XIV, a mayor número de documentos resumidos corresponde un mayor número de datos sobre los escolares ultramontanos y concretamente españoles.

Los datos que esta fuente ofrece están lejos de haber sido convenientemente explotados, al menos en relación al volumen de información existente; tal vez, por paradoja, esto se deba a la amplitud de posibilidades. Para Chartularium Studii Bononiensis, reproduciendo íntegramente documentos de los Memoriali junto a otros de protocolos notariales, se han publicado los años 1265-1269 y la primera mitad de $1286{ }^{31}$. Una obra muy anterior, la de M. Sarti y M. Fattorini, realizó acertadamente el despojo entre 1265 y $1294{ }^{32}$, limitándose a los datos esenciales para la historia jurídica y universitaria y obviando la publicación de documentos completos. Sin dudas aquellos criterios dieciochescos están muy superados, pero lo limitado de su ambición hace aquella empresa más sencilla de completar. Por sí mismos, los Memoriali pueden aclarar aspectos ahora oscuros de la vida del Estudio, dentro o no de proyectos internacionales como los de $\mathrm{G}$. Orlandelli, S. Stelling-Michaud y A.Luschin von Ebengreuth ${ }^{33}$.

Esta tarea de simplificación en el uso de los Memoriali, que nos proponemos iniciar en estas páginas, podría agilizarse con un instrumento aún más flexible. Desde 1333, los documentos tasados en los Memoriali se resumen aún más sintéticamente en un segundo registro, el de los Provvisori. Puede accederse, así, por una doble vía a la documentación del siglo XIV, y del XV hasta 1452: en extenso en los Memoriali, y en síntesis en

30 L. CONTINELLI, Inventario: 79 y 80 para 1291,81 y 82 para $1292,83,84$ y 85 para 1293,86 y 87 para 1294, 88 y 89 para 1295, 90 y 91 para 1296, 92 y 93 para 1297, 94, 95 y la mitad del 97 para 1298,96 y la mitad del 97 para 1299 y 98 y 99 para $1300 ; 171,172$ y 173 para 1331, 174, $175,176,177$ y la mitad del 181 para 1332 , y 178, 179, 180 y la mitad del 181 para 1333: 44 entre 1265 y 1280,34 entre 1281 y 1290,20 entre 1291 y 1300,23 entre 1301 y 1310,18 entre 1311 y 1320,30 entre 1321 y 1330 y 10 entre 1331 y 1333.

31 G. ZaCCAGnINI y L. COLINI-BALDESCHI, Chartularium., cit. (varios volúmenes), y L. FerRara y G. TAMBA, Chartularium., v. XIV, vol. cit.

32 M. SARTI y M. FatTorini, De claris, II, Bononiae, 1888-1896, págs. 307-332.

39 A. LUSCHIN von EBENGREUTH, Vorläufige Mitteilungen über die Geschichte deutscher Rechtshörer in Italien, «Sitzungsberichte der Kaiserlische Akademie der Wissenschaften in Wien, Phil.-Hist. Classe», 125, Wien, 1892, págs. 19 y ss., tomado como modelo posteriormente. 
los Provvisori ${ }^{34}$. El esquema organizativo de los Provvisori es en todo similar al de los Memoriali, con unos seis códices anuales, aunque más reducidos en este caso. Los Provvisori, además de los códices en pergamino descritos hasta ahora, tienen una serie en papel, menos legible pero que permite salvar eventuales lagunas de la serie principal. En teoría, pues, se dispone de un doble acceso a los documentos de los estudiantes españoles en Bolonia desde 1333, siendo los Provvisori especialmente sintéticos y por lo tanto susceptibles de un estudio veloz. Sin embargo, mientras que la condición personal de los miembros del Estudio aparece siempre en los Memoriali, raramente se refleja en los Provvisori, lo que los hace inútiles para el trabajo que aquí nos interesa. De hecho, en un instrumento como los Provvisori no tiene sentido que se refleje la profesión (scholarius, magister, etc.) de los contrayentes, especialmente porque, en este caso, carecía de efectos jurídicos. Los Provvisori no pretenden sustituir el verdadero registro, los Memoriali, sino sólo reunir datos con finalidad fiscal. Se comprende, así, la decisión de S. Stelling-Michaud ${ }^{35}$ de usar básicamente los Memoriali. Faltando la documentación estrictamente universitaria, es razonable centrarse, como punto de partida, en las décadas de mayor acumulación de datos de los Memoriali (entre finales del siglo XIII y 1330/1333), sin renunciar a obtener por otros medios datos complementarios, tanto en las fuentes que quedan mencionadas más arriba como en los archivos eclesiásticos y privados (bastante decepcionantes, por lo demás).

Como se ve, cualquier investigación sobre la presencia universitaria española en Bolonia en estas fechas ha de contar con problemas de información: no tanto de su escasez, como de su desorganización. Intentamos ante todo proponer aquí un esquema para su uso sistemático, aplicable en futuras ocasiones, además de esbozar unas primeras conclusiones sobre las décadas que parecen de contenido más interesante. Una dificultad que podría consiclerarse insalvable es que, siendo los estudiantes tradicionalmente considerados "pauperes", una fuente hacendística como los Memoriali podría ser inadecuada para acceder a ellos; sin embargo, de la abundante presencia de transacciones que incluyen escolares resulta que esa pobreza era relativa, y no necesariamente liga-

34 A.I. PINI, Società artigianali e locazioni d'opera a Bologna prima e dopo la peste del 1348 , en Aspetti della vita economica medievale. Atti del Convegno di Studi nel X Anniversario della morte di Federigo Melis, Firenze, 1985, pág. 791.

35 S. Stelling-MichaUd, L'Université, 1955, págs. 7-12. G. TaMBA, In margine all'edizione del XIV volume del "Chartularium Studii Bononiensis", "Atti e Memorie della Deputazione di Storia Patria per la Romagna», XXXIII, 1982, págs. 151-168, sobre la lentitud de su edición. 
da a una verdadera indigencia (puesto que estudiar era un lujo realmente al alcance de pocos europeos). El dinero era, sí, una cuestión capital en la Universidad medieval, pero los documentos nos muestran una comunidad española que recibe abundantemente remesas de sus familias y préstamos de los banqueros locales, lo que es una garantía para afirmar que los Memoriali recogen datos sobre una parte significativa de los estudiantes. Bolonia dispuso de una red financiera adaptada a estas necesidades, con ramificaciones en toda Europa y bastante poco respetuosa de los criterios morales de la Iglesia y del municipio (donde los Estatutos de 1250 fijaban un límite del $20 \%$ anual, y del $1 \%$ en el caso del cambio de moneda, en buena parte por influencia de Accursio y Cino de Pistoia). Los estudiantes reclamaron sistemáticamente el cumplimiento de estas normas que les protegían, lo que significa que no se respetaban ${ }^{36}$. Con frecuencia, las operaciones de cambio encubren un préstamo con intereses elevados; esta situación, desfavorable para los escolares, nos permite ahora conocer aspectos fundamentales de su vida y estudios en Bolonia, que de otra manera se habrían perdido.

\section{METODOLOGÍA}

El único gran proyecto de investigación que ha pretendido abarcar los estudios clasicos de historia jurídica e institucional junto a una visión de la vida de escolares y maestros en Bolonia ha sido el de Sven Stelling-Michaud. Su Corpus Scholarium Bononiensium (Ultramontanorum) Medii Aevi sigue siendo, aunque incompleto, un intento excepcional, a parte los trabajos del «Istituto per la Storia dell'Università» para completar el Chartularium Studii Bononiensis. El modelo concebido para el caso suizo no es aplicable sin más al caso español, pero los problemas de ambas investi-

36 S. Stelling-Michaud, L'Université, págs. 88 y sS. A.I. PINI, Discere, págs. 104 y ss. F. MELIS, Sul finanziamento degli allievi portoghesi del Real Colegio de España di Bologna nel xV secolo, «Studia Albornotiana», XIII, "El Cardenal Albornoz y el Colegio de España», III, Bolonia, 1973, págs. 417-434. A.I. PINi, La presenza dello Studio nell'economia di Bologna medievale, en $O$. CAPITANI dir., L'Università a Bologna. Personaggi, momenti e luoghi dalle origini al xvI secolo, Milano, 1987, págs. 85-112, y L. DAL PANE, Lo «Studio» e l'economia della città, in Atti del Convegno Internazionale di Studi Accursiani, I, Milano, 1968, págs. 41-53. O. CAPITANi, Introduzione, en O. CaPITANI, L'etica economica medievale, Bologna, 1974, págs. 9 y 19. Cf. Lc VI, 35. "Mutuum date, nihil inde sperantes". O. CAPITANI, Sulla questione dell'usura nel Medio Evo, en O. CAPITANI, L'etica, págs, 24-25 y 29. J.T. NoONAN, Operazioni bancarie, en O. CAPITANi, L'etica, pág. 154. J. GiLCHRRIST, L'applicazione pratica delle teorie, en O. CAPITANI, L'etica, pág. 170. C. Violante, Per lo studio dei prestiti dissimulati in territorio milanese (secoli $x-x 1$ ), in Studi in onore di Amintore Fanfani, 1. Antichità e Alto Medioevo, Milano, 1962, págs. 643-735. A.l. PINI, L'arte del cambio a Bologna nel XII secolo, «L’Archiginnasio», 57, Bologna, 1962, pág. 22. 
gaciones son, si no idénticos, sí simétricos ${ }^{37}$ : las fuentes y su interpretación, las dudas sobre los resultados prácticos de una metodología prosopográfica que es necesario aplicar para obtener resultados en estas circunstancias. El mismo profesor suizo varió con frecuencia sus criterios, lo que en parte explica que ninguna de las fases de su proyecto se haya concluído ${ }^{38}$. Tan importante como la investigación concreta sobre los españoles es ahora, pues, la verificación de las posibilidades del método y de los presupuestos de Stelling-Michaud; no es esta una contribución esencialmente metodológica, pero algunas de las conclusiones de las páginas que siguen se habrán de ceñir a tal campo, a partir de las premisas documentales e historiográficas que quedan apuntadas, más que a la descripción de un momento de historia universitaria española.

En cuanto a la metodología inmediatamente aplicable, sólo un despojo de las fuentes documentales arriba mencionadas puede dar una nueva visión, cuantitativa además de cualitativa, de la presencia española en el Estudio boloñés. Un método cuantitativo de base estadística puede aclarar aspectos como la evolución general, la evolución de la distribución regional y las variaciones sociales y económicas. Incluso si el alcance de esta investigación es necesariamente muy limitado, la clasificación de documentos, por una parte, y de personas, por otra, podrá eventualmente extenderse en el futuro ${ }^{39}$. Esquemas anteriores que han sido propuestos para este análisis tienden a parecer demasiado rígidos y prefabricados, y sobre todo inadaptados a esa variedad que es la característica esencial de la vida universitaria medieval; de ahí arrancan dificultades metodológicas que en este caso no sólo no se intentan ocultar sino que se trata de solucionar en lo posible ${ }^{40}$.

Tanto A. García y García como S. Stelling-Michaud han considerado que los primeros treinta años del siglo XIV, momento de transición entre

37 J. VERGER, Sven Stelling-Michaud and the History of Universities, "History of Universities", 8, Oxford, 1989, págs. 201-210.

38 J. Verger, Sven Stelling-Michaud, pág. 205.

39 J. PAQUeT, Les matricules, págs. 80 y ss. P. DENLEY, University Records, Social History, and the Creation of Large Databases, «History of Universities», 8, Oxford, 1989, págs. 219-229, con varios ejemplos del posible tratamiento de la documentación universitaria. W. FriJuofF, Grandeur des nombres et misères des realités: la courbe de Franz Eulenburg et le débat sur le nombre d'intellectuels en Allemagne, 1576-1815, en Les Universités européennes du xvie au xvme siècle. Histoire sociale des populations étudiantes, I, Paris, 1986, págs. 23-63, y W. FRIJHOFF, Surplus or deficit? Hypothèses sur le nombre réel d'étudiants allemands à l'époque moderne (1576-1815), «Francia», 7, 1979, págs. 173-218.

40 L. C. SCHwinges, Europäische Studenten des späten Mittelalters., en A. PATSCHOVSKY y H. RABE, dir., Die Universität in Alteuropa, Konstanz, 1994, págs. 129-146. I. CloulAS, L'inventaire automatisé des actes notariés: principes d'analyse et résultats d'expérimentation aux Archives $\mathrm{Na}$ tionales de Paris, in Informatique et Histoire Médiévale, Rome, 1977, págs. 127-131. 
dos siglos y entre dos modelos de Universidad, son la clave para comprender la presencia de ultramontanos en Bolonia y su influencia en sus países de origen. El último esplendor del Estudio medieval antes de los grandes cambios, coincidió además con el final del apogeo de la presencia española entre los estudiantes y con uno de los momentos menos conocidos del ciclo universitario petroniano; un período de crisis en múltiples sentidos, que llevó a la práctica desaparición del "modelo" universitario boloñés ${ }^{41}$. Toda la Universidad europea sufrió en aquellas décadas una convulsión general, que fue intelectual, con las doctrinas de Marsilio, Ockam y Juan de Jandun, la desaparición de la glosa tradicional, la Lectura de Cino de Pistoia, y el triunfo del aristotelismo y de la dialéctica, pero que en Bolonia fue además organizativa ${ }^{42}$.

Todas estas razones son suficientes para justificar la elección del período 1298-1330 como el más adecuado para, desde las fuentes descritas, intentar aplicar un modelo de estudio integral de historia universitaria. Bolonia estuvo desde un buen principio en el centro de la peregrinatio académica de muchos hispani. Bolonia ofrecía unos conocimientos jurídicos, por un lado, y una libertad asociativa, por otro, que la hacían especialmente atrayente, hasta que la cambiante situación política y económica vino a limitar aquellas cualidades. En 1299, con el regreso de los Lambertazzi, Bolonia quedó pacificada tras una larga guerra. De inmediato, los estudiantes volvieron a afluir en grandes grupos, y el esplendor pareció regresar. Al menos hasta el inicio de un nuevo conflicto en 1306, esto pareció posible ${ }^{43}$. Sin embargo, estas luchas, y la progresiva dependencia de las escuelas respecto de los poderes políticos, hicieron que la Universidad fuese perdiendo mucho prestigio exterior; sucesivas crisis entre 1321 y 1330 , que se analizarán a continuación desde el punto de vista español, llevaron a la definición de un nuevo Estudio como consecuencia de la menguante posición de los no italianos en el mismo. Las fuerzas ciudadanas (patricios, municipio, obispos), aunque más débiles, gozaron frente a los poderes universales, tradicionales protectores de la comunidad universitaria y en especial de los estudiosos de Derecho, del privilegio de la pre-

41 G. FASOLI, Bologna nell'età medievale (1155-1506), en A. FERRI y G. Roversi, dir., Storia di Bologna, Bologna, 1978, págs.127-190; aunque superada, interesa todavía para la evolución política A. GorRETTA, La lotta fra il comune bolognese e la signoria estense (1293-1303), Bologna, 1906. La crissi del Estudio en A. SoRBELLI, Storia dell'Università di Bologna, Volume I, II Medioevo (sec. Xi-XV), Bologna, 1940, pág. 327, y C. CAl.CATERra, Alma Mater Studiorum. L'Università di Bologna nella Storia della cultura e della civiltà, Bologna, 1948, pág. 106.

42 J. Verger, Le Università nel Medioevo, Bologna, 1993, pág. 215. F. Calasso, Medio Evo del Diritto, Milano, 1954, págs. 563 y ss.

43 G. FasOLI, Bologna, págs. 154 y ss. 
sencia constante. Para la ciudad, lo esencial no era el saber, sino la actividad económica generada por el mismo y la conservación del orden público burgués; en este sentido, el cambio en la Universidad fue radical, con un recíproco descubrimiento entre Estudio y ciudad, a lo largo de tres décadas, a través de unas tensiones que con frecuencia tuvieron protagonismo español ${ }^{44}$.

\section{EL «SIGLO ESPAÑOL». MARTÍN JIMÉNEZ: UNA VIDA EN BOLONIA}

Entre 1268 y 1302, un cierto Martinus Hispanus aparece con frecuencia en la documentación boloñesa. Su actividad en el Estudio y en la ciudad ha sido objeto de algunas menciones en la bibliografía al uso, pero su biografía no ha sido todavía escrita. La vida de este clérigo español, maestro en Bolonia, sirve para marcar la transición entre dos siglos radicalmente diferentes por lo que se refiere a la presencia hispana en el Alma Mater, y para dar inicio a nuestro despojo documental de las tres primeras décadas del siglo XIV.

En efecto, entre los primeros documentos de los Memoriali que hemos examinado se encuentran varios tipos distintosdador de la iglesia y hospital de Santa. María de la Mascarella en 1268-69; b) las de referencias a este personaje: a) Las relativas a Martinus Eximini Yspanus, comendador, b) Martinus Eximini, de Teruel, en 1276 y 1282; c) las del maestro canonista Martinus Eximini Yspanus en 1281-82; d) las de Martinus Egidii de Seminis, rector ecclesie de Cuba, cesaraugustensis diocesis, en 1282; y, en fin, e) Martinus Hispanus, profesor de lógica en $1275^{45}$. Las menciones de los cuatro primeros tipos pueden identificarse sin problemas con un

44 H. DE Ridder SYMoEns, La place de l'Université de Bologne dans la mobilité des étudiants européens, en Universitates e Università. Atti del convegno, Bologna 16-21 novembre 1987, Bologna, 1995, págs. 85-86. A. García y García, Escolares ibéricos en Bolonia, 1300-1330, en A. García y Garcia, Derecho común, págs. 21-45. G. Ross।, "Universitas scholarium» e Comune (sec. XII-XIV), «Studi e memorie per la storia dell'Università di Bologna», n.s., I, Bologna, \{956, págs. 173-266. V. VITALE, // dominio della parte guelfa in Bologna (1286-1326), Bologna, 1901. La participación de los estudiantes en la vida política en G. ZACCAGNINI, Rapporti fra lettori e scolari allo Studio di Bologna dal secolo XII al principio del secolo xvi, "Studi e memorie per la Sioria dell'Università di Bologna», 17, Bologna, 1944, págs. 163 y ss.

45 Respectivamente en a) 1268 , noviembre, 5. Bolonia: A.S.B., Memoriali, Amadore della Croara, y 1269, enero, 2, Bolonia: A.S.B., Memoriali, Semprebene del Nero; b) M. Sarti y M. Fattorini, De claris II, págs. 315 y 321 ; c) M. SARTI y M. FATTORINI, De claris II, págs. 320 y 321 . A. GaRcía $Y$ GaRcia, Escolares, págs. 39-40, n. 66 y 67 (sugiriendo la identidad entre ambos personajes); d) M. SARTI y M. FATTORINI, De claris II, pág. 321; Egidii parece una lectura errónea de Eximini; e) M. SARTI y M. Fattorini, De claris I, pág. 593. 
único universitario español, clérigo vinculado a Roncesvalles que realizó estudios completos siendo comendador en Italia y que tras licenciarse permaneció en Bolonia como maestro; las menciones del quinto tipo presentan más dudas, pudiendo tratarse de un homónimo. El canónigo Martín Jiménez está, pues, en Bolonia como estudiante de leyes desde al menos 1268; sobre esta parte de su biografía, sin embargo, no conviene detenerse aquí; baste decir que, llegado al Estudio gracias a la Mascarella, la dirigió en un momento de esplendor pero la abandonó para desarrollar su propia carrera en los años finales del siglo XIII, cuando en Bolonia coinciden algunos maestros españoles con el inicio del auge numérico de los estudiantes ${ }^{46}$. Sólo tenemos la certeza de que está en la Mascarella hasta el 2 de enero de 1269, con el hospital funcionando plenamente ${ }^{47}$. Después, y $\sin$ que conste un enfrentamiento con Roncesvalles, Martín se independizó, aunque consta que siguió siendo escolar cuando menos hasta el 11 de agosto de 1274; el 21 de diciembre de 1282 parece ser ya miembro del colegio de doctores, y de hecho en 1286 patrocinó un candidato para la entrada en el colegio de canonistas ${ }^{48}$.

Como maestro canonista, su prestigio en Bolonia es incontrovertible, como prueba la embajada que la ciudad le encargó en 1294, junto al civilista Gardino y a su colega canonista Bonincontro, en la corte del conde de Romagna Hildebrandino. El 27 de septiembre de 1297, en los días no lectivos entre los dos años académicos, Martín Jiménez fue encargado por las Universidades («sindicus et procurator rectorum et universitatis scholarium ultramontanorum et citramontanorum") de percibir 150 libras en préstamo de los banqueros florentinos della Scala, para pagar con ellas el salario del canonista de Narbona Stephanus Boverii ${ }^{49}$. En este momento

\footnotetext{
46 No es este el lugar de resumir la vida institucional de Mascarella y la presencia de Martinus Eximinis en ella. Para el período anterior a su muerte en 1300, véase P. TAMBURRI, Presencia institucional de Roncesvalles en Bolonia (s. XII-Xvi), "Hispania Sacra», 49, Madrid, 1997. En general, F. CAlzoni, Storia della chiesa parrocchiale di Santa Maria in via Mascarella [...], compilata da, Bologna, 1785, pág. 22. P. Rodriguez PONGA, en el meritorio trabajo (inédito) al que se aludía al comienzo, recuerda un «Martinus Hispanus», aragonés, que sin duda se identifica con éste, y que se distingue también por su larga permanencia en Bolonia y por su actividad pública, siendo desconocidas sus obras como canonista

${ }_{47}$ M. SARTI y M. FatTorini, De claris, II, pág. 315, en 1276, pág. 320, en 1281, pág. 21, en 1282, y, como maestro, M. SaRTi y M. Fattorini, De claris I, pág. 483.

48 M. Sarti y M. FattorinI, De claris I, págs. 483-484; C. Ghirardacci, Della historia di Bo logna, Bologna, 1596 (reed. R.I.S., t. XXXIII, pág. I, ed. A. SorbeLlı, Bologna, 1932), lib. X. A.L. TRombetrI, L'esame di laurea presso lo Studio bolognese. Laureati in diritto civile nel secolo XV, en G.P. Brizzı y A.I. PINI, Studenti, págs. 147 y ss., además de G. CEnCETti, La laurea nelle Università Medievali, «Studi e memorie per la storia dell'Università di Bologna», 16, Bologna, 1943, págs. 249-273, y L. PAOLINI, La laurea medievale, en O. CAPITANI, dir., L'Università a Bologna. Personaggi, momenti e luoghi dalle origini al XVI secolo, Milano, 1987, págs. 133-156.

49 M. SARTi y M. FatToRini, De claris l, pág. 484.
} 
de máxima gloria académica y política, el 1 de julio de 1298, fue testigo del nombramiento del arcediano de Bolonia Guido di Baysio. Con estos pocos datos, Martín Jiménez deja de sí una imagen de maestro ultramontano perfectamente insertado en la sociedad civil boloñesa. Como canonista, no produjo una obra relevante y conocida, pero en cambio tuvo una considerable práctica docente, política y probablemente forense, que le reportaron excelentes contactos en la ciudad y una fortuna personal no desdeñable. Como contrapartida, su italianización fue total, y Martín Jiménez, en el momento de su muerte, había cortado todos los vínculos con la comunidad española, que no aparece representada en la compleja documentación de su testamentaría. Consciente de su decisión de quedarse para siempre en Bolonia, él se hizo en todo italiano, y, a diferencia de otros célebres maestros españoles, más activos científicamente pero menos partícipes de la vida boloñesa, no volvió a España ni siquiera a morir.

Nada menos que once documentos en los Memoriali de 1300 se refieren a Martinus Hispanus y a sus bienes. Sabemos que el maestro murió en Bolonia o su comarca a lo largo de la primera mitad del año, porque el 12 de mayo vivía todavía, en las proximidades de S. Andrea degli Ansaldi; en esa fecha compró un solar en Borgo Panigale a Lodomintus Johannis de Cento, por 59 libras, tres sueldos y cuatro dineros. Todavía el 20 de junio vendió a un cierto Vandinus diversos terrenos por 607 libras y 7 sueldos. Cifras, como vemos, bastante considerables ${ }^{50}$, en un momento inmediatamente anterior a la muerte del jurista. En efecto, aunque no sabemos la fecha ni el lugar exactos, y no hay rastro de su testamento en la documentación notarial, todo lleva a pensar que falleció cerca de Bolonia pero fuera de la ciudad propiamente dicha (en las poblaciones donde se situaba buena parte de sus intereses). Sin rastro de su testamento, tal vez porque no fuese debidamente registrado, ya el 25 de julio ${ }^{51}$ Paganus de Caxate, milanés, nombró procuradores en Bolonia (Francesco de Medios de Milán y el dominico Gaspar) para recuperar un crédito de cien libras de los herederos de Martín por deudas de éste. Considerando que la noticia del fallecimiento debería haber llegado a Lombardía al menos una semana antes, Martín Jiménez pudo morir entre el 20 de junio y tal vez el 15 de julio de 1300. Si había llegado a Bolonia entre los 20 y los 30 , y se había doctorado más o menos cinco años después, el canonista tendría entre 55 y 65 años al morir.

50 L. CONTINelli, L'archivio, págs. 71-74: volúmenes 98 (primer semestre), 99 (primer y segundo semestre) y 100 (parcialmente, segundo semestre). A.S.B., Memoriali, 098, 1300; 1 . 242 r. [243r.], 4 (I. 25-29). A.S.B., Memoriali, 98, 1300; f. 125r.-125v., 3 (l. 46-58 y 1-26).

51 A.S.B., Memoriali, 99, 1300; f. 187v., 3 (I. 18-23). 
Cinco días después, el 30 de julio, aparece por primera vez el heredero de Martín. Bonifacio de Langlano, en tal condición, pagó en esa fecha 89 libras a Francesco Allamanni de' Guarinis por una pequeña viña de algo más de una hectárea en Borgo Panigale que el maestro había comprado poco antes de morir y no había pagado todavía. Esto nos permite afirmar que su muerte había sido totalmente inesperada, mientras estaba todavía consolidando su situación patrimonial en los inmediatos alrededores de la ciudad, a partir de un sólido prestigio forense y docente. De Bonifacio, el heredero lombardo, no sabemos casi nada; raramente estaba en Bolonia atendiendo sus intereses, y así, por ejemplo, el 29 de agosto, Martino Thomaxini de Marsiliis era su procurador en la ciudad, representado a su vez por fray Rodolfo, de la Orden de San Juan de Jerusalén. Al día siguiente, 30 de agosto, este fray Rodolfo, el dominico Giovanni da Faenza y Martino de Marsiliis, como procuradores de Bonifacio, venden la viña de Borgo Panigale comprada un mes antes. En este documento, aunque se confirma el origen milanés de Bonifacio, se explica su vinculación con BoIonia, y por consiguiente con el español Martín, al llamársele «canonicus bononiensis» 52 .

El 6 de septiembre, como saldo parcial de la parte de la herencia (bienes o créditos) situada fuera de la ciudad y de su territorio, Bonifacio recibió 114 libras del banquero Gomes Zantis de Pistoia, ejecutor del testamento en aquella ciudad. El 7 de octubre, el ya citado Paganus de Caxate (a través de sus procuradores fray Gaspar y Francesco de Medios) recibieron 100 libras del testamento de Martín, tal vez por disponer los ejecutores de suficiente liquidez en aquel momento, gracias a la remesa del mes anterior. El 27 de noviembre, Bonifacio vendió una finca en Borgo Panigale a Rolandino Lamberti Bonçagnis por 374 libras; la mayor parte de los bienes inmuebles de Martín Jiménez se concentran en una zona muy concreta en el Noroeste de Bolonia. El mismo día, nombró otros dos procuradores - Paxanus de Altedo y el doctor Conadoris de' Guidonispara cobrar algunas deudas impagadas de Martín en Bolonia. Tres días después, a través de Horiaus pagó a los tres anteriores procuradores 60 libras que Bonifacio les debía por gastos hechos en la gestión de la herencia del español ${ }^{53}$. Sin embargo, el complejo proceso de asunción y li-

52 A.S.B., Memoriali, 99, 1300; f. 269r., 1 (I. 3-13). A.S.B., Memoriali, 099, 1300; f. 351 v., 3 (I. 35-43). A.S.B., Memoriali, 99, 1300; f. 282r., 2 (I. 20-30). La viña era de unas cinco «tornature», y fue vendida por 110 libras a un cierto Bonundo, que evidentemente no hizo un buen negocio.

53 A.S.B., Memoriali, 100, 1300; f. 313v., 5 (I. 47-59). A.S.B., Memoriali, 99, 1300; f. 223v., 1 (I. 9-16). A.S.B., Memoriali, 100, 1300; f. 89r.-89v., 2 (I. 63-70 y 1-18). A.S.B., Memoriali, 100, 1300; f. 89v., 1 (I. 19-26). A.S.B., Memoriali, 099, 1300; f. 311 v., 2 (I. 13-30). 
quidación del patrimonio (razonablemente extenso pero no enorme) no había terminado.

El 19 de agosto de 1301, en efecto, Bonifacio pagó a Borghexanus Ugolini 200 libras que Martín Jiménez le debía. El 29 del mismo mes Bonifacio de Loglano, esta vez sirviéndose de los procuradores habituales, recibió 90 libras que Liurgungo [?] Alberti y Jacobus de Placi debían a Martinus Ispanus. El 12 de octubre, Bonifacio vendió una casa en el mismo Borgo Panigale, con un terreno menor de una hectárea, heredada del maestro Martín, a Prone [?] Pellegrini Symoni por 89 libras. En cambio, el 2 de noviembre (mediante el procurador Amadore Albertini) tuvo que pagar una deuda, del mismo origen, de 40 florines, a Anselmo de Bérgamo. Finalmente, Bonifacio consiguió liquidar la herencia en 1302. El 5 de abril, Venturino Bresani de Valleriis recibió de un procurador del milanés Bonifacio de Langlano - Brabanaxius de Azoguidis- 30 libras boloñesas que le debía Martinus Ispanus ${ }^{54}$.

La muerte de Martín Jiménez, aparentemente súbita, dejó su obra patrimonial sin terminar, al menos en relación a las expectativas que su óptima inserción social en Bolonia le permitía sin duda mantener. Su patrimonio fundiario, sin ser enorme, podría haberse convertido en la garantía de una vejez tranquila para un clérigo jurista español que llevaba más de treinta años viviendo como un boloñés. De su heredero, el italiano Bonifacio, no se conoce nada, ni siquiera la relación que tuvo con el causante. Puede pensarse que se trató de un discípulo del español, elegido como heredero por una persona sin vínculos familiares en su patria de origen. Por lo que dejó ( $y$, al faltarnos el testamento, no sabemos nada de sus bienes muebles y especialmente de sus libros), Martín Jiménez parece haber tenido una vida profesional bastante fructífera; sin duda no era el porvenir que le reservaban sus superiores de Roncesvalles cuando lo enviaron a la Mascarella, pero, quedándose en Italia, había obtenido una posición muy respetable en la ciudad, como punto de partida de un siglo que vio, sucesivamente, el final de la presencia significativa de maestros españoles, el auge y declive de la comunidad estudiantil y, fuera del período que a continuación nos ocupará, su definitiva consolidación con el Colegio de España.

54 L. Continelul, L'archivio, págs. 74-76; Volúmenes 100 (parcialmente, segundo semestre), 101 (primer semestre) y 102 (segundo semestre). A.S.B., Memoriali, 102, 1301; f. 383r. [386r. ], 4, (1. 21-34). A.S.B., Memoriali, 102, 1301; f. 86v., 1 (1. 7-16). A.S.B., Memoriali, 102, 1301; f. 109r., 3 (I. 20-36). A.S.B., Memoriali, 102, 1301; f. 426r., 6 (I. 36-42). 1302, L. CONTINELLI, L'archivio, págs. 76-79: Volúmenes 103 (primer semestre), 104 (segundo semestre) y 105 (segundo semestre). A.S.B., Memoriali, 103, 1302; f. 170r. (I. 39-46). 


\section{LA PRESENCIA ESPAÑOLA DEL APOGEO A LA CRISIS: 1299-} 1321

«... erant hic tunc tempore bene milia scholarium ${ }^{55} \ldots$... A falta de matrículas hasta fechas muy posteriores, la primera duda sobre los españoles en Bolonia es su número exacto y las variaciones del mismo del s. XIII al XIV, cuestión que se intentará resolver pero sobre la que nunca habrá una precisión absoluta. Según S. Sven Stelling-Michaud, los estudiantes eran unos dos mil en 1300, dos tercios de ellos ultramontanos, lo que no es poco en una ciudad de unos 50.000 habitantes. Se considera generalmente, en proporción a esto, que los españoles serían unos cincuenta cada año, entre nuevas llegadas y estudiantes avanzados. Los Memoriali entre 1299 y 1330, sin embargo, sólo reflejarían datos sobre de un 30 a un $50 \%$ del total de aquéllos, si se respetan los porcentajes observados en suizos e italianos ${ }^{56}$.

Antes de dar una respuesta en lo posible definitiva, que sólo puede venir dado por los Memoriali y las fuentes complementarias, hay que recordar lo que todos los estudios coinciden en subrayar: el número de maestros españoles, importante en el XIII, se reduce rápidamente en el XIV ${ }^{57}$. El nexo universitario se limitó progresivamente a los solos estudiantes, y después se redujo también en este ámbito. Por excepción, en $1299{ }^{58}$ no aparece ningún documento de los Memoriali referido a los españoles, muy probablemente ausentes de Bolonia por la situación de práctica guerraa civil en la ciudado. En 1300, en cambio, en tres volúmenes, dieciséis documentos se refieren a los estudiantes españoles, aunque hay circunstancias excepcionales que lo explican: son también dieciséis los documentos, entre 1300 y 1302, los referidos, como acabamos de ver, a la herencia del maestro Martín Jiménez ${ }^{59}$.

Dejando aparte lo ya visto, el 3 de julio Pedro Pérez de Villarrasa, de Mallorca, estudiante "catalanus» reconoce una deuda de 2100 sueldos torneses de plata con Guillermo Ferrer, hijo del mallorquín Bernardo. Son testigos del acto Berenguer, hijo de Guillermo Fuxer, de Mallorca, scholar

\footnotetext{
55 A.I. PINi, Discere, pág. 64.

56 S. SteLLING-MichaUd, L’Université, págs. 38 y ss.

57 A. GARCIA Y GARCIA, La penetración, pág. 582. Se da además una concentración a partir de 1350.

58 L. Continelli, L’archivio, págs. 69-71. Volúmenes 96 y 97 de los Memoriali, el último no totalmente.

59 L. CONTINELLI, L'archivio, págs. 71-74 (vols. 98, 99 y parcialmente el 100).
} 
Bononie, y Johannes Gerardi, de Narbona ${ }^{60}$. El 20 de julio ${ }^{61}$, el italiano Dominicus Johannis Açonis se compromete a pagar a Guidus Deodati, estudiante de Derecho de Barga (Lugo), 36 libras en un plazo de seis meses por Codex y dos Digestos; testigos del acto son otros dos gallegos, de los que sólo es legible el nombre de Rodolfo Domínguez, hijo de Jacobus. Varios meses después, el 30 de noviembre, Pedro Jiménez, canónigo de Roncesvalles, realiza diversos nombramientos relativos a la gestión de la encomienda de la Mascarella ${ }^{62}$.

En uno de los contratos más interesantes de este momento, el 11 de diciembre, Pedro Baioli de Barcelona confió a Ghisalbertus Pergaminus textos jurídicos valorados en 700 libras boloñesas para que el italiano se

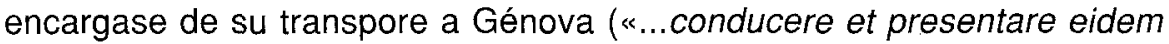
d. Petro in civitate Janue») ${ }^{63}$. No es una biblioteca pequeña, especialmente para un estudiante, lo que hace pensar en una estancia larga en Bolonia y en una buena posición. Se trataba de «duo Digesta Vetera cum apparatu domini Accursii, duos Codices cum apparatu domini Accursii, Digestum Novum cum apparatu Accursii, Infortiatum cum apparatu Accursii, Volumen cum apparatu d. Accursii, Sumam Açonis, Decretales cum appparatu d.Bernardi, et Speculum domini Guillelmi Durantis (...) quos quidem libros omnes sollidos, integros et immacullatos". El contrato recibió la forma legal de cambio de moneda, 370 libras boloñesas por 112 libras y 19 sueldos de groses torneses, que era la fórmula habitual de disimular un préstamo a interés prohibido; los libros se entregan formalmente "nomine pignoris et ypothece". Sin embargo, es en esta ocasión un procedimiento para obviar las rigurosas normas boloñesas contra la exportación de libros jurídicos. En este acaso, un estudiante, que parece haber terminado sus estudios en Italia, desea llevarse consigo los libros comprados, aunque para esto sea necesario recurrir a un fraude de ley. Entre los cinco testigos del contrato aparece de nuevo Pedro Pérez de Villarrasa. El año

60 A.S.B., Memoriali, 100, 1300; f. 153v., 1 (I. 5-17). A. García y García, Escolares, pág. 42, n. 90; ibídem, pág. 36, n. 42, y págs. 32-33, n. 11. A.S.B., Memoriali, 99, 1300; f. 400v., 3 (I. 2238). A. Garcia Y García, Escolares, pág. 38 , n. 61.

61 Parcialmente publicado por G. ORLANDELl, // libro, pág. 43, doc. 14. A.S.B., Memoriali, 100, 1300; f. 298r., 4 (l. 28-36). El topónimo «Barga» aparece igualmente en las cercanías de Lucca, pero «lucenses" identifica a los españoles frente al itálico «lucanenses» (tanto en contextos cultos como en el uso común). El problema se presenta varias veces en la documentación notarial boloñesa que nos ocupa.

62 A.S.B., Memoriali, 99, $1300 ;$ f. 247 r.-247 v., 6 (I. 50-60 y 1-7). P. TAmBurri, Presencia institucional, pág. 351.

63 Parcialmente publicado por G. OrLANDELLi, // libro, pág. 48, doc. 37, por A. García y García, Escolares, págs. 24-25, y por A. GaRcíA Y GaRcíA, La penetración, pág. 579. A. GaRcía Y García, Escolares, pág. 42, n. 81, «Pedro o Pani Barch». 
concluyó con un contrato, del 14 de diciembre, por el que el doctor jurista Franciscus de Saxolinis prestó 60 libras al canónigo Guillermo, hijo del miles Raimundo de Villamarín, y a Gerardo hijo de Bernardo Palarolo, ambos estudiantes de la «natio» de los «catalani» 64 .

1301 está recogido en tres volúmenes de los Memoriali ${ }^{65}$. Seis documentos nos interesan, aunque de cuatro de ellos ya hemos hablado al tratar de Jiménez. El 23 de junio de 1301, dos corresponsales del banco florentino Acciauoli, Bonifacius Blanchi Cose y Benvenuto Bonaçunte, garantizan el transporte a Génova de 24 libros jurídicos («iuris canonici et civilis") valorados en 520 libras, propiedad de Hugo de Hermo y Pedro Sánchez de Aragón ${ }^{66}$, "utriusque iuris doctores». Como testigos, Jaime («Jacobus») de Tardaro, Lanfranco di Michele, y el doctor canonista Sancho de Savena. A continuación, en otro orden de cosas, el 19 de julio Semidi de Morama, representando al español Sebonus Bitigotis («de Spania»), paga a Mellinus y Mapheus, hijos del mercader Luterius, 60 libras que le había prestado anteriormente ${ }^{67}$. Con esto terminó el año desde el punto de vista de la actividad económica de los españoles.

Ya en 1302, hay cinco documentos que se refieren a los españoles, uno de los cuales referido a la herencia de Martín Jiménez ${ }^{68}$. El 7 de julio Raimundo Bonacursio de Toledo y el maestro boloñés Coruolinus Compagnonis de Corbeleriis se reconciliaron públicamente, sin mencionar, por desgracia, las causas de la querella ${ }^{69}$. El 16 de octubre, los estudiantes españoles Miguel Miguélez Botero, vicario della diocesis tarraconense de Castellón, Gerardo de Bernardo Palazuelo, de Barcelona, y Berenguer hijo de Guillermo Fuxer, de Mallorca (ya presente en 1300), y el doctor boloñés Franciscus de Saxolinis reciben solidariamente un préstamo de 80 libras del florentino Gucio de Agolantibus ${ }^{70}$. En un do-

\footnotetext{
64 A.S.B., Memoriali, 99, 1300; f. 253v., 2 (I. 12-16). A. GARCiA Y GARCiA, Escolares, pág. 36, n. 39.

65 L. CONTINELLI, L'archivio, págs. 74-76: en el 101 hay también algunos documentos del primer semestre, en el 102 algunos del segundo y en el 100 los demás, con otros del año anterior.

66 Parcialmente publicado por G. ORLANDELLI, // libro, pág. 51, doc. 51, y por A. GARCíA Y GARCíA, Escolares, pág. 25. A.S.B., Memoriali, 101, 1301; f. 173v.[172v.], 4 (I. 16-22). A. GARCíA Y García, Escolares, pág. 37, n. 52. A. Gafíla y García, Escolares, pág. 42, n. 89.

67 A.S.B., Memoriali, 102, 1301; f. 455v.[458v.], 5,(I. 43-510). A. García Y GARCíA, Escolares, pág. 44, n. 102.

68 L. CONTINELLI, L'archivio, págs. 76-79, tres volúmenes de los Memoriali: v. 103 (primer semestre), 104 (segundo semestre) y 105 (segundo semestre).

69 A.S.B., Memoriali, 104, 1302; f. 307r. [306r. ], 1 (I. 15-23). A. Garcia y García, Escolares, pág. 43, ก. 93 .

70 A.S.B., Memoriali, 104, 1302; f. 99r., 1, (1. 10-15). A. García Y García, Escolares, pág. 41, n. 75 ; pág. 36, n. 35 ; págs. 32-33, n. 11.
} 
cumento de la misma fecha ${ }^{71}$, los tres estudiantes españoles se compromenten solidariamente a responder de las obligaciones contraídas por el maestro italiano junto a ellos. En definitiva, los tres españoles se sirvieron de la garantía del maestro para obtener un préstamo, pero en realidad ellos tres eran los únicos deudores. Fueron testigos comunes a ambos actos los españoles Panelonis d. Fusio [?] y Esteban Sueiro, canónigo de Silos, con Raynaldus «de Ybernia». El 16 de noviembre $\mathrm{Pe}-$ trus Jacobini "capelle S.Nicholai burgi S.Felicis de Bononia» vendió parte de sus textos jurídicos («unum volumen «Institutionum», tres libros «Codicis» in alipis ligneis, coopertis de corio albo, sic incipientes: «Imperatoriam Maiestatem», secundum «Dedit idem» et ultimum incipit «Deboen. solitario" ") a Filipo Rolandi de Ramponibus por 29 libras, siendo testigos el italiano Arnoldo Rizardi, el inglés Rogerio, y el estudiante español Miguel ${ }^{72}$.

Por causas seguramente más relacionadas con la turbulenta vida política interna de la ciudad y de la Universidad que a la situación de los reinos hispánicos, durante más de dos años, en 1303-1304, no se hallan documentos notariales boloñeses que hagan referencia a estudiantes o maestros españoles; aunque esto no significa necesariamente una ausencia total de los mismos, puede permitir suponer una reducción muy considerable ${ }^{73}$. Entre 1303 y 1307 se dieron múltiples pasos hacia un control efectivo del Estudio por las autoridades municipales, y así, en 1304 , la concesión de doctorados fue sometida al control comunal. Sucesivamente, el "Comune», inspirado y controlado por la familia Pepoli, empezó a subvencionar los emolumentos de los maestros juristas más importantes del momento (Jacopo Belvisi, Giovanni d'Andrea, Jacopo Bottrigari y Pietro Boattieri), demasiado costosos para una Universidad en la que las finanzas estaban sin duda muy afectadas por la drástica disminución de los ultramontanos. Para los Pepoli, ésta era una manera de garantizar el control municipal sobre la Universidad y su propio control cuasi señorial sobre el municipio; un cambio, como se ve, profundo, y contrario a la tradición universitaria ${ }^{74}$.

71 A.S.B., Memoriali, 104, 1302; f. 99r., 2, (I. 16-18).

72 Parcialmente publicado por A. Garcia Y García, Escolares, págs. 25. A.S.B., Memoriali, 105, 1302; f. 75v., 3 (l. 15-21). A. García Y García, Escolares, pág. 41, n. 76.

73 L. ConTINELLI, L'archivio, págs. 79-81, volumen 106 para el primer semestre y el 107 para el segundo. A.S.B., Memoriali, 107, 1303; f. 325 I., 3 (l. 26-31), del 26 de septiembre de 1303. L. CONTINELLI, L'archivio, págs. 82-84 (108-primer semestre-y 109-segundo semestre-).

74 R. GRECl, L'associazionismo, págs. 34 y ss. La lucha de los ultramontanos contra el Comune: A. SORBELLI, La "Nazione" nelle antiche Università italiane e straniere, "Studi e memorie per la storia dell'Università di Bologna», 16, Bologna, 1943, págs. 171 y ss. 
En 1305, en medio de estas transformaciones, reaparecieron los españoles, en un único documento del 31 de mayo ${ }^{75}$. En aquella fecha, el boloñés Alberto Guidoni vendió una casa a Miguel «de Yspania» por 28 libras, junto a Santa Maria «delle Muratelle». Con cuatro testigos italianos, este documento es una prueba más de la gran presencia española en la parroquia de S. Cristoforo de Saragozza, como vamos a ver. Aunque A. García y García identifica a Michael Johannis con el homónimo canónigo de Sigüenza, presente un año después en Bolonia, no hay evidencias definitivas; también podría identificarse con Miguel de León, rector de los ultramontanos en 1308-1309 ${ }^{76}$. Rector en 1304-1305 era Pedro de Costa, pero no aparece en los Memoriali de aquellos años ${ }^{77}$.

Los volúmenes 112 y 113 corresponden a los dos semestres de 1306 . Dos documentos incluyen actores españoles; el 18 de enero ${ }^{78}$ Juan de Ludrino y Bonetus de Ripoll, junto al borgoñón Guiçardus Galiani, recibieron 116 florines de Charatus Raynerii, agente local de los banqueros pistoyeses Clarentis, dejando algunos libros como prenda. El 19 de marzo, Juan Mini Diéguez, canonista español y canónigo de Castrojeriz, recibió de Miguel Ispanus, canónigo de Sigüenza, un libro valorado en 80 liras boloñesas (el Speculum de Guillermo Durante) que anteriormente la había prestado para que lo utilizase como garantía de un préstamo del banco florentino de Agolantis; el librero Nicola Vergillii de Suricis fue testigo y perito del empeño ${ }^{79}$. En $1307^{80}$ sólo hay un documento que nos concierna. El 4 de febrero, el catalán Berenguer de Chillano ${ }^{81}$ recibió 250 florines

75 L. CONTINELLL, L'archivio, págs. 84-86-Volúmenes 110 (primer semestre) y 111 (segundo semestre). A.S.B., Memoriali, 110, 1305; f. 36 1r., 3 (I. 29-36). A. García y GarcíA, Escolares, pág. 41, ก. 76.

76 A. Pérez MARTin, La precedencia del Rector del Colegio de España. Su defensa frente a la Universidad de Bolonia en 1565, "Studia Albornotiana", XXXV, «El cardenal Albornoz y el Colegio de España», IV, Bolonia, 1979, pág. 704, C. MALAGOLA, I Rettori nell'antico Studio bolognese e nella moderna Università di Bologna. Note storiche sul Rettorato e serie dei Rettori, en C. MALAGOLA, Monografie storiche sullo Studio bolognese, Bologna, 1888, págs. 1-128, y C. MALAGOLA, Serie dei Rettori e dei Vice-Rettori, Reggenti e Pro-Reggenti nell'antico Studio e nella moderna Università, in C. MALAGOLA, Monografie, págs. 129-220.

77 A. PÉrez Martín, La precedencia, pág. 704, C. Malagola, / Rettori, pág. 1-128, y C. MaLAGOLA, Serie, págs. 129-220.

78 L. CONTINELLI, L'archivio, págs. 86-88. El primer documento parcialmente publicado por $G$. Orlandelli, // libro, pág. 73, doc. 158. A.S.B., Memoriali, 112, 1306; f. 352v., 4, (l. 22-28). En A.S.B., Memoriali, 112, 1306, f. 352 v., 3 (l. 15-21), el documento del borgoñón.

79 Documento parcialmente publicado por G. OfLANDELLI, // libro, pág. 73, doc. 159.A.S.B., Memoriali, 112, 1306; f. 128v., 1 (1. 15-28). A. Garcí Y Garcia, Escolares, pág. 39, n. 64, aunque parece leerse «Johannes Mini Didaci" y no "Johannes Nuni Didaci». Ibídem, pág. 41, n. 76, sobre Miguel Ispanus.

80 L. CONTINELLI, L'archivio, págs. 88-91.

81 A.S.B., Memoriali, 114, 1307; f. 203r., 1 (l. 7-15). A. García y García, Escolares, pág. 45, n. 108. 
de oro de su familia a través del mercader Petrus Abrini de Perpiñán, que los remitió a su vez al florentino asentado en Bolonia Guardo dei Salvi. Ya en $1309^{82}$, nos encontramos con un documento de mucho mayor interés; el 2 de mayo, Gombaldo García de Vergua ${ }^{83}$, aragonés, sacerdote de la diócesis de Zaragoza y estudiante de cánones, recibió en cambio de Bonifacius Roxe, agente del banco Acciaiuoli, 206 libras de sueldos turonenses por 293 florines de oro por dos meses; la operación financiera, no demasiado importante por su volumen, sí lo es por demostrar que el cambio diferido seguía sirviendo para disimular préstamos en otro caso legalmente imposibles. Algunos de los testigos son españoles, y otros bien podrían serlo: Bornius Dominici «de Yspania», de Ripoll ${ }^{84}$ "et nunc scolaris Bononiae», Hugo de Donato, Pedro Jiménez de Naval, aragonés, Benedacio de Bonaroda, y Nicolás Blanco, junto a Tommaso de Peniriis, representante del fiorentino Stefano di Uguccione.

En $1310^{85}$ nos encontramos con una situación similar a 1308, cuando los únicos documentos notariales referidos a españoles son los propios de la Mascarella, que aquí no nos interesan más que marginalmente. El 18 de agosto de $1311^{86}$, Bernardo Arnáldez de Castellón, estudiante de la «natio» catalana, recibió en cambio de Petrus Gerardini, agente de Napoleone de' Clarissimis, 46 libras boloñesas por 23 florines a oro a un mes, en un nuevo caso de préstamo disimulado de cambio diferido. En $1312^{87}$ hay tres documentos interesantes para la presente investigación. El 16 de mayo ${ }^{88}$, el aragonés García Aznar recibe en préstamo del banquero de Siena Nuntio Fuschi 90 florines de oro, dejando como garantía dos caballos; el 15 de septiembre, es el también español Pedro Amorabilis el que recibe de Jacobus Açuçii 14 florines por dos meses; finalmente, el mismo día, Fortún Pérez Amorabilis, hijo del anterior, ofreció un caballo como garantía del préstamo recibido por su padre. Aunque habría mucho que razonar sobre la condición de estudiantes de estos tres personajes (en especial de la del padre, por razones de edad), A. García y García considera con autoridad que probablemente io eran ${ }^{89}$.

82 L. ContinetLi, L'archivio, pág. 93-96 (Memoriali 118 y 119).

83 A. García y García, Escolares, pág. 36, n. 37.

84 A. García y García, Escolares, pág. 34, n. 23, con un nombre diferente: «Bonico Dunco Hispano de Ripoll».

85 L. CONTINELLI, L'archivio, págs. 96-99.

86 A.S.B., Memoriali, 123, 1311; f. 168r., 4 (I. 45-50). L. ContinelLI, L'archivio, págs. 99-101.

A. García y García, Escolares, pág. 33, n. 13.

87 L. CONTINELLI, L'archivio, págs. 101-105 (Memoriali 124 y 125).

88 A.S.B., Memoriali, 124, 1312; f. 119v.-120r., 2 (I. $49-56$ y 1-2).

89 A.S.B., Memoriali, 125, 1312; f. 209r., 2 (I. 33). A. García Y Garcia, Escolares, pág. 42, n. 80. A.S.B., Memoriali, 125, 1312; f. 209r., 3 (I. 34-37). A. GARCía Y GARCíA, Escolares, pág. 35, n. 32. 
Un documento llama la atención en 1313: el 20 de junio, los catalanes Raimundo Raimúndez Gota y Guillermo Pérez Brastichani reciben en cambio de Rodulfus, hijo del maestro Albertus, 32 libras boloñesas por 32 teóricos groses venecianos a dos meses ${ }^{90}$. Los documentos son dos en $1314{ }^{91}$. El 21 de febrero ${ }^{92}$ el estudiante tolosano Petrus Baralis, considerado español por A. García y García, y el italiano Johannes de Falcinella se comprometen, por una disputa relativa a la muerte de un caballo de propiedad común, a someterse al arbitraje de los escolares Antonio de Orense y Luca da "Urbeveteri» (Civitavecchia: otra vez un español y un italiano). El 5 de diciembre el catalán Pedro Pérez Façe, del condado de Urgel, nombró a su mujer Amanda Alegii su procuradora en Bolonia; fueron testigos Berenguer Coregonis, catalán, y Lorenzo Pérez o Peris de Valencia, y es la presencia de estos dos estudiantes la que confirma que Pedro Pérez era también escolar aunque estuviese casado ${ }^{93}$.

Los volúmenes de $1316{ }^{94}$ contienen dos documentos de interés: el 19 de febrero Gerardo de Guillermo de Sancto Lerio, catalán, recibe del boloñés Francesco Bandini da Roncore 50 libras boloñesas a cambio de 50 groses venecianos a un mes, ofreciendo un caballo como garantía y con Monducio de Pacis y Ponce Pons de Castellario como testigos ${ }^{95}$; el 5 de agosto, Antonio de Rota de Murcia obtiene de Thomaxinus Bentii, agente de los Peruzzi de Florencia, 40 florines de oro a cambio de una cantidad no especificada en moneda turonense. Esta transacción es además excepcional por no estar concertada en moneda boloñesa, pero no ofrece más particularidad que la de prescindir incluso de la formalidad de fingir una entrega que disimule mejor el préstamo. Los testigos fueron Jacobus Benasi de Florencia, Pedro Gómez, canónigo de Toledo, Alfonso Rodríguez, escolar en Bolonia y canónigo de Cartagena que reaparecerá en 1322, y Bernabé de Guillermo. Tal vez pueda identificarse el canónigo de Toledo con el rector de los ultramontanos juristas en 1317-1318, Pedro Cemerii ${ }^{96}$.

90 L. ContinelLI, L'archivio, págs. $105-109$ (126 y 127). A.S.B., Memoriali, 126, 1313; f. 310v., 5 (I. 35-39). A. García y Garcia, Escolares, pág. 43, n. 94, y pág. 37, n. 46

\$1 L. ContinelLI, L'archivio, págs. 109-112 (Volúmenes 128 y 129).

92 A.S.B., Memoriali, 128, 1314; f. 384r., 4 (l. 34-54). A. GarCía Y GARcía, Escolares, pág. 45, n. 112, «Pedro Bacal de Tolosa».

93 A. García y Garcia, Escolares, pág. 42, n. 87; pág. 32; pág. 39, n. 65.

94 L. CONTINELLI, L'archivio, págs. $112-115$ y 117-118 (130 y 132) para 1315 (vacío), y, págs. 115-118 (Volúmenes 131 y 132), para 1316.

95 A.S.B., Memoriali, 131, 1316; f. 316r., 3 (ł. 38-51). A. García Y García, Escolares, pág. 36 , n. 36 y pág. 43, n. 92 .

96 A.S.B., Memoriali, 132, 1316; f. 280r., 3 (I. 38-51). A. García Y García, Escolares, págs. 31 32, n. 4, si bien con apoyo documental diferente. Sobre Pedro Gómez, ibídem, pág. 42, n. 88. Sobre Alfonso Rodríguez, pág. 31, n. 2. Sobre el rector, A. PÉREZ MARTín, La precedencia, pág. 704, C. Malagola, I Rettori, págs. 1-128, y C. Malagola, Serie, págs. 129-220. 
España en la Universidad de Bolonia: vida académica y comunidad nacional...

Del 10 de mayo de $1316{ }^{97}$ es el único documento judicial penal que implica en estos años a estudiantes españoles en la Curia del Podestà; el bedel Graciadeus, el escribano Nicholaus y el borgoñón Giraldus, criado del estudiante Ottorino, entre otros, son testigos en esa fecha de las heridas que Menghus Jacobi Pischatoris causó con un cuchillo al español Martín de Vanello, civilista aragonés. Según A. García y García «Vanello» debe identificarse con Uncastillo (Zaragoza), pero esta población aparece claramente identificada en otros documentos de los mismos años.

En $1317^{98}$ hay dos documentos que implican directamente a estudiantes españoles. El aragonés («de Villa provincie Aragonie») Jaime de Bernardo, recibió 70 libras por 72 groses venecianos en cambio diferido a dos meses el 29 de septiembre ${ }^{99}$. El 2 de diciembre, en cambio, fue el catalán Jaime de Guillermo Calber, civilista, el que recibió 104 florines en un préstamo no disimulado del florentino Lippo de' Lapi, agente de Michele Guidolocti. Otros tres catalanes, Chimiro Alemán, Gerardino de Santiago y Martín Julián Conheneii fueron los testigos. No es seguro que este Jaime de Guillermo sea el mismo Jaime de Montjuich de Barcelona, maestro civilista en Bolonia y comentarista de los Usatges de Barcelona, que G.M. Brocá consideró todavía en vida en $1321^{100}$. Como 1308 y 1310, 1318 se caracteriza por reunir documentación notarial que, en lo relativo a los españoles, se refiere sólo a la Mascarella; en esta ocasión, es un grupo de estudiantes el que aparece como residente en la encomienda (de hecho, son testigos de un pago): el comendador junto a Alfonso Gil de Baeza, Accendo Martínez de Ayesa, García Pérez de Olcoz, Juan de Aragón, Mateo González, Pedro lbáñez de Chinelghi y Sancho Pérez de Caparroso ${ }^{101}$. Paralelamente, ante la Curia del Podestà comparecía Petronius Benenati Barberi para acusar a los hermanos Raimundo, Boneto y Bernardo Raimúndez de Torre, estudiantes, de agredirle y robarle; por

97 A.S.B., Curia del Podestà, Giudici ad Maleficia, Carte di Corredo, Maestri e scolari 13011317, Fascicoli estratti II, busta 35, 1316 ( $1^{\circ}$ Semestre) (Studio) Scolari e Maestri, doc. n. 9 [Documento en papel, c. $150 \times 250,16$ líneas]. Sobre Martín de Vanello, A. Garcia y Garcia, Escolares, pág. 41, n. 73.

98 L. ContinelLI, L'archivio, págs. 118-121 (133 y 134).

99 A.S.B, Memoriali, 134, 1317; f. 172r., 1 (l. 12-20). A. García y García, Escolares, pág. 38, ก. 53.

100 A.S.B, Memoriali, 134, 1317; f. 225r., 4 (l. 33-38). A. García Y GarcíA, Escolares, pág. 38, n. 54. Sobre Jaime de Montjuich, G.M. Brocá, Juristes, pág. 488. Martinus, en A. García Y García, Escolares, pág. 40, n. 68.

101 L. ContinelLI, L'archivio, págs. 121-125. (Volúmenes 135 y 136). A.S.B., Memoriali, 135 , 1318; f. 49r., 3 (I. 30-39). A. GARcía Y GARcía, Escolares, pág. 35, n. 29; pág. 31, n. 1; pág. 35 , n. 33; pág. 44, n. 101. Una vez más, nos remitimos a P. TAMbuRRI, Presencia institucional, passim. 
desgracia, esta acusación es el único testimonio existente de la presencia de estos catalanes en Bolonia ${ }^{102}$.

En $1319{ }^{103}$, último año de normalidad en la evolución de la presencia española en el Estudio (puesto que 1320, como se verá, representa un crecimiento velocísimo en las presencias documentadas, y 1321 es el principio de una crisis profunda), disponemos de tres documentos de interés. El 22 de junio ${ }^{104}$, Berenguer Sarre de Monbianco, catalán y civilista, recibió de Jacobus Cochi Pacis, de la sociedad florentina de los Arsini, 84 libras en cambio diferido de 100 florines de oro, con Bernardo Martínez de Perpiñán y los italianos Johannes Lançe de Garexendis, Bartholus Ubaldi, Asinarius Ferexii de Florencia y Jacobus Becharii de Bechariis como testigos. El 12 de septiembre ${ }^{105}$, este Bernardo y su hermano Guillermo de Leonardo Martínez, civilista, pagaron a Fiughio Bandini, agente de los Peruzzi, 163 florines que habían recibido en préstamo, siendo testigos los escolares hispanos Bartolomé Martínez de Nissella, rosellonés, Fondrighius y Remengardo Hominisdei de Perpiñán. Finalmente, el 29 de septiembre ${ }^{106}$, Arnaldo Roches de Rocheta, español, y Amodeus Boni recibieron de Pablo Lodovyci y Bombologno Jacobi de Lodoytis 160 libras por 80 florines de oro, en préstamo disimulado.

Como se ha visto, el despojo de los documentos de los 21 años entre 1299 y 1319 muestra diferencias de fondo con otro hecho, tiempo atrás, sobre una base documental muy parecida; la comparación gráfica entre ambos estudios arroja algunas luces sobre la cuestión ${ }^{107}$. A. García y García encontró en su despojo documental sólo 82 documentos, con 114 estudiantes españoles y 154 menciones a los mismos; en realidad, el material disponible ensancha el campo de estudio en un $20 \%$ en todos los sentidos ${ }^{108}$. Incluso sin considerar las diferencias cuantitativas y en composición, es evidente la diferente distribución a lo largo del tiempo de la muestra estudiada por A. García y García respecto a los datos definitivos de los Memoriali. Las divergencias mayores son dos: ante todo, A. García y García minusvaloró la recuperación de la afluencia desde 1321, considerándola casi nula cuando en realidad fue prácticamente total entre 1322

102 A.S.B., Curia del Podestà, Giudici ad Maleficia, Carte di Corredo, Studio. Maestri e scolari 1318-1348 (fascicoli estratti), busta 65,1318 ( $1^{\circ}$ Semestre) [Documento en papel, $300 \times 250,17$ líneas].

103 L. Gontinelli, L'archivio, págs. 125-128 (Volúmenes 137 y 138).

104 A.S.B., Memoriali, 137, 1319; f. 543v., 1 (1. 7-15).

105 A.S.B., Memoriali, 138, 1319; f. 309v. [310v.], 3 (I. 29-42).

106 A.S.B., Memoriali, 138, 1319; f. 236v., 4 (l. 41-49).

107 A. Garcia Y García, Escolares, gráficos págs. 20 y 13.

108 A. García Y García, Escolares, pág. 35. 
y 1324; por otra parte, valora excesivamente la importancia de la recuperación de 1328-1330, que parece haber permanecido siempre por debajo del $50 \%$ de las cifras máximas de comienzos de siglo y de comienzo de los años $20{ }^{109}$.

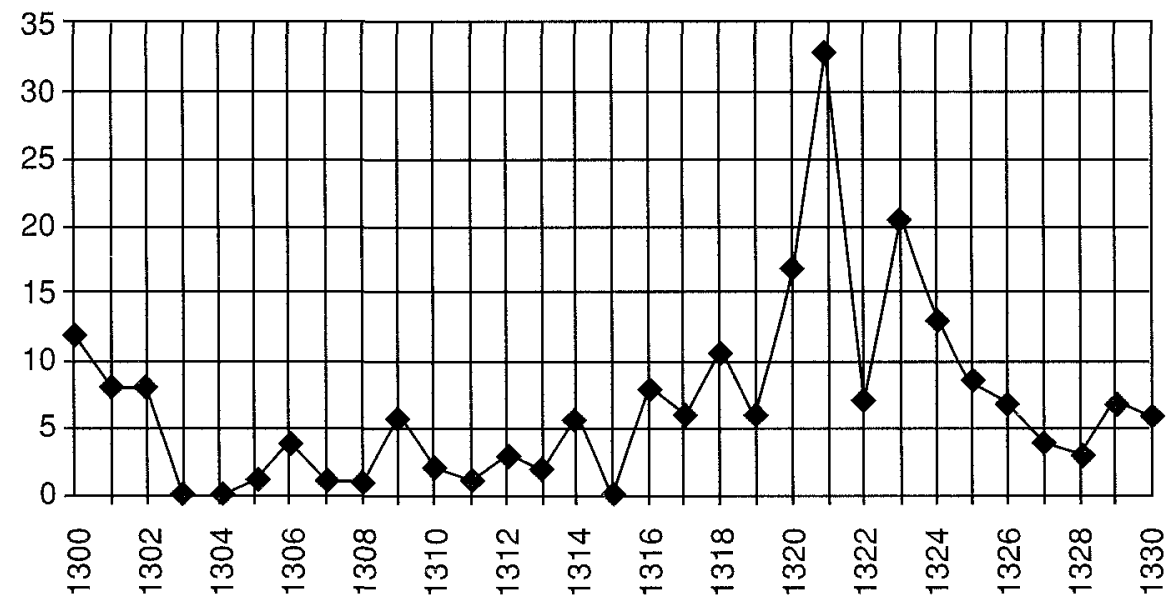

Estudiantes españoles en Bolonia (1300-1330).

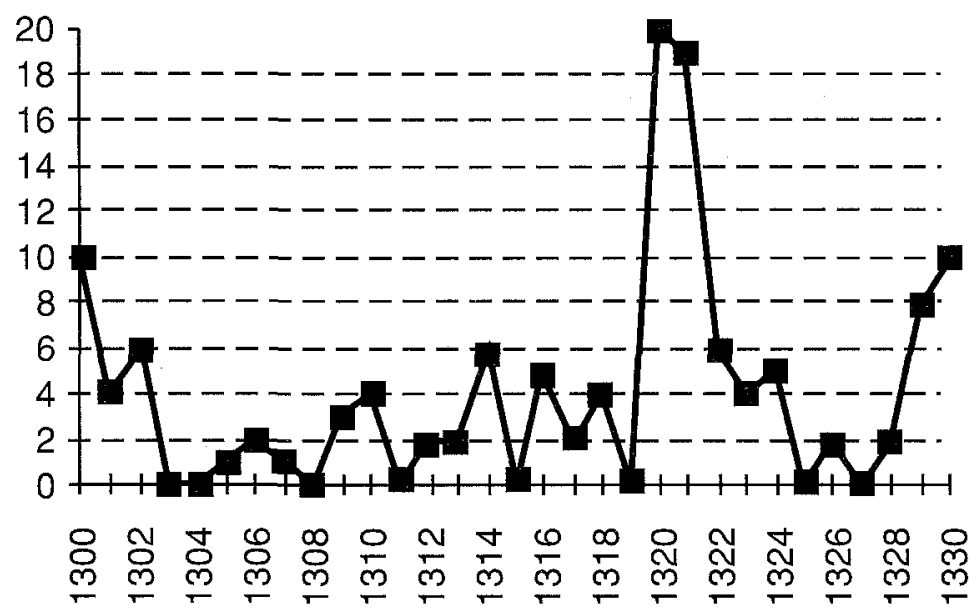

Estudiantes españoles (1300-1330) según A. García y García.

109 A. Garcia y Gabcía, Escolares, pág. 21. 
En cuanto al contenido, estamos viendo que los resúmenes que componen los Memoriali identifican casi siempre a cada uno de los estudiantes españoles con el nombre, la filiación y el lugar de origen (aunque no siempre figuran los tres elementos). Esta práctica plantea problemas no siempre fáciles de resolver. Para empezar, hay evidentes problemas de comunicación entre los notarios boloñeses y los escolares hispanos, problemas de comprensión que se reflejan en la plasmación escrita de los datos ${ }^{110}$. Así aparecen grafías aberrantes, a menudo increíbies o incomprensibles. Otra cosa son las variantes ortográficas de los nombres, incluso cuando se refieren a la misma persona o familia; mucho más difícil de resolver es el caso de ciertos estudiantes que se identifican más de una vez de modo diferente y contradictorio. Esta situación ha impedido la aplicación de esquemas rígidos y ha impuesto una consideración individualizada de cada caso. Junto a la grafía, hay otros problemas en la identificación de estudiantes. De algunos españoles se conoce sólo el lugar de origen, sea o no identificable; además, no siempre están claros, entre los siglos XIII y XIV, los límites entre topónimos y protoapellidos (un problema especialmente presente entre los catalanes). No faltan casos de homónimos casi contemporáneos, lo que obliga a servirse de otros datos contenidos en la documentación. Ante este variado panorama, no cabe establecer reglas fijas, sino estudiar en detalle los problemas de cada caso ${ }^{111}$.

De esta manera, es preciso recurrir a varios criterios combinados para reunir todas las menciones a cada español. Del mismo modo, se trata de evitar confusiones entre personajes; en la mayor parte de los casos, basta recurrir al lugar de origen o a la data de los documentos. En último extremo, los datos académicos contribuyen a solucionar algunas identificaciones. También en los topónimos de origen (unidos de manera no siempre clara al nombre propio) hay una gran variedad ortográfica; sobre el contenido de esta parte del nombre, hay que distinguir los nombres de la diócesis de proveniencia y el resto de los topónimos. La identificación geográfica en los Memoriali, como se ha visto, tiene por único criterio válido fijar qué nombre utilizaba efectivamente el estudiante en cuestión en BoIonia. La ambigüedad de las fuentes era reconocida ya en el XIV: en 1306 la nación germánica de juristas estableció en la matrícula la obligación de identificarse mediante el lugar de nacimiento y por ningún otro. Pero ni si-

\footnotetext{
110 Los detalles técnicos en J. PAQUET, Les matricules, págs. 57 y ss.: fonética frente a

${ }_{111}$ Desde el punto de vista de los teóricos de la informatización de la prosopografía histórica, C. Bourlet, A. Guillaumont, y J.-L. Minel, Intelligence artificielle et prosopographie, "Le médiéviste et l'ordinateur», 15, 1986, pág. 7.
} ortografía. 
quiera en este caso, que no es el de los españoles, las normas no parecen haberse cumplido. Son frecuentes, por otra parte, los topónimos idénticos o susceptibles de confusión ${ }^{112}$.

Los españoles del Estudio boloñés, organizados como queda dicho, representaban aproximadamente, por lo general, un décimo de los ultramontanos en Bolonia, por detrás sólo de los germánicos. Entre los españoles se incluían todos los peninsulares «a montibus Experiae», concepto retomado en 1377 por Gil de Albornoz al fijar las condiciones para el acceso a su Colegio ${ }^{113}$, y el mismo límite se ha adoptado en este trabajo. Se ha hablado ya del problema de los "catalani» y de la «natio» que llevaba su nombre ${ }^{114}$; pertenecer a la nación no implica proceder de Cataluña, sino de uno de los dos instrumentos de la presencia española en Bolonia: poseer dos «nationes» supone una posición privilegiada de la comunidad española, pero, en nuestro caso, obliga a ciertas cautelas.

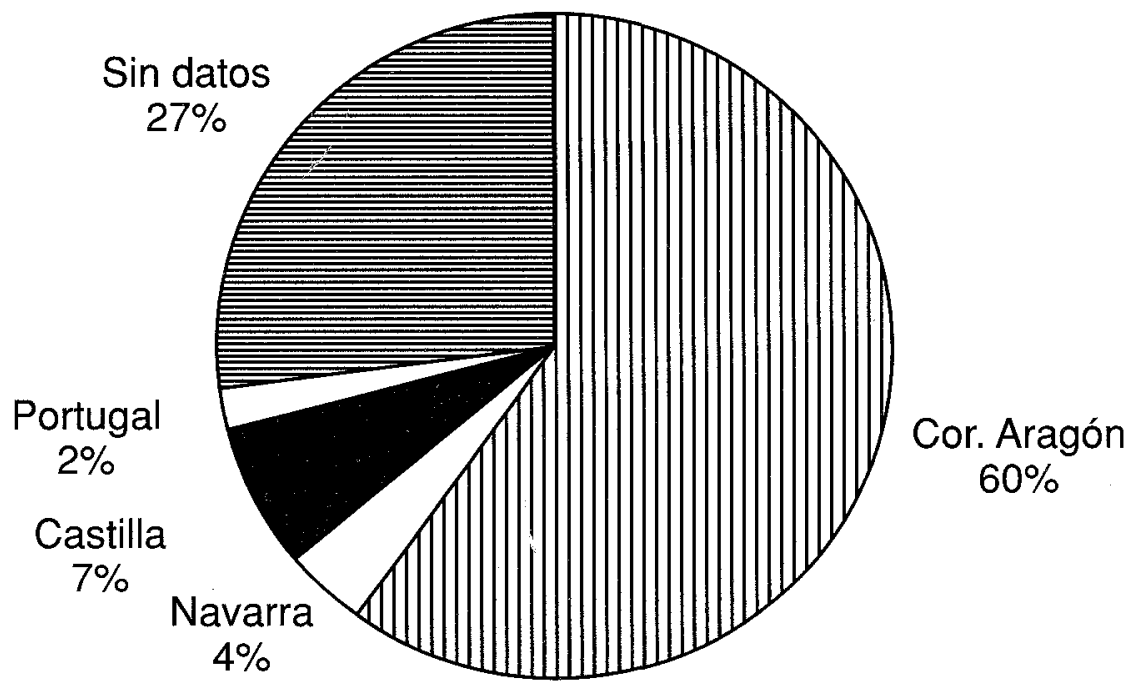

Origen de los estudiantes españoles, 1300-1330.

112 H. DENIFlE, Die Statuten, pág. 361.

113 A.l. Pini, Discere, pág. 64. A. PÉrez Martín, Proles Aegidiana, «Studia Albornotiana», XXXI, Bolonia, 1979, vol. I, págs. 39-40.

114 A.I. PIN1, Discere, pág. 67. 
La Corona de Aragón, en toda la variedad de su estructura compleja, fue una constante de la Edad Media italiana. La presencia de estudiantes catalanes, valencianos y aragoneses no deja de ser una consecuencia de unas relaciones que, permanentes, desbordaron lo económico y lo político para adquirir un contenido cultural. En particular, los aragoneses propiamente dichos, como los valencianos (súbditos de los respectivos reinos dentro de la construcción política aragonesa), son aproximadamente un $5 \%$ de los españoles y tienden a pertenecer (pero no siempre ni exclusivamente) a la natio de los catalanes.

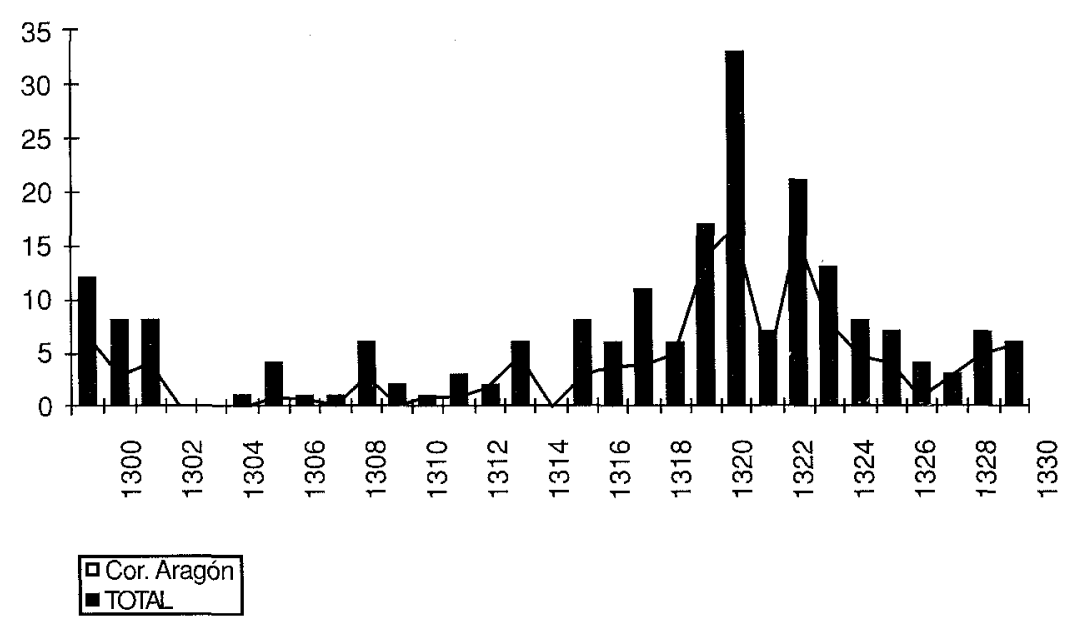

Estudiantes de la Corona de Aragón entre los estudiantes españoles en Bolonia, 1300-1330.

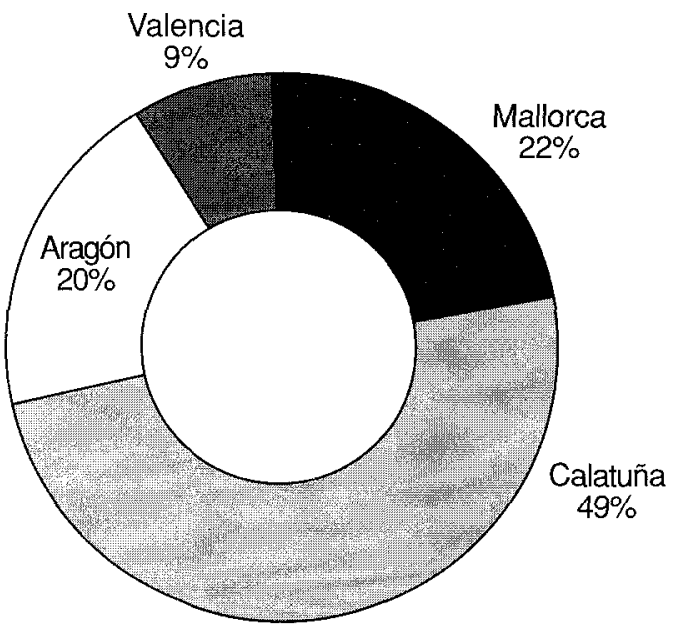

Origen de los estudiantes aragoneses, 1300-1330. 
El profesor García y García, partiendo de sus propios datos, atribuyó a los catalanes una presencia mayoritaria entre los españoles en Bolonia (el $48,2 \%$ de los mismos). Esta cifra parece exagerada, incluso si incluimos todos los súbditos del rey de Mallorca como catalanes, pero sin duda el Principado aportaba en el siglo XIV ( $y$ antes) el principal contingente regional ${ }^{115}$. Como vamos a ver, de los Memoriali resulta una presencia catalana ligeramente inferior y en cambio una llamativa contribución mallorquina (continental e insular). A efectos de esta clasificación, no hemos considerado catalanes a los roselloneses, políticamente mallorquines, y han sido completamente excluidos todos los casos dudosos de languedocianos y otros franceses meridionales. Un puñado de ejemplos, sin embargo (el más conocido de los cuales es el Jaime de Valencia que originó la crisis de 1321), son llamados "de Tolosia»; parece que su vinculación con la ciudad francesa es, en general, académica (Estudio de procedencia).

Con respecto a los catalanes y a su identificación en Bolonia, se plantean una serie de dudas que la documentación no siempre aclara. El principal problema es la existencia de una "natio catalanorum» en la Universidad de juristas ultramontanos. No todos los miembros de esa nación eran catalanes, como parece demostrado, y no sólo en el caso de Bolonia ${ }^{116}$; otros españoles prefieren tal afiliación, sin un criterio geográfico absoluto, y a todos los efectos puede hablarse, en el Estudio medieval, de dos naciones hispanas («Catelonia» e «Hispania», como se ha visto). Hasta tal punto fue numerosa la comunidad de. una u otra manera identificada como catalana que, en el centro de la Edad Media boloñesa, surge un segundo problema para localizar a sus componentes: al menos una familia boloñesa se llama $\mathrm{De}$ Catellanis, con algunos ejemplos incluso de un nombre propio Catellanus. Sin que pueda asegurarse que la familia en cuestión sea española de origen, sí conviene recordar el hecho por la confusión que introduce ${ }^{117}$.

115 A. García y García, Escolares, pág. 21. F. Tomás y VAL.Jente, Manual, págs. 201-203, atribuye a los catalanes una participación especialmente importante dentro de un número de españoles genéricamente definido como «elevado».

116 E. Veronese Cesaracciu, Spagnoli e Portoghesi all'Università di Padova nel ventennio 1490-1510, «Quaderni per la Storia dell'Università di Padova», 11, Padova, 1978, pág. 39.

117 M. FANTI, Prima dell'Archiginnasio: dalla curia Bulgari alle scuole di San Petronio, en L'Archiginnasio: II palazzo, I'Università, la Biblioteca, s. I. [Bologna], 1988, págs. 18-64, demás de G.N.P. ALIDOSI PASQUALI, Li dottori forestieri, pág. 50. La «torre dei Catalani», propiedad de esta familia y no alejada de la que entonces era zona universitaria, fue centro de prostitución antes de 1350 (una actividad siempre ligada al Estudio). Era, además, la zona ya entonces preferida por los españoles para vivir y la misma en la que había de instalarse después el colegio de D. Gil de Aibornoz. La familia de Catellanis, por otra parte, también ha dejado muestras directas de su persistencia en Bolonia entre 1280 y 1330 , por ejemplo en una compraventa inmobiliaria de Guillermo 


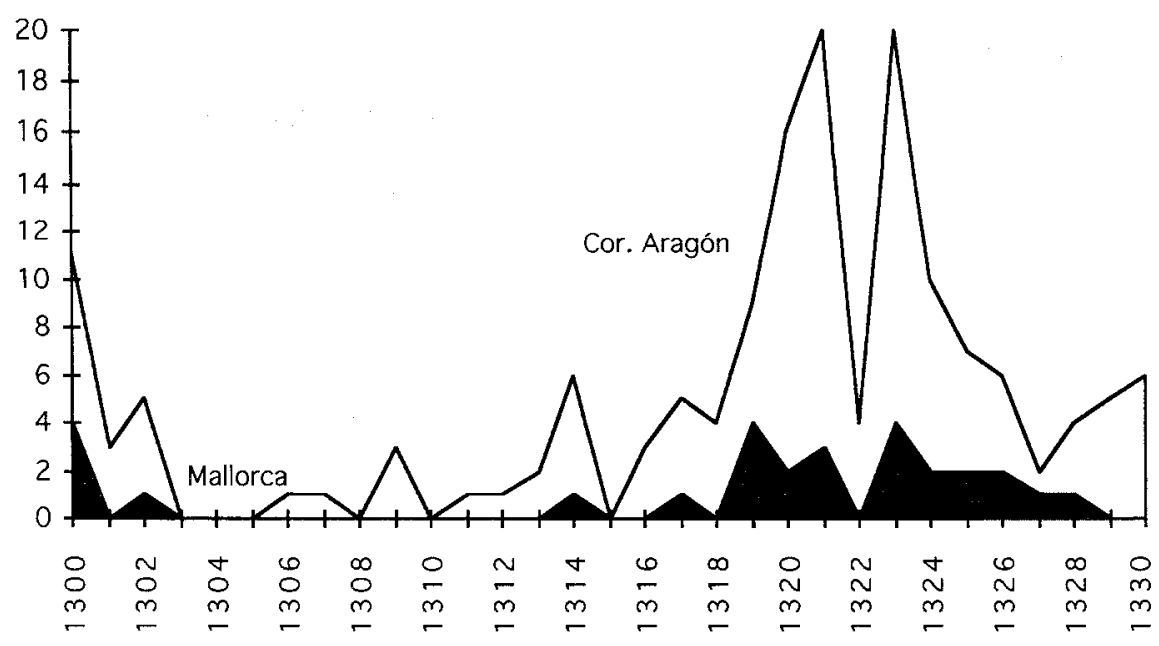

Estudiantes del Reino de Mallorca, 1300-1330.

Mallorca, como se ha señalado, supone una situación particular. La frontera nororiental del mundo hispánico no estaba entonces fijada con claridad, y, entre los siglos XIII y XIV existió un espacio político intermedio, claramente perteneciente al ámbito aragonés, pero incluyendo tierras que, como Rosellón (con Perpiñán), Cerdaña, Conflent y Vallespir, y dos tercios de Montpellier, son actualmente francesas. Desde la muerte de Jaime I (1276), junto a las Baleares, el Reino de Mallorca, con esta parte continental (pirenaica), mantuvo completa autonomía y una serie de reyes propios que parte de Jaime (II), hermano de Pedro III de Aragón ${ }^{118}$. Las Baleares, en especial, tuvieron una personalidad diferenciada, con una notable peculiaridad jurídica; al haber permanecido fuera del dominio estable del reino de Toledo, no estaba vigente en ellas el Fuero Juzgo visi-

de Catellanis registrada en el Memoriale de julio de 1299. A.S.B., Memoriali, 97, 1299; f. 94 r., 4 (I. 5-14). La cuestión es compleja y aquí sólo es posible plantearla en sus líneas esenciales; sería interesante, por ejemplo, estudiar la formación de "Catellanus», tal vez sobre el modelo de «Franciscus", sin duda anterior.

118 J.A. MARAVAll, El concepto de España en la Edad Media, Madrid, 1981, págs. 80-102. D. ABULAFIA, A mediterranean emporium: the catalan kingdom of Majorca, Cambridge, 1994, pág. 292. R. GlBerT, Historia general del Derecho español, Granada, 1968, pág. 142 (la independencia formal se mantuvo hasta Pedro IV el Ceremonioso, en 1343: R. GiberT, Historia, pág. 143). 
España en la Universidad de Bolonia: vida académica y comunidad nacional...

godo ${ }^{119}$, de tal manera que el Derecho común, meramente ornato intelectual en principio en el resto de España, y en todo caso no directamente aplicable hasta fechas posteriores. Por consiguiente, y hasta 1483, cuando Fernando el Católico dio a la Universidad de Mallorca los privilegios del Estudio de Lérida ${ }^{120}$, los juristas mallorquines necesitaban una formación específica que explica una afluencia a Bolonia comparativamente desproporcionada; esta posición absolutamente excepcional explica que se recurriese a ellos ante una necesidad técnica atípica, como fueron las leyes palatinas de Pedro IV ${ }^{121}$, y que lo mallorquines presentes en Bolonia, además de numerosos (como puede apreciarse en el gráfico), parezcan especialmente ricos y activos.

Castilla, a principios del siglo xIV y contrariamente a la situación del siglo anterior, aportó pocos escolares al grupo español en Bolonia. Sin duda hubo razones internas que lo explican, incluso políticamente, pero sobre todo hay que considerar la competencia de otros Estudios más cercanos, como los de la Francia meridional y, naturalmente, Salamanca ${ }^{122}$. Entre los castellanos presentes prevalecen los de las «tierras nuevas" meridionales, no tanto andaluzas cuanto manchegas. Algunos de los del Norte del espacio castellano-leonés plantean problemas peculiares, como

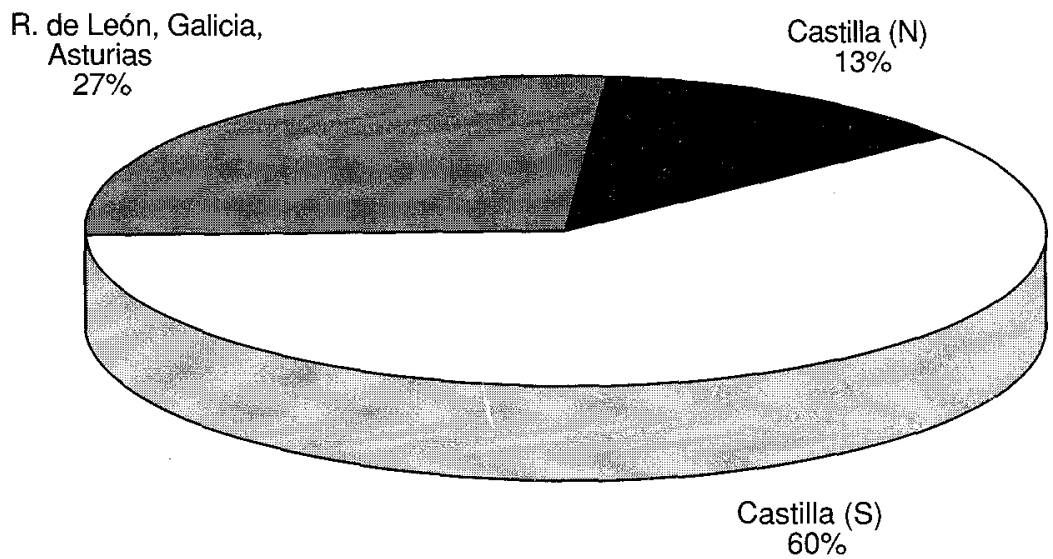

Estudiantes castellanos, 1300-1330.

19 R. GIBERT, Historia, pág. 117.

120 C.M. AJo G., y SÁINZ DE ZÚNIIGA, Historia de las Universidades hispánicas. Origenes y desarrollo desde su aparición hasta nuestros días, I: Medievo y Renacimiento universitario, Ávila (Madrid), 1957, pág. 324.

121 R. GiberT, Historia, págs. 118 y 144.

122 J.A. Maravall, El concepto, págs. 197 y ss, y 122 y ss. 
los venidos de Lugo y su obispado, llamados lucenses y, por consiguiente, susceptibles de confusión con los lucanenses (toscanos de Lucca), que se ha intentado aclarar en cada caso.

La presencia portuguesa, imposible de separar en este caso de las otras regiones peninsulares, fue cualitativamente importante, sobre todo, por las carreras posteriores de los estudiantes en Bolonia. Plenamente partícipes en la vida colectiva de la comunidad española, tuvieron también acceso al Colegio albornociano.

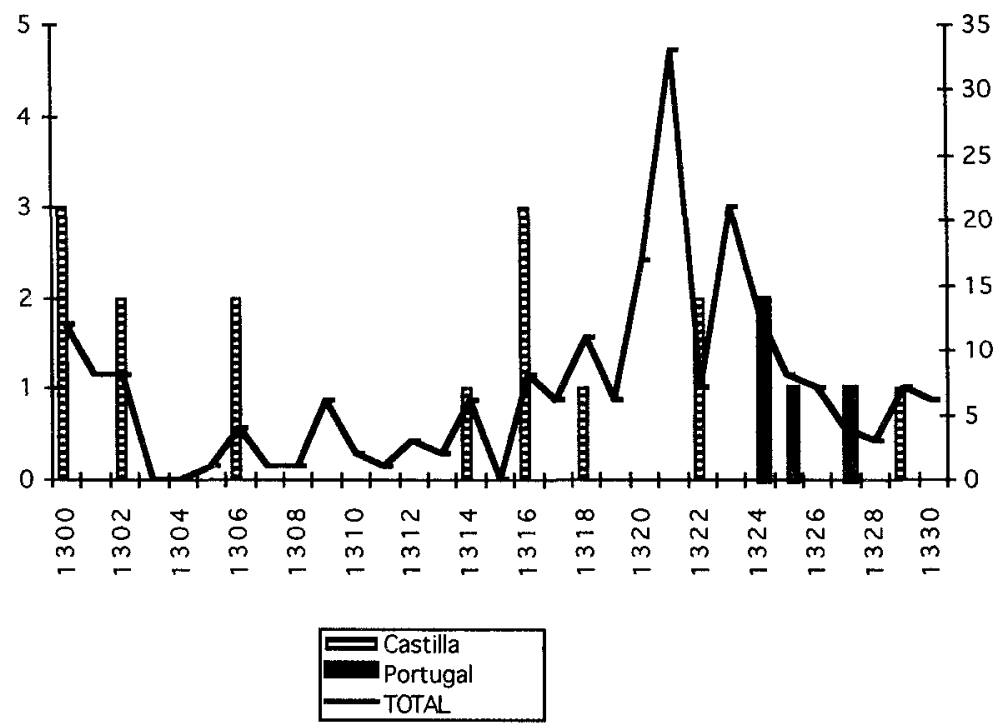

Castellanos y portugueses entre los estudiantes españoles.

Los navarros, por el contrario, en una fase de actividad reducida y decadencia del hospital de Roncesvalles en Bolonia, dejan de acudir a Italia en cantidades relativamente apreciables, por lo que vemos, y tal vez pueda pensarse que se concentraron en las Universidades francesas, con las que los vínculos políticos eran evidentes.

Mucho más problemáticos que cualquier clasificación por el origen son los análisis sociales. Como primer problema, no pocos de los estudiantes españoles documentados son nobles o podrían serlo; este punto sólo se aclara en algunas ocasiones ${ }^{123}$, porque el elemento uni-

123 A.l. P|NI, Discere, pág. 68. 

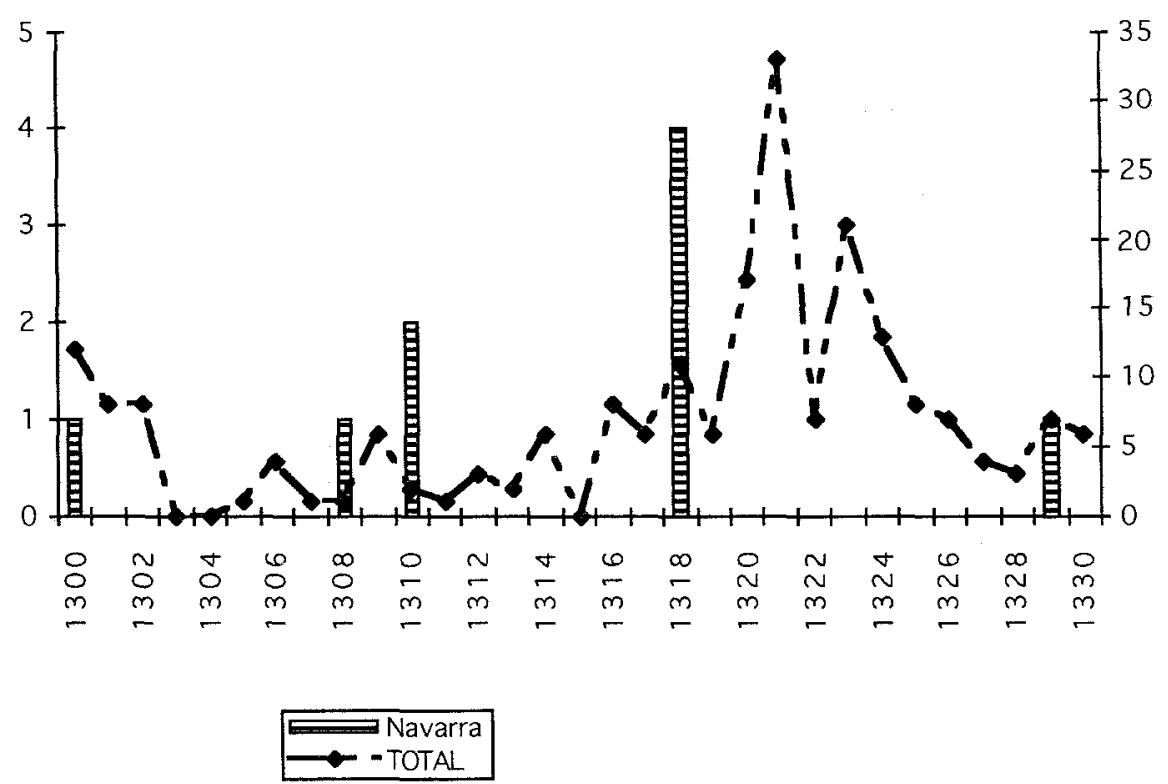

Navarros entre los estudiantes españoles, 1300-1330.

ficador es un relativo bienestar material que iguala a todos estos «pauperes». Esta pobreza, queda ya dicho, es relativa, genérica, a veces sólo una fórmula literaria. Desde otro punto de vista, todos los estudiantes deberían poderse clasificar como clérigos o laicos; una vez más, lo que falta en los documentos son datos, salvo en los contados casos en que se ha hecho alusión a este interesante aspecto. Con respecto la clero secular, la palabra «clericus» induce frecuentemente a dudas, ya que implica sólo la recepción de las órdenes menores, es decir, un estatuto administrativo peculiar. Partiendo de apreciaciones de este tipo, se ha dicho que el porcentaje de clérigos entre los estudiantes en Bolonia es mayor que en otras Universidades (el $70 \%$ para S. Stelling-Michaud), pero esto no parece demostrable, especialmente frente a una comunidad española compuesta por una mayoría de civilistas y con un $20 \%$ de clérigos según A. García y García ${ }^{124}$. Los laicos son, pues, la mayoría, en un contexto netamente clerical en el sentido más amplio, es decir, intelectual.

124 A.I. PINi, Discere, págs. 70-71. A. Garcia Y GARcía, Escolares, págs. 21-22, con una ponderación razonada del porcentaje de clérigos. 
Los estudiantes llegaban muy jóvenes a Bolonia, en ocasiones cono no más de quince años; aunque se ha demostrado que los ultramontanos eran mayores, en general, que los citramontanos, esto no parece aplicarse a un grupo característicamente no clerical como los españoles. Se ha encontrado incluso algún caso de minoría de edad civil. Sea como fuere, nadie ignoraba que el ciclo de estudios duraba entre seis y ocho años, durante los cuales el joven habría de estar en la «subiectio» de un «magister» o «dominus»: la elección del maestro principal determinaba así el curso de una carrera académica, y en cierto modo toda la vida académica. Ser aceptado por un maestro era indispensable para estudiar y para ser miembro de la «natio» y la «Universitas» correspondientes ${ }^{125}$. La relación entre escolares y maestros fue, pues, el cimiento de la Universidad y, aunque el modelo boloñés de Universidad colocó en principio a los maestros bajo la virtual dependencia de los estudiantes, precisamente en el primer tercio del XIV se vivió una aceleración de la inversión de las posiciones tradicionales, gradual en principio y brusca desde 1321; también las autoridades boloñesas estaban interesadas en controlar a los maestros, procediendo en su contratación cuando los estudiantes empezaron a no tener la fuerza económica para hacerlo.

Las versiones y matices contradictorios sobre la vida de los estudiantes se remontan a la propia Edad Media. Hasta mediados del XII, en todo caso, las condiciones del Estudio y sus componentes fueron buenas en general. En el centro de esta vida, naturalmente, las materias estudiadas; aunque no aceptemos las cifras de A. García y García, en este caso sí que son muy razonables los porcentajes por él propuestos sobre las Universidades de pertenencia. Ante todo, la mitad aproximadamente no declara qué estudios realiza ${ }^{126}, y$, entre los que lo hacen, un tercio son los civilistas, otro los canonistas y el resto genéricamente «juristas». Pero además del Estudio, Bolonia ofrecía todo lo necesario para la comodidad de varios miles de estudiantes, incluso en medio de luchas políticas y epidemias, como es el caso en el XIV. Alimento, alojamiento, vestido y libros fueron controlados por las autoridades para evitar unos abusos a la larga dañinos, al tiempo que se favorecian los mecanismos privados para financiar los estudios ${ }^{127}$ A nadie se ocultaba que la presencia de estudiantes era, en sí misma, una de las razones del bienestar de la ciudad y de su relativa estabilidad ${ }^{128} .1321$ no fue la primera ocasión en la que se produjo un chantaje

\footnotetext{
A.I. PINI, Discere, págs. $72-74,76$ y 83.

A.I. PINI, Discere, págs. 88. A. GaRCíA Y GAACiA, Escolares, pág. 21.

A.I. PINI, Discere, págs. 47, 98-104 y passim.

A.I. PINI, Discere, pág. 50.
} 
multilateral en el que las dos partes (ciudad y estudiantes extranjeros), equilibradas en fuerzas, hubieron de pactar en beneficio del Estudio.

Se ha dicho, en definitiva, que ${ }^{129}$ "la vida del estudiante medio no ha dejado huellas», y tal vez sea cierto, pero tenemos los elementos para reconstruirla en sus elementos esenciales ${ }^{130}$. Con un calendario lectivo que iba desde octubre (8 ó 18) hasta agosto, todavía hacia 1300 no se había apagado el recuerdo de los «clerici vagantes» de siglos anteriores; la vida universitaria distaba mucho de ser puro trabajo intelectual, y las fiestas y diversiones eran parte de la vida corporativa. Fiestas fijas y fiestas ocasionales (como las licenciaturas), amén de las diversiones permanentes ofrecidas por la ciudad, más o menos honestas, marcaban un ritmo tan importante, desde el punto de vista de la formación de los jóvenes españoles, como las propias lecciones. Cantantes, tabernas, juegos y baños eran elementos permanentes del paisaje boloñés, y la documentación judicial nos ha permitido ver juego ilegal, deudas, peleas sangrientas, incluso una acusación de violación. El burdel, por su parte, aparece como una realidad permanentemente unida al Estudio en este momento, con centros como la «corte» de los Bulgari y la ya citada «torre de los Catalani» ${ }^{131}$, y sólo reformadores morales muy severos aspiraron a erradicar el abuso de esta compañía. Precisamente en torno a estos lugares se concentraban las habitaciones y casas preferidas por los españoles ${ }^{132}$, puesto que las expulsiones políticas anteriores a 1300 (la de los gibelinos en especial) permitieron que cada grupo nacional de ultramontanos dispusiese de una zona de la ciudad en el área universitaria, lo que ha dado lugar a algunos debates eruditos.

Los historiadores locales han debatido largamente el nombre de «Via Saragozza» en Bolonia, excepcional vestigio hispánico medieval en la toponomástica boloñesa. Es seguro que el nombre de la calle es anterior a la fundación en ella, en 1364 , del Colegio de España ${ }^{133}$; tampoco es com-

129 H. RASHDALL, The Universities, vol. 3, pág. 435.

130 A.I. PINI, Discere, págs. 90, 95 y 109.

131 A.I. PINI, Discere, pág. 112. A. D'Amato, I domenicani e /Università di Bologna,, Bologna, 1988, pág. 133, sobre el intento de alejar la prostitución de la zona de la «Corte» de los Bulgari.

132 C. MESINI, Gli spagnoli, pág. 55. A.I. PINI, Discere, pág. 80.

133 M. FANTI, Intorno al nome della «Via Saragozza» in Bologna, en «Studia Albornotiana", XXXVI, El Cardenal Albornoz y el Colegio de España, V, Bolonia, 1979, págs. 365 y ss.; M. FANTI, Le vie di Bologna. Saggio di toponomastica storia e di storia della toponomastica urbana. Opera promossa dal Comune di Bologna, Bologna, 1974, págs. 631-638.; la hipótesis tradicional sobre el origen del nombre de la calle y su relación con la sede del Colegio de España en G. ZANTI, Nomi et cognomi di tutte le strade, contrade e borghi di Bologna, dicchiarando la origine de principii loro, Bologna, s.d., pág. 56; C. MESINI, Gli spagnoli, págs. 56-59, recogiendo las noticias de autores anteriores. 
pletamente seguro, por otra parte, que haya una relación directa con la ciudad española de Zaragoza ${ }^{134}$. Los datos son aparentemerite contradictorios. Los estudiantes ultramontanos del antiguo Estudio tuvieron por costumbre permanente y casi universal vivir en núcleos compactos y estables dentro del recinto municipal, lo que ha dado lugar a topónimos urbanos relativos a Alemagna, Inglaterra, Holanda, Linguadoca o Hungría. El más antiguo datado es Alemagna, al menos de $1110{ }^{135}$. La cuestión que nos ocupa estriba, pues, en saber si "Saragozza» pertenece a la misma serie, lo que permitiría conocer el centro de la presencia española en BoIonia desde el siglo xII y explicaría el emplazamiento, en la misma zona y en el siglo XIV, del Colegio de España. Una parte de las casas sobre las que se levantó el actual Colegio era conocida, ciertamente, como «las casas del prior de Zaragoza» desde 1118, ininterrumpidamente hasta $1364{ }^{136}$, y no sería extraño que los españoles a los que el testamento de D. Gil de Albornoz se refiere tuviesen allí su alojamiento. Sin embargo, algunos datos producen cierta perplejidad. Ante todo, la abundante documentación muestra que toda la zona fue conocida muy pronto por el nombre de la ciudad española ${ }^{137}$; además, en la región de Bolonia otras ciudades y pueblos (Budrio, Castel S. Pietro) tienen también su «Saragozza», probablemente por influencia no directamente española, sino del modelo boloñés, puesto que ya en el siglo XV éste fue el nombre de un barrio entero («contrada») ${ }^{138}$. Aunque no hay una prueba definitiva (que tampoco existe en otros casos), parece más razonable buscar, por analogía y considerando todos los indicios, una explicación en la presencia de universi-

134 Hay que rechazar sin dudas que exista una derivación directa desde el nomen imperial augústeo; fonéticamente la reducción de Caesaraugusta a Zaragoza-Saragozza no es posible en los dialectos italianos, mientras que es propia de las lenguas neolatinas españolas: los distintos argumentos se recogen en L. FRATI, Intorno, págs. 367 y ss., siendo igualmente imposible la relación con ciertos topónimos italianos.

35 M. FANTI, Le vie, pág. 111.

136 Archivo del Real Colegio de España [en lo sucesivo A.C.E.], Instrumenta praediorum urbanorum, Caja I, 1 (P. BeRTRÁn RoIGÉ, Catálogo del Archivo del Colegio de España, Bolonia, 1981, pág. 69):

1364, noviembre, 2, Bolonia: Aghinolfo Delfini (Dalfini) vende por 250 libras boloñesas a Fernando Álvarez de Albornoz, procurador y sobrino del cardenal Gil de Albornoz, una casa Ilamada "del Priore» entre las parroquias de S. Maria «delle Muratelle» y de S. Cristóbal de «via Saragozza».

A.C.E., Instrumenta praediorum urbanorum, Caja I, 6 (P. BERTRÁN RolGÉ, Catálogo, pág. 70):

1364, noviembre, 2, Bolonia: Giovanni Giacomo Delfini (Dalfini) vende por 750 libras boloñesas a Fernando Álvarez de Albornoz, procurador y sobrino del cardenal Gil de Albornoz, dos casas en la parroquia de S. Maria «delle Muratelle».

137 M. FANTI, Intorno, págs. 369-371, donde se recogen una decena de documentos anteriores a 1250 .

138 M. FANTI, Intorno, pág. 374. C. MESINI, Gli spagnoli, págs. 58 y ss. 
tarios, al ser difíciles de aceptar otras interpretaciones, como una posible participación de boloñeses en la reconquista de la ciudad del Ebro en el mismo año de $1118^{139}$.

Las evidencias de la presencia española en el área durante los siglos XII y XIII son, pues, bastantes ${ }^{140}$. Los Memoriali ofrecen, ahora, pruebas de una presencia constante también en la primera parte del siglo XIV, lo que en sí mismo es importante pata toda la historia posterior de los estudiantes españoles a partir de la fundación del Colegio de España. Hasta 1330 es frecuente el uso del nombre "Saragozza» para el conjunto del barrio y sus habitantes ${ }^{141}$. Incluso, en un documento del 31 de mayo de $1305^{142}$, el estudiante español Miguel "de Yspania» compró al boloñés Alberto Guidoni por 28 liras una casa cerca de Santa María «delle Muratelle». La única compra inmobiliaria en Bolonia por un español en estas fechas muestra la preferencia por una zona que sus compatriotas no han abandonado entre los siglos XIII y XX. "Saragozza", así, no puede no ser un topónimo de origen español llegado a través del Estudio; era además un barrio característicamente universitario, lo que marcó esa prodigiosa continuidad ${ }^{143}$.

Desde el punto de vista de la vida universitaria de los españoles, uno de los temas capitales, tanto en una perspectiva financiera como valorando el impacto intelectual de Bolonia, es el de los libros. La herencia de Martín Jiménez nos ha permitido conocer su notable patrimonio, aunque no su biblioteca, a diferencia de otros casos más afortunados. Los libros, en ocasiones llevados de vuelta a España son un indicio múltiple: sobre la posición económica del estudiante, sobre su formación y sobre las ideas difundidas en España, por ejemplo. A. García y García ${ }^{144}$ se refiere a seis documentos alusivos a los textos jurídicos de los españoles, entre los que se encuentran Digestos viejos con la glosa acursiana, Digestos nuevos, Volumina, la Summa de Azzone, las Decretales, el Speculum iudiciale de Guillermo Durante, Códices, las Institutiones y otros varios.

139 M. FANTI, Le vie, págs. 451 y 131 . Para ulteriores detalles sobre el topónimo «Saragozza» cfr. A.I. PINI, Le ripartizioni territoriali urbane di Bologna Medievale. Quartiere, contrada, borgo, morello, quartirolo, «Quaderni culturali bolognesi», 1, Bologna, 1977, págs. 1-50.

140 A. García Y García, El Studium, pág. 48.

141 Por ejemplo, en A.S.B., Memoriali, 158, f. 51 v., 1 (líneas 1-17) -1326, octubre, 12, Bolonia-, Satturnio «de Saragotia» es heredero en un testamento en el que figura claramente como boloñés.

142 A.S.B., Memoriali, 110, f. 361 I., 3 (líneas 19-36).

143 A.I. PINI, Le ripartizioni, págs. 25-26. M. FANTI, Prima, pág. 17: los desplazamientos de la Universidad dentro de la ciudad.

144 A. Garcia y Garcia, Escolares, págs. 24-25. 


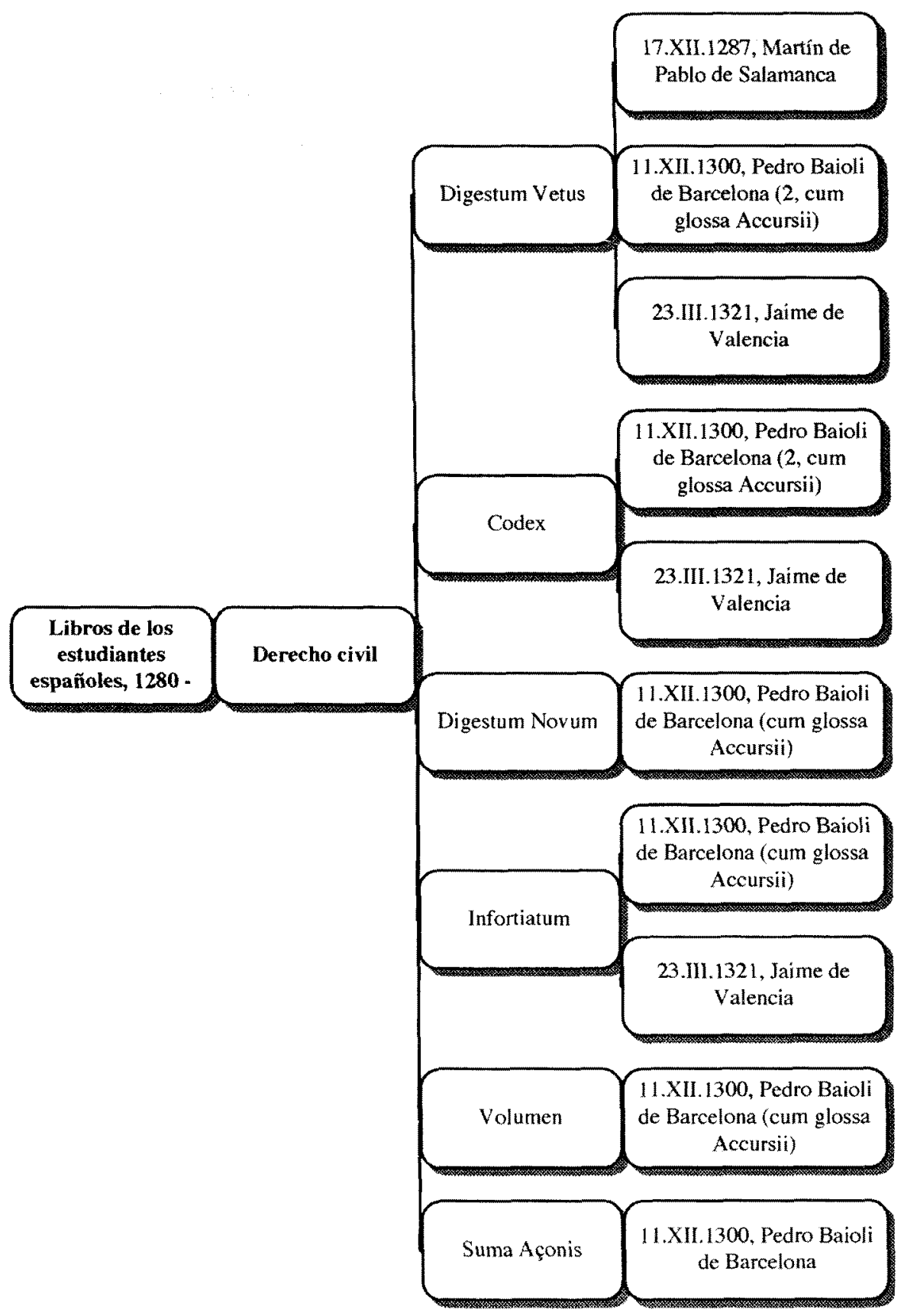




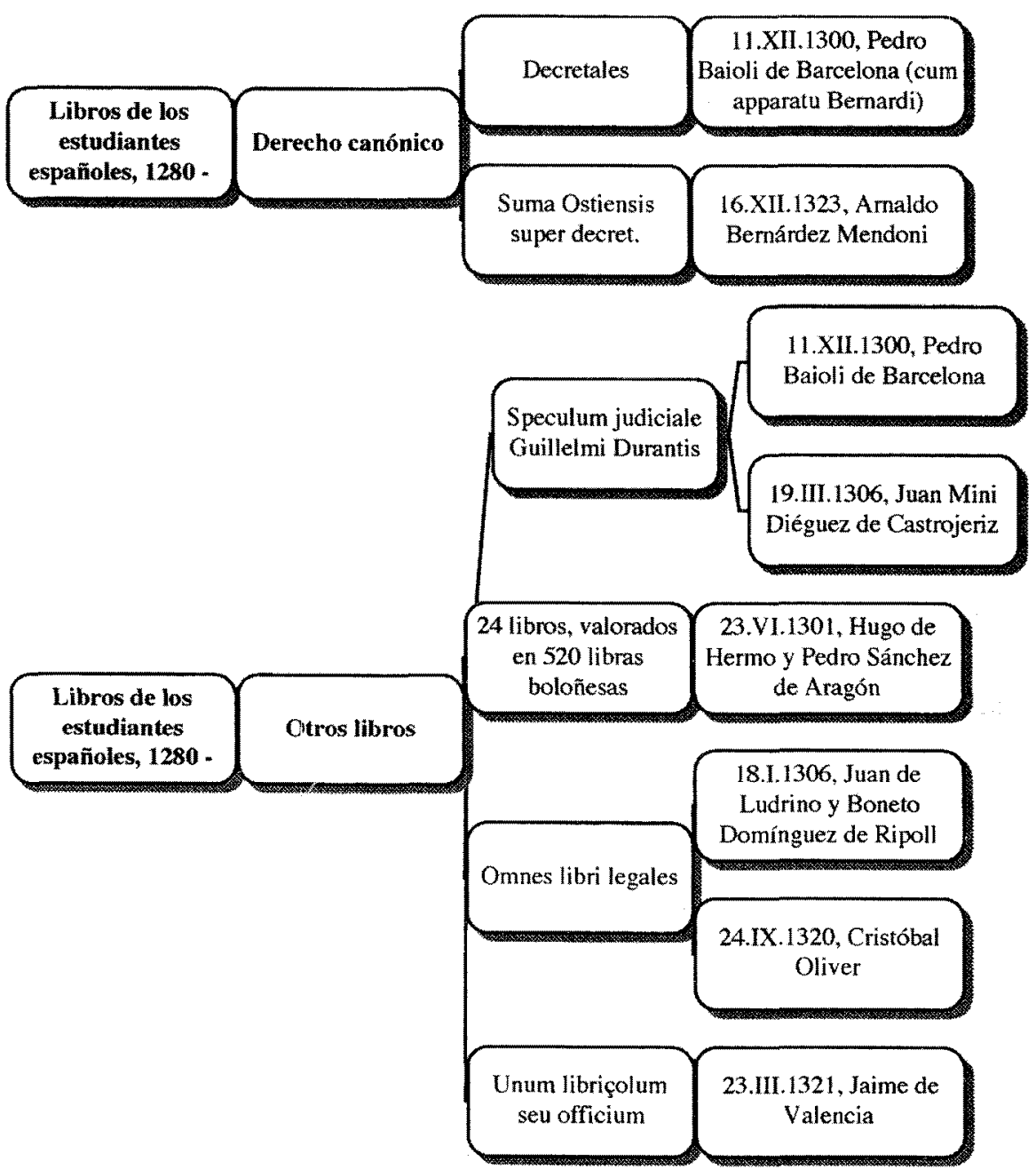

La documentación publicada, junto con los datos que resultan de los Memoriali, permite una aproximación cuantitativa a los libros poseídos por los españoles, junto a las ya tradicionales consideraciones cualitativas ${ }^{145}$. En los esquemas que se adjuntan quedan recogidos los libros

145 G. Orlandell1, // libro; A. García Y García, Escolares; y A. Garcia y García, La penetración, passim, cit.; el contenido e historia de los libros encontrados, F. CALASso, Medio Evo, págs. 522 y ss. Además B. Brugi, Il catalogo dei libri degli stationarii negli statuti della Università 
que, entre 1299 y 1330 aparecen como propiedad de españoles, y en algunos casos llevados a España. Según S. Stelling-Michaud ${ }^{146}$, el comercio librario era una actividad económica de la máxima importancia, siendo el libro un artículo de lujo, y parece que las primeras bibliotecas jurídicas españolas se formaron más con las remesas de los estudiantes que mediante importaciones masivas ligadas a la presencia de maestros extranjeros ${ }^{147}$.

La relativa normalidad que estos años reflejan en la comunidad de estudiantes juristas hispanos en Bolonia se corresponde con la "dulcis iuventus» que muchos de ellos eran conscientes de estar viviendo y que después recordarían con nostalgia ${ }^{148}$. Tras unos años en la ciudad petroniana, que sólo unos pocos dilataban hasta la licenciatura (costosa y no imprescindible para iniciar una buena carrera como jurista), la mayor parte de los españoles dejaban el Estudio y volvían a España, ricos de ciencia, de libros y sobre todo de experiencias. De sus biografías posteriores sabemos muy poco y requerirían una investigación detenida desde el punto de vista español; lo cierto es que la inestabilidad de la ciudad y del Estudio truncó pronto esta normalidad, satisfactoria para todas las partes, y llevó a una crisis que, teniendo como protagonista colectivo a los españoles, puso en riesgo la continuidad del Alma Mater.

\section{LOS ESPAÑOLES EN LA CRISIS DEL ESTUDIO (1321). JAIME DE VALENCIA}

La muerte del estudiante Jaime de Valencia marcó la cima de la presencia española en Bolonia y el inicio de una rápida decadencia. Los documentos más citados entre los que han servido para preparar estas páginas son los regestos notariales y las actas judiciales relativos a este caso criminal y a la leyenda nacida de él. En su conjunto, el caso sirve

bolognese dei giuristi, "Studi e memorie per la storia dell'Università di Bologna», 5, Modena, 1920, págs. 1-44, B. Brugl, Per la Storia del commercio dei libri legali nel Medioevo, "Miscellanea lucchese di studi storici e letterari in memoria di Salvatore Bongi», Lucca, 1931, págs. 175-181, A. PÉREZ MARTín, Büchergeschäfte in bologneser Regesten aus den Jahren 1265-1350, "lus Commune», 7, 1979, págs. 7-49, y G. ZaccAGNisl, // costo, págs. 33-36. En general, J. DestreZ, La "pecia" dans les manuscrits universitaires du XIII et xIV siècles, Paris, 1935, y G. ORLANDELLI, $1 /$ codice scolastico bolognese, en O. CAPITANI, dir, L'Università a Bologna. Personaggi, momenti e luoghi dalle origini al XV/ secolo, Milano, 1987, págs. 113-132. Algunos detalles sobre el precio de los libros en G. Zaccagnini, Appunti, págs. 33 y ss.

146 S. Stelling-MICHAUd, L'Université, págs. 100 y ss.

147 A. Garcia y GaRcía, En torno al Derecho, pág. 67.

148 A.I. PINi, Discere, págs. 49, 132 y 136. 
para dibujar un panorama íntegro de la inserción de los españoles en las nationes, con sus fuerzas y sus debilidades. Con seguridad, y más allá de un arraigado mito literario, Jacobus Jacobi de Valencia era un estudiante español de Derecho en el Estudio de Bolonia. Poco antes de 1321 estableció una relación, cuyo alcance exacto nos es desconocido, con Giovanna, hija del notario boloñés Michele di Bonaventura de' Zagnoni, de Argile (en la actual provincia de Bolonia), sobrina, por otro lado, del canonista Giovanni d'Andrea. Frente a la oposición cerrada de la familia italiana, parece ser que surgió en el ánimo del estudiante la intención de secuestrar a Giovanna, para forzar un matrimonio imposible en otro caso, y más en una situación política en la que el "negro» Zagnoni, pese a su parentesco con el Andrea, consejero de los Pepoli, no podía menos que enfrentarse a los estudiantes ${ }^{149}$. Más allá, y en especial sobre Jaime de Valencia, Jacobus Jacobi, poco se sabe con certeza. Jacobus Jacobi de Tolloxia (Oliexia), de Valencia, ultramontano civilista, no aparece en la documentación antes de los hechos que llevaron a su muerte. Se ha dado por supuesto que provenía del Estudio de Tolosa (Francia): no es extraño, de hecho, encontrar personajes llamados según su anterior lugar de estudios, pero en este caso no hay otras pruebas ${ }^{150}$.

Una noche de marzo de 1321, en una fecha que ninguna de las fuentes detalla (aunque en todo caso antes del 23, fecha del testamento que estudiaremos a continuación), diecisiete estudiantes ultramontanos, con algunos españoles entre los que destacaba este Jacobus, armados con espadas, arcos y ballestas, se reunieron junto a la casa en la que se alojaba el protagonista de esta historia. Según sus acusadores, y probablemente, se habían comprometido a forzar la entrada en casa del notario antedicho (en la misma zona universitaria de San Prócolo); eran simplemente los amigos de Jacobus Jacobi, convencidos por éste de lo injusto de su situación respecto a Giovanna Zagnoni y del acuerdo de ésta. Sin embargo, sus planes de secuestro habrían sido revelados al padre, que organizó en la noche de autos una convincente resistencia armada en su casa. Jaime

149 Todavía es imprescindible para una visión global de la migración y los detalles del crimen F. FILIPPINI, L'esodo degli studenti da Bologna nel 1321 e $/ /$ "Polifemo" dantesco, «Studi e Memorie per la Storia dell'Università di Bologna», 6, Bologna, 1921, págs. 105-185. Más reciente A.I. PINI, Discere, págs. 128-131 (en conexión con otros desórdenes universitarios: 1215, 1265, 1274, $1289,1301,1306,1310$, ibidem, págs. 128 y ss.). Filippini tuvo el mérito de situar el conflicto universitario en el contexto político ciudadano (A.I. PINI, F. Filippini storico del Cardinale Albornoz, "Studia Albornotiana», XXXV, «El cardenal Albornoz y el Colegio de España», IV, Bolonia, 1979, págs. 377-412, especialmente pág. 393)

150 A. García y García, Escolares, y A.S.B, Curia del Podestà, Giudici ad Maleficia, Libri Inquisitionum et testimonii, 105, 1321, $1^{\circ}$ Semestre, 2, fol. 4v.-6v. [Fascículo en papel, 16 folios, 250 $\times 350]$. 
y sus amigos, tras la lucha, se retiraron hacia la casa del español, donde pronto fueron rodeados por los secuaces de Zagnoni y resistieron con violencia. El podestà Giustinello di Teselgardi di Fermo, responsable máximo del orden público en este caso, arrestó al valenciano y a algunos de sus cómplices, aunque algunos (españoles y extranjeros) consiguieron escapar, y Thomas de Trochiariis de Firmo, su juez ad maleficia (criminal), le condenó a muerte. El 23 de marzo de 1321 el español dictó su testamento y se realizó un inventario de sus bienes, firmado por sus amigos Pedro de Torrente y Guillermo Torracii, los dos clérigos. El 30 de marzo la sentencia fue ejecutada, sin esperar posibles apelaciones y revistiendo todas las características de parcialidad y apresuramiento de un linchamiento legal.

Una vez más la jurisdicción criminal, en una situación tensa de por sí, se convertía en causa de enfrentamiento entre la ciudad y el Estudio. A pesar de las inmunidades pontificias e imperiales (la Autentica Habita), la situación no era clara, y las amenazas y abandonos se habían encadenado durante dos siglos. En 1244 había sido un estudiante asesinado la causa de una migración, que había llevado a nuevas y recíprocas concesiones. Sin embargo, la única garantía de los estudiantes era su fuerza colectiva frente a la ciudad, nunca firmemente institucionalizada; así, ochenta años después, la situación se planteaba casi idéntica, salvo que los estudiantes carecían de apoyos frente al partido más fuerte en un municipio dividido: sólo el partido, por el momento derrotado, de los Pepoli, podía ayudarles ${ }^{151}$. Fuera de estos términos, el resto de la leyenda literaria de Jacobus Jacobi carecen de confirmación documental ${ }^{152}$.

Tenemos, en primer lugar, el testamento de Jaime de Valencia, en veintitrés líneas del volumen 141 de los Memoriali ${ }^{153}$. De una manera conmovedora, declaró allí su inocencia, antes de nombrar legatario de sus bienes al húngaro Gregorio, implicado muy directa y violentamente en la lucha contra Zagnoni. Mandó que con sus bienes se pagasen sus deudas, tanto a su criado Parisio como a los propietarios de la casa en la que vivía (seis libras y cinco sueldos). En otro orden de cosas, hizo devolver a

151 H. KOEPPLER, Frederick Barbarossa and the schools of Bologna. Some remarks on the "Authentica Habita», "English Historical Review», 54, 1939, págs. 577-606. M. NIwINSKI, Un documento per la storia dello Studio bolognese nel secolo XII, "Studi e memorie per la storia dell'Università di Bologna", 10, Bologna, 1930, págs. 203-212. G. Rossı, "Universitas scholarium", págs. 173-266.

152 C. Ghirardaccl, Della historia, v. II, pág. 4. F. Filippinı, L'esodo, sobre los orígenes del mito.

A.S.B., Memoriali, 141, 1321; f. 31r.-31v., 2 (I. 27-51 y 1-12). 
España en la Universidad de Bolonia: vida académica y comunidad nacional...

los estudiantes Juan de Urgel ${ }^{154}$ y Pedro de Picardía unos libros que le habían dejado como garantía de sendos préstamos. Sus herederos y comisarios, en todo lo demás, fueron otros dos clérigos valencianos, civilistas: Pedro de Torrente y Guillermo Torras ${ }^{155}$. Su herencia, de sencilla ejecución, tenía dos partes fundamentales, a saber, por un lado, los libros (un Código vetus y un inforciatus, y un Digesto), y, por otro, pequeñas sumas de dinero que se le debían. Es notable señalar que no poseía dinero en efectivo; en conjunto, un patrimonio razonable para un estudiante pero totalmente insuficiente para enfrentarse a uno de los grandes partidos boloñeses. Al menos solo. No hay que olvidar las circunstancias en las que se redactó el testamento; condenado a muerte, Jaime testa sobre los bienes que evidentemente poseía, pero con toda probabilidad había dispuesto de su numerario por otros medios más seguros. Con seguridad, los bienes que aparecen en el testamento estaban bloqueados, y desde luego los libros iban a estarlo en breve, no tanto por razones fiscales como para evitar su exportación. La figura de Jaime de Valencia, a través de su testamento, es la de un estudiante no rico pero tampoco pobre, con unos años de presencia en Bolonia y sorprendido por la desgracia cuando sólo podía apoyarse en sus condiscípulos.

La manera en la que se encadenan los acontecimientos sucesivos es muy reveladora del funcionamiento del Estudio y de la posición relativa de los españoles. Ante todo, a lo largo del episodio, se perciben signos de una coordinación entre los estudiantes; esto, importante para los planes de Jaime, cualesquiera que fuesen, lo habría de ser aún más para la respuesta común a la agresión. El Estudio, nacido de la solidaridad de todos sus miembros, sólo podía subsistir con ella y prescindiendo de divisiones nacionales o de otro tipo ${ }^{156}$. Del mismo modo, se debe señalar la importancia capital, no sólo en este caso sino en lo que a través de él conocemos de la vida universitaria, de los escolares extranjeros, y, en especial, de los españoles. Más que de su número, que ya ha quedado valorado en las páginas anteriores, la fuerza del grupo hispano parece venir dada por su coherencia interna y por sus excelentes relaciones con los elementos más caracterizados de otras naciones (así, el que era entonces rector de los húngaros). En tercer lugar, junto a la organización de los estudiantes y

154 A. GARCíA y García, Escolares, pág. 45, n. 111. A.S.B., Memoriali, 141, 1321; f. 30v-31r., 2 (l. 36-47 y 1-15): Johannes de Urgellis.

155. A. Garcia y Garcia, Escolares, pág. 43, n. 91 (Petrus de Tornente, rector ecclesie de Montechatono), y A.S.B., Memoriali, 139, 1320; f. 355v., 2 (I. 29-42) (Guillelmus Toracii diocesis, rector ecclesie de Spiocha).

156 A. Sorbel.l, Storia, págs. 154 y ss. 
al peso de lo español, se ha de destacar la centralidad del Estudio en la ciudad y en su política interna, condicionada por las escuelas, fiel reflejo a su vez de las banderías políticas. Con estos tres elementos, Estudio y ciudad se enfrentaban sobre el cadáver de Jaime.

Se ha visto cómo en estos años la presencia hispana en Bolonia alcanzó su máximo absoluto y relativo de la época. Así, cabe pensar que el protagonismo español en la lucha con la ciudad no sólo se debió al origen del valenciano, sino también al altísimo porcentaje de sus compatriotas entre los juristas ultramontanos. En 1320, en seis documentos de los Memoriali (cinco préstamos disimulados y un testamento), se nos muestran los nombres de dieciocho estudiantes españoles. En todos los casos, los estudiantes están agrupados según su nación, y aparecen algunos de los protagonistas de los sucesos del año siguiente, aunque no el mismo Jaime. Desde el 12 de enero de 1320, cuando los civilistas catalanes Guillermo Golberto y Esteban Guillermo de Rota reciben, a través de los Peruzzi, 137 florines de oro ${ }^{157}$, empiezan a reunirse el grupo de españoles que había de participar en la expedición nocturna de 1321. Alumnos de Jacopo Butrigariis, fueron condenados junto a Jaime y, como veremos, dejaron Bolonia entre los primeros; no es casualidad que Butrigariis fuese un conocido enemigo del Podestà y partidario de los Pepoli. Esteban Guillermo de Rota aparece en otros documentos de $1320^{158}$, junto a varios ultramontanos, especialmente catalanes y mallorquines. Del mismo modo, los seis aragoneses civilistas García Fernández, Juan Pérez da Tarazona, Martín de Vanello, Rodrigo Fernández, Sancho Jiménez Jordán de Uncastillo y Sancho Fernández se asociaron para recibir un préstamo ${ }^{159}$. Por excepción, el 24 de septiembre aparece un español aislado en un documento no económico en un contexto italiano (Guillermo de Tarrasa en un testamento) ${ }^{160}$, pero el resto de los documentos de la segunda mitad del año respetan los usos asociativos de los hispanos ${ }^{161}$. El 12 de noviembre

157 A. García y García, Escolares, pág. 36, n. 41, y pág. 35, n. 27. A.S.B., Memoriali, 139 , 1320; f. 153r., 1 (l. 11-16). A.S.B., Memoriali, 139, 1320; f. 355v., 2 (l. 29-42): Guillielmus Golberti de Cathelonia y Stephanus Guillelmi de Rota; Jacobus de Miragliis es un comerciante catalán que aparece como testigo y transmisor de la orden.

158 A. Garcia y GARcía, Escolares, pág. 41, n. 74 (Matheus Guercius Alexandri Guercii).

159 A. García Y Garcia, Escolares, pág. 36, n. 34. A.S.B., Memoriali, 139, 1320; f. 78v., 1 (I. 1-10) (Garsia Friandi de Vanello de Aragonia); ibídem, pág. 39, n. 63 (Johannes Petri de Taraçona); ibídem, pág. 41, n. 73 (Martinus de Vanello de Aragonia, presente ya en 1316); ibídem, pág. 44, n. 99 (Rodricus Friandi de Vanello de Aragonia); ibídem, pág. 44, n. 100 (Sancius Siminis Çordani de Unducastello).

160 A. García y Garcia, Escolares, pág. 37, n. 49. A.S.B. (Guillelmus de Teracia), Memoriali, 140, 1320; f. 176r.-176v., 6 (1. 53-59 y 1-12).

161 A. García y Garcia, Escolares, pág. 33, n. 14. A.S.B., Memoriali, 140, 1320; f. 337r.-337v., 7 (1. $47-50$ y $1-3)$. 
de 1320, en fin, Martín Romeo de Tortosa, Antonio Ansaldo de Galiana y el húngaro Jacobus Martini, recibieron un préstamo conjunto, que es además una prueba más de las excelentes relaciones de los hispanos con otros ultramontanos, y en especial con los magiares ${ }^{162}$.

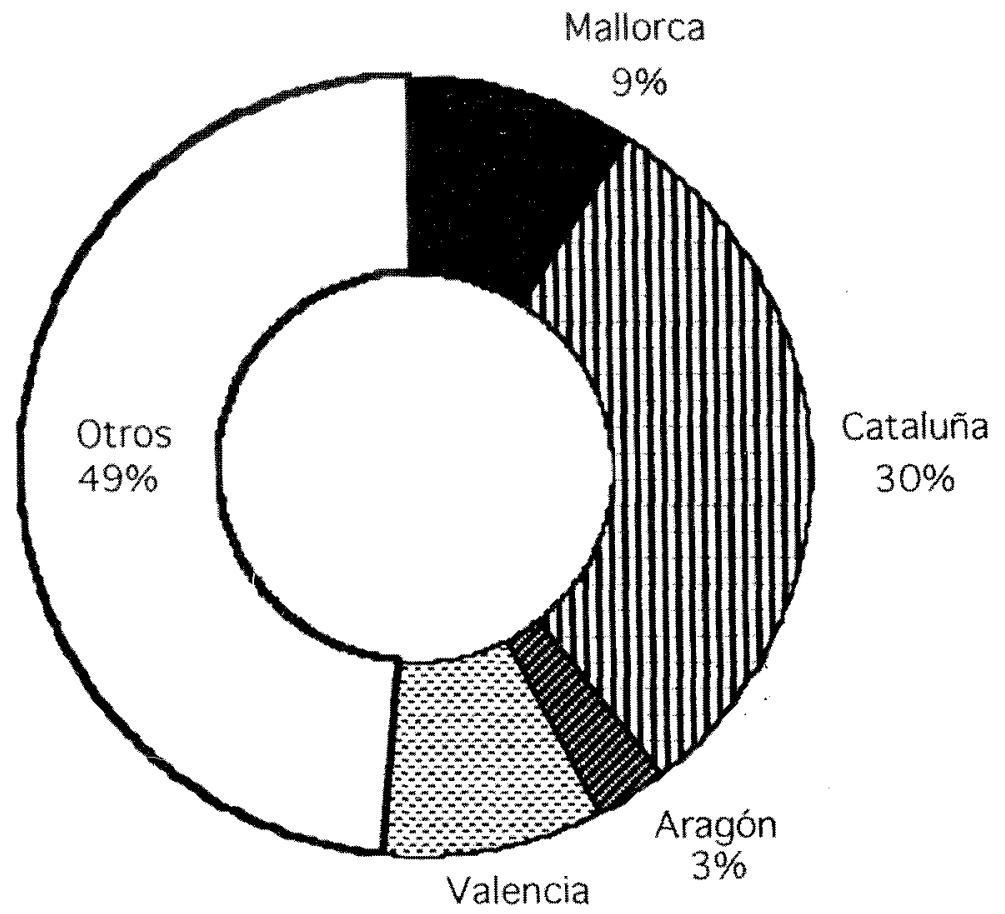

Los estudiantes españoles en 1321.

1321 había empezado como terminó 1320; Antonio Ansaldo de Galiana, el húngaro Jacobus Martini y algunos otros recibieron un préstamo

162 A. García y García, Escolares, pág. 41, n. 72 y 11 (Martinus Romei). A.S.B., Memoriali, 140, 1320; f. 542v., 1 (1. 1-9). A. Sorbelli, Storia pág. 166. A. García y Garcia, Escolares, pág. 31 , n. 3 (Anthonius Ansaldi de Gallionis). Este Jacobus de Hungaria archidiaconus Neugradensis, rector de los ultramontanos en 1320-21 y cabecilla de la emigración, ya había representado los intereses colectivos de los españoles antes de su rectorado. Como miembro del consejo estudiantil ayudó a Giovanni d'Ândrea a redactar los nuevos Estatutos de los juristas en 1317. C. PIANA, Nuovi documenti, pág. 28, y G. ZaCCAGNINI, La vita, pág. 16. El húngaro tuvo después una brillante carrera eclesiástica, llegando a ocupar la sede episcopal primada (Esztergom) en su país natal. 
conjunto ${ }^{163}$. Sus grandes necesidades financieras pueden explicar, en los meses siguientes, algunos de sus pasos en las negociaciones para solucionar la crisis con Bolonia. Sin embargo, la muerte de Jaime de Valencia marcó una discontinuidad: dieciocho escolares aparecen en 1320, pero en 1321 son nada menos que treinta y dos (dos de los cuales ya presentes el año anterior) y sólo siete en 1322, por efecto de la migración. La Universidad de los ultramontanos alcanzó una floreciente estabilidad hacia 1320 , al menos en lo tocante a los españoles, experimentó una actividad anormal en torno al enfrentamiento y recibió con toda su fuerza el impacto del mismo, caracterizado por un partido político que intentó imponerse al Estudio y una Universidad de marcado signo español que quiso resistir.

La protesta de los estudiantes no vino tanto por la muerte de su compañero en sí mismo, sino ante todo por la absoluta impunidad de sus asesinos, que ni siquiera fueron acusados y que tuvieron la complicidad manifiesta de los jueces. Por desgracia, no se conserva la condena original del español, pero conocemos la versión de sus acusadores por la denuncia contra otro de los expedicionarios, el húngaro Gregorio, herido en la lucha tras una feroz resistencia individual en la que hizo uso con gran eficacia de armas de todo tipo. Parece que el supuesto intento de rapto nocturno fue la culminación de una lucha más larga, puesto que, si bien el español y sus amigos iban armados al encuentro de la joven, no es menos cierto que se les había preparado una emboscada. Tras esto, el podestà, aunque predispuesto por ser «negro» él mismo, debía aplicar la ley con una equidad que no mostró.

Mas allá de las circunstancias más o menos novelescas, hay que adelantar que las causas del enfrentamiento fueron más antiguas y complejas que una mera cuestión de amores. Federico I había reconocido la plenitud de la jurisdicción criminal a los rectores de los ultramontanos, pero la ciudad nunca lo había aceptado plenamente; hemos entrevisto ya algunos ejemplos anteriores de disputas en este sentido, hasta que en 1310 había sido el podestà el encargado ${ }^{164}$. Tradicionalmente, las leyes habían sido aplicadas con benevolencia a los escolares por el hecho de serlo, pero, en este caso, había sido precisamente la causa de su condena: además de para afirmar la jurisdicción municipal, la condena de Jaime parece evidentemente orientada a castigar la amistad entre el Estudio y los Pepoli y a

163 A. García y García, Escolares, pág. 31, n. 3. A.S.B., Memoriali, 142, 1321; f. 133v., 2 (l. 1018). El 28 de enero el también catalán Conrado Bernárdez efectuó una operación del mismo tipo (40 libras) teniendo como testigo a Pedro Baile. A.S.B., Memoriali, 141, 1321; f. 404r., 6 (I. 38-45).

164 G. Rossi, "Universitas scholarium», pág. 247. 
demostrar su inutilidad para el primero. Una sentencia de muerte contra un estudiante, además fulminantemente ejecutado, era una rareza en lo que la Universidad llevaba de vida.

Desde entonces fue evidente que se trataba de una condena política. No era la primera vez que Romeo Pepoli tenía que enfrentarse con el podestà, con el gremio de notarios y con parte del Consejo de los Ochocientos para salvar a partidarios suyos en procesos viciados por las banderías ${ }^{165}$. En los primeros meses de 1321, Bolonia estaba más dividida que nunca, y para muchos era evidente que los Pepoli aspiraban a establecer un señorío hereditario sobre la ciudad, eliminando las instituciones que, como los poderes judiciales del podestà y los estatutos municipales, limitaban su poder; en este sentido, la detención y muerte del español eran una derrota política para los Pepoli ${ }^{166}$. El Estudio era uno de sus grandes apoyos, y dentro de él especialmente los ultramontanos. Los güelfos «negros», ejecutando a Jaime de Valencia y persiguiendo a sus amigos, intentaban eliminar una posición sentida como de privilegio y prepotencia, más allá de las circunstancias concretas. La persecución se agravó progresivamente, siempre por razones políticas, y en cierto sentido la salida de Bolonia era también una huida, además de un medio de presión.

Los primeros estudiantes que huyeron, a Imola, fueron los directamente implicados en la refriega, reforzados continuamente a medida que aumentaba la tensión en Bolonia entre los escolares y las autoridades y que hacían su efecto las llamadas de los exiliados. Espontáneo o no, el abandono de Bolonia fue muy veloz. Entre la batalla nocturna, inmediatamente anterior al 23 de marzo, y la ejecución de Jaime el 30 debió comenzar el éxodo de ultramontanos. No puede saberse si los Pepoli siguieron directamente los pasos dados por los estudiantes, pero éstos fueron guiados fuera de la ciudad por sus propios rectores, implicados en algún caso en lo sucedido; de cualquier forma, sin mostrar nunca apremiante necesidad de dinero, el grupo de Imola, aunque en principio no mayoritario, se consideró desde el principio representante de todo el Estudio ${ }^{167}$. El 6 de abril, los de Imola empezaron negociaciones con Siena y con otras Universidades

165 F. FiLIPPINI, L'esodo, pág. 114, y H. Denifle, Die Statuten, pág. 359.

166 G. Rossı, “Universitas scholarium», pág. 248. Con ocasión de un incidente similar en 1316, con idéntico trasfondo político y jurisdiccional (aunque sin participación española y sin delitos de sangre), los Pepoli se sirvieron de Giovanni d'Andrea para negociar con los rectores, que amenazaban con un abandono en masa del Estudio.

167 Filippini no valoró la importancia de este aspecto, aunque conocía inmejorablemente la documentación sobre la presencia de ultramontanos; F. FILIPPINI, L'esodo, pág. 116. 
que podían acogerles, mientras que incitaban a todos a reunirse con ellos frente al injusto trato recibido de Bolonia.

Una de las grandes bazas para el éxito de esta emigración política fue la personalidad del rector de los juristas ultramontanos, el húngaro Jacobus. Estrechamente relacionado con los españoles, había sido de los primeros en tener que ir a Imola, junto a su compatriota Gregorius, y fue decisivo al atraer fuera de Bolonia al grueso de los juristas extranjeros. Según F. Filippini ${ }^{168}$, los estudiantes marcharron precipitadamente y pensando en un exilio breve, es decir, dejando deudas por pagar, contratos por resolver, libros y otros bienes por recuperar, y de hecho parte de las negociaciones sucesivas versaron sobre estos asuntos ${ }^{169}$. De esta manera, se demostraba una vez más que el nervio del Estudio en este momento de su historia eran los juristas, especialmente los ultramontanos, que en esta ocasión se alzaban para, en nombre de la legítima institución universitaria, y no contra ella sino contra la injerencia municipal, reparar desde el exterior las injusticias padecidas en Bolonia.

La innecesaria dureza de sus enemigos ayudó al éxito de la emigración entre los ultramontanos. Giustinello de Fermo, a partir de un caso aislado, pretendió atacar los fundamentos de la inmunidad jurisdiccional escolar, con una severidad que redujo el Estudio a la mínima expresión. Por temor, por solidaridad o por ambición debida a las ofertas de otrús Estudios y de otras ciudades, las escuelas de Bolonia se quedaron prácticamente sólo con los estudiantes citramontanos (y en su mayoría boloñeses), mientras que los extranjeros, encabezados por húngaros y españoles, negociaban hábilmente sus bazas. Especialmente significativa, para valorar el peso de la emigración, es la actitud de los profesores juristas. Se conoce, ya a comienzos de abril, la toma de posición favorable a los estudiantes de los canonistas Paolo dei Liazari y Andrea Ciaffi de Pisa, del conocido civilista Jacopo Butrigariis y del doctor Paolo Sullimani.

La situación ambigua del canonista más importante del momento, Giovanni di Andrea, es excepcional, como se ha dicho, porque políticamente estaba ligado a los Pepoli y por lo tanto a los estudiantes, pero por otro

168 F. Flitppini, L'esodo, pág. 116.

169 En cuanto a los germanos, ningún estudiante de esta natio figura inscrito en Bolonia en 1321, e incluso los que no abandonaron la ciudad dejaron las clases. Hubo siempre delegados alemanes en Ímola, y muchos marcharon a Siena cuando se decidió aceptar aquella oferta; G. KNOD, Deutsche Studenten in Bologna (1289-1562). Biografischer Index zu den Acta Nationis Germanicae Universitatis Bononiensis, Berlin, 1899, pág. 61. 
lado era de Giovanna Zagnoni ${ }^{170}$. Juan de Andrés es, pues, el profesor que mejor sirve para comprender la difícil posición de los maestros ante la crisis de 1321. Activo en la política universitaria, más de una vez había servido de portavoz de los estudiantes en el seno del Colegio de doctores, y en 1317 había ideado una reforma de los estatutos de los juristas, que, apoyada por los ultramontanos y en especial por los españoles, había sido rechazada por los intereses boloñeses, con gran malestar en el Estudio. Como consecuencia, en 1319 había fomentado una emigración de estudiantes a Padua, donde había aceptado una oferta para enseñar durante unos años ${ }^{171}$. Si bien aquella Universidad había nacido en 1222 - ya entonces como consecuencia de una disidencia de estudiantes y maestros de Bolonia-, la aportación de 1319 fue una de las que consolidó su relanzamiento en el siglo XIV, además de mostrar el descontento latente en Bolonia y su posible expresión a través de un éxodo en masa. Hay que añadir que Juan de Andrés tenía relaciones profesionales con los españoles; el catalán Ramón Berenguer, por ejemplo, era alumno suyo y estaba en Bolonia en 1321, y volvió en 1323. Vicente Anforis también fue su discípulo, y en estas fechas era amigo de los muy activos alumnos de Jacopo Butrigariis ${ }^{172}$. En definitiva, aunque sus lazos familiares lo acercasen a los «negros» Zagnoni, la posición personal del canonista nunca fue equí-

170 No se olvide la doble posición de dependencia de los maestros en el modelo «bolonés» de Estudio, A. Sorbelli, Storia págs. 178 y ss. Liazari fue el primer maestro boloñés que fue a Siena, anticipando la elección de los escolares; A. SorbelLI, Storia pág. 100. M. SARTI y M. FATTORINI, De claris II., págs. 104 y ss. Andrea Ciaffi se había enfrentado en los meses anteriores con el podestà, que había condenado a su discípulo milanés Roberto Visconti; F. FILIPPINI, L'esodo, pág. 111. No debe sorprender la decisión de Butrigariis, muy vinculado a la política de los Pepoli. M. Sarti y M. Fattorini, De claris I., pág. 299. F. Calasso, Medio Evo, pág. 579. G. ZaccaGNINI, Notizie inedite intorno ad alcuni illustri dottori dello Studio bolognese dei secoli XII e XIV, "Studi e Memorie per la Storia dell'Università di Bologna», 14, Bologna, 1938, págs. 176-177. Sobre Giovanni d'Andrea, F. FilipPINI, L'esodo, pág. 116, F. Calasso, Medio Evo, págs. 585-586, M. SARTI y M. Fattorini, De claris, I, págs. 216, 296, 454, 494ye passim; y M. Sarti y M. Fattorini, De claris $I I$, págs. 300 y 345 .

171 C. PIANA, Nuovi II, pág. 28. A.S.B., Curia del Podestà, Giudici ad Maleficia, Carte di Corredo, Studio. Maestri e scolari 1318-1348 (fascicoli estratti), busta 65, 1319 (Studio), Scolari e Maestri, n. 5, 250 [Documento en papel, $300 \times 150,9$ líneas]. A. SorbelLI, Notizie di professori e insegnamenti in Padova prima del 1222, "Studi e memorie per la storia dell'Università di Bologna", 7, Bologna, 1922, págs. 117-128; hubo intentos similares hacia 1350: A. Favaro, Di un tentativo per procurare una nuova emigrazione di scolari dallo Studio di Bologna a quello di Padova intorno alla metà del secolo XIV, «Nuovo Archivio Veneto", n.s., 31, 1916, págs. 251-259, y, del mismo, Ancora del tentativo di procurare una nuova emigrazione di scolari dallo Studio di Bologna a quello di Padova intorno alla metà del secolo XIV, "Atti e Memorie della Deputazione di storia patria per le province di Romagna», s. IV, 7, Bologna, 1917, págs. 195-202.

172 A. García y García, Escolares, pág. 43, n. 95 (Raymondus Berengerii de Montadi de ToIloxa de Catelonia). A.S.B., Memoriali, 141, 1321; f. 115v., 2 (I. 10-22). Ibídem, pág. 44, n. 105 (Vincencius Anforis de Yspania Scolaris Bononiae in Studio in decretalibus). 
voca, puesto que como maestro era mucho lo que tenía en juego en aquellas circunstancias.

La posición del civilista Jacopo Butrigariis es aún menos dudosa. No por casualidad lo hemos visto como maestro de dos de los españoles que dirigieron la salida de Bolonia (Guillermo Golberto y Esteban de Rota), y también de un Raimundus Bernardi que probablemente era español puesto que aparece en varios documentos junto a dos alumnos españoles del maestro d'Andrea ${ }^{173}$. Sabemos algo más de Esteban de Rota gracias a la documentación de la Curia del Podestà, puesto que aparece con un papel significativo en los desórdenes que llevaron a la muerte de Jaime de Valencia ${ }^{174}$. Jacobus de Buttrigariis estaba por lo tanto en excelentes relaciones tanto con los Pepoli como con los ultramontanos, atraídos por su prestigio, y esto explica doblemente (por consideraciones económicas y políticas) su actuación a favor de los emigrados.

La formación de las Universitates de estudiantes y maestros se había hecho, en principio, siguiendo el modelo de los municipios y las corporaciones profesionales, y gozó en su origen de protección municipal. En Bolonia, sin embargo, desde muy pronto las autoridades locales intentaron imponer su autoridad mediando entre escolares y profesores, atrayéndose a los doctores con la intención de reducir la autonomía universitaria. La libertad del Estudio estuvo garantizada siempre que hubo unidad de acción entre unos y otros; y ambos grupos recurrieron a la emigración (efectiva 0 amenazada) para someter al municipio a su voluntad. Algunas migraciones no unánimes fracasaron, y terminaron por nutrir otros Estudios italianos; la migración de 1321 es singular precisamente por ser la última que vio a maestros y estudiantes unidos, y la última que tuvo éxito en sus peticiones. De hecho, la ciudad había descubierto tiempo atrás un punto débil en la fuerza del Estudio: la posibilidad de tener el apoyo de parte de los profesores subvencionándoles. Por esto, la crisis de 1321 fue el término de una larga tradición, ya que por primera vez una migración estudiantil no fua inmediatamente seguida por los maestros, puesto que por razones políticas y pecuniarias sólo algunos la secundaron. Afortunadamente para los escolares, los principales profesores estuvieron con ellos, pero el cambio era ya evidente ${ }^{175}$.

La solidaridad de los maestros más prestigiosos, en cualquier caso, redujo el Estudio residual en Bolonia a casi nada. El municipio, a pesar de

174 F. FILIPPINI, L'esodo, págs. 162-165.

175 A. SORBelL.I, Storia págs. 182 y ss. 
su enemistad hacia una comunidad universitaria esencialmente partidaria de los Pepoli, no podía permitirse un daño permanente de esta envergadura al prestigio y la economía de la ciudad. El riesgo era que el Estudio como tal abandonase Bolonia para siempre, puesto que sin ultramontanos no había atractivo suficiente para los grandes docentes, que ejercieron desde el principio una presión sobre las autoridades al menos equivalente a la que éstas ejercían sobre ellos. El partido "negro» tuvo que aceptar, de esta manera, que el nuevo Capitán del Pueblo, Pietro Foresi de Pistoia, fuese de hecho nombrado por los Pepoli y empezase a negociar una paz tolerable para todos; como siempre hasta entonces, la ciudad tenía que ceder, al menos en parte. En Imola, mientras tanto, todos estaban de acuerdo en pedir reparaciones por los daños padecidos y medidas para impedir que se repitiese, aunque el alcance de esto no estuvo en principio claro. Jacobus de Hungría, a la cabeza de la revuelta, declaró solemnemente que el Estudio había abandonado Bolonia, mientras aumentaba el número de estudiantes que dejaba la ciudad con sus bienes y sus libros, como se deduce de los documentos relativos a los españoles desde finales de marzo: era la lógica tradicional del «modelo boloñés» aplicada una vez más.

Pietro Foresi, sirviéndose de Butrigariis, intentó cortar la emigración en sus inicios mandando al conocido civilista a Imola a negociar. Era evidente que tanto uno como otro eran, en alguna medida, partidarios de los estudiantes - discípulos directos de Butrigariis algunos-, y fácilmente se pudo llegar el 6 de abril a un principio de acuerdo, basado en la libertad inmediata de los cómplices de Jaime de Valencia, encarcelados aún, a cambio del reconocimiento de la condena de éste y del retorno a Bolonia. Parecía ser el fin de una brevísima lucha ${ }^{176}$.

Pero los mismos estudiantes, incluso después del acuerdo, estaban descontentos, y en pocos días la situación cambió completamente. Es probable que las concesiones del municipio no hayan sido nunca satisfactorias por completo para los congregados en Imola, sobre todo porque su número, y por consiguiente su poder de contratación y su radicalidad, aumentaban a ojos vista. Lo cierto es que el 4 de mayo el Consejo del Pueblo fue informado de las nuevas condiciones de los escolares -que examinaremos a continuación-y de que en consecuencia las negociaciones, que no habían cesado en teoría, tendrían que volver a empezar. La capacidad de los emigrados de conseguir mayores ventajas, sin duda aumentada en aquel mes, tenía sólo un posible límite: en Imola no podía prose-

176 F. FILIPPINI, L'esodo, pág. 117. 
guir sus estudios. Así, incluso para volver a Bolonia, lo que nunca dejó de ser la voluntad común de todos, era necesario buscar un acomodo académico en otro Estudio, aunque fuese temporalmente. El alejamiento de Bolonia podía resultar largo, y los estudiantes no podían esperar años. El número y los objetivos comunes eran las fuerzas de la emigración, pero en Imola ambas se podrían deteriorar, amenazando incluso la unidad del grupo. Otras ciudades podrían ofrecer condiciones muy aceptables que hiciesen posible la espera y, al mismo tiempo, se convirtiesen en otros tantos argumentos contra Bolonia. Conscientes de esto, los líderes ultramontanos recibieron ofertas de otros Estudios incluso antes de recibir la respuesta boloñesa a la segunda propuesta.

Siena se presentó pronto como la más atractiva para los ultramontanos exiliados ${ }^{177}$. Desde hacía tiempo, la ciudad toscana ofrecía altos salarios a maestros prestigiosos, intentando convertirse en sede de un Estudio general como el de Bolonia. El Estudio de Siena fue consecuencia de la voluntad política del municipio, sobre todo como afirmación de prestigio y de poderío. El Estudio existía allí desde mediado el siglo xili, pero en su primer siglo de vida fue poco brillante, al menos fuera de Italia; su principal público eran italianos que, por razones económicas o políticas decidían no ir a Bolonia. Por su origen, fue gibelino, y tardó en conseguir el rango de Estudio general. Los ultramontanos de Bolonia podían significar un gran refuerzo cuantitativo y un gran impulso a su prestigio. El conflicto de 1321 fue observado con satisfacción por todos los Estudios competidores, y más cuando generó una migración estudiantil 178; Siena supo ser la primera en ofrecer facilidades especiales a los que la eligiesen para terminar sus carreras, tal vez por la experiencia de un caso similar, aunque mucho menos importante, en 1298; también Padua y Florencia intentaron en aquellas semana atraerse al menos a parte de los exiliados, y todas enviaron delegados a Imola ${ }^{179}$.

Guglielmo de Ciliano, un maestro que se había formado en Bolonia, fue el enviado de Siena. No se conoce la oferta que hizo a los dirigentes

\footnotetext{
177 F. FILIPPINI, L'esodo, pág. 118. G. Minnucci y L. KosuTA, Lo Studio di Siena nei secoli XIVxvi. Documenti e notizie biografiche, Milano, 1991. L. BaNCHI, Alcuni documenti che concernono la venuta in Siena nell'anno 1321 dei Lettori e degli Scolari dello Studio Bolognese pubblicati e illustrati da--, «Giornale Storico degli Archivi Toscani», 5, Firenze, 1861, págs. 237-247 y 309-331; G. Prunal, Lo Studio Senese dalle origini alla "migratio» bolognese (sec. Xl1-1321), «Bullettino Senese», 3, Siena, 1948, págs. 53-79; G. PRunAl, Lo Studio senese dalla «migratio bolognese» alla fondazione della "Domus sapientiae» (1321-1408), "Bollettino senese di storia patria», 57, Siena, 1950, págs. 122-127. G. CENCEtTI, Lo Studio Senese dalle origini, págs. 61 y ss.

178 L. BANCHI, Alcuni, págs. 238 ss.

179 F. FILIPPINI, L'esodo, págs. 122 y 124-126.
} 
de los ultramontanos, pero lo que se sabe supone un gran esfuerzo por parte del Estudio toscano ${ }^{180}$. El municipio aportó seis mil florines para financiar la venida de estudiantes, incluyendo sus mudanzas desde Imola; se pidió a Aviñón la licencia para conceder grados en teología, que Bolonia no poseyó hasta finales de siglo; y grandes gastos fueron realizados para hacer la ciudad más agradable para los extranjeros, e incluso se alquilaron casas para alojar a todos los que llegasen. La organización del pequeño Estudio, aunque inferior a la de Bolonia, y desde luego no preparada para asumir todo el contingente de ultramontanos, pareció suficiente por lo menos para una estancia breve ${ }^{181}$. Pero el gasto más importante, aunque no el mayor, fueron las cantidades directamente entregadas a los rectores y cabecillas de los estudiantes para que se adoptase la decisión de ir a Siena: se confiaba en que todos seguirían a los que ya habian dirigido el éxodo desde Bolonia, generosamente recompensados por esta segunda parte de la emigración. Tal vez otras posibles alternativas habrían sido más interesantes científicamente, pero lo cierto es que Siena, además de conveniente para el patrimonio y las carreras de alguno, no era una opción despreciable en sí misma, y, por una u otra razón, fue colectivamente elegida cuando hubo que buscar una salida a la situación.

Entre los documentos publicados por L. Banchi ${ }^{182}$ se encuentran los relativos al pago por Siena de los gastos de viaje de los estudiantes y de sus libros. Lando Buoncompagni y Guido Buondoni viajaron varias veces a Bolonia para recoger los libros y otras propiedades de los emigrantes, y esto a pesar de las rigurosas prohibiciones. Conocemos los nombres de tres ultramontanos directamente subvencionados por el municipio sienés, y de ellos dos son españoles: Antonio y Martín «de Catelonia» (con toda probabilidad Martinus Romei, clérigo de Tortosa, en Bolonia en 1320 y Antonio Ansaldi de Galiana, canónigo de Mallorca, muy implicado en la vida universitaria boloñesa en 1320-21 y muy pronto asentado en Siena). Antes de terminar mayo, y después de unas negociaciones breves aunque intensas y evidentemente onerosas, los estudiantes empezaron a llegar a Siena ${ }^{183}$. Materialmente no hubo problemas, sino más bien una general satisfacción, pero pronto se pudo ver que faltaban los grandes maestros cuyo prestigio había hecho a los escolares venir desde España. El exilio, en estas condiciones, podía permitir afrontar el diálogo con Bolonia con

180 No hay documentos que confirmen lo dicho por las crónicas sienesas; véase L. BANCHI, $A /$ cuni, pág. 240.

F. FILIPPINI, L'esodo, pág. 124.

L. BANCHi, Alcuni, págs. 309 ss. Documento 1.

L. BANCHI, Alcuni, pág. 244. 
calma y en buena posición, pero la generosidad de Siena no bastaba para sustituir permanentemente el reconocimiento universal de que gozaba el Alma Mater y sus títulos. El obstáculo para Siena no era de gasto, sino estrictamente jurídico y político; la lentitud pontificia en reconocer definitivamente el estatuto de Estudio General a la ciudad toscana hacia imposible un asentamiento definitivo. Para la mayoría de los ultramontanos, pues, la marcha hacia el Sur había sido sobre todo una maniobra táctica en la negociación con Bolonia. Para un abandono definitivo habrían elegido un verdadero Estudio General, lo que en cualquier caso colocaba a Padua (la Universidad que había acogido a Giovanni d'Andrea dos años antes) y Nápoles, al menos, en mejor posición que Siena. Los españoles, como caso concreto, podían obtener en Salamanca estudios de igual o mayor renombre, y sólo Bolonia justificaba el viaje a Italia ${ }^{\$ 84}$.

Contrariamente a lo mantenido por F. Filippini, no todos los ultramontanos dejaron Bolonia tras la muerte del valenciano, o, al menos, no lo hicieron de inmediato. Hasta 21 de los 33 españoles localizados en Bolonia en 1321 aparecen precisamente después del 23 de marzo. Ya hemos visto a Vicente Anforis, canonista y discípulo de d'Andrea, en Bolonia el 14 de mayo, en plena crisis entre la ciudad y los emigrados, junto a Ramón Berenguer, otro canonista mallorquín, continuador de la «peregrinatio academica” (estudiante enTolosa, como Jaime de Valencia, y todavía en BoIonia en 1323). Su caso no fue único: menos de un mes después, el 12 de junio, el aragonés Juan Guido ${ }^{185}$, canónigo (tanssorerius) de Tarazona, hizo la paz con el boloñés Eollogius Mathioli. Del 27 de junio es uno de los mayores cambios diferidos (préstamos) de esta parte del siglo XIV: los catalanes Bernardo Ibáñez y Simón Aullinerii ${ }^{186}$, con un grupo de otros extranjeros, recibieron del florentino Duccio Furli 1200 libras, siguiendo la práctica habitual de asociarse para conseguir mejores condiciones. Después del verano, el 21 de octubre, el catalán Bernardo Corradi ${ }^{187}$ obtuvo, en dos operaciones diferentes, dos préstamos disimulados, con otro catalán, Blaxius Tucrii, como testigo de la primera, y a Blaxius Bartolomei Blaxii, que puede o no ser el mismo personaje, de la segunda. Francisco lbáñez, Juan y Martinus Guidonis son los otros testigos del segundo documento, mientras que Bernardo Tucrii ${ }^{188}$ lo es de los dos. El 6 de no-

184 F. FILIPPINI, L'esodo, págs. 124-126.

185 A. García y García, Escolares, pág. 38, n. 60. A.S.B., Memoriali, 141, 1321; f. 65v., 2 (1. 18-28)

186 A.S.B., Memoriali, 141, 1321; f. 141r., 9 (I. 70-78).

187 A.S.B., Memoriali, 143, 1321; f. 267r., 1 (I. 4-11). A.S.B., Memoriali, 143, 1321; f. 267 r., 2 (i. 12-19).

188 A. Garcia y García, Escolares, pág. 34, n. 19. 
viembre 9 españoles, Berenguer de Perpiñán ${ }^{189}$, Berenguer Raimundo, Bernardo Arardi, Bernardo de Salmo, Gualtriano de Villanueva, Guillermo Reinaldo, Jaime Galgerán, Pedro Pérez y Pedro Martínez recibieron 400 florines empeñando 8 caballos. Se trata sin duda de escolares, a pesar de lo anormal del caso, y A. García e García los considera probablemente juristas y no mercenarios.

¿Qué sentido tiene la presencia en la ciudad de ultramontanos y de maestros aliados suyos en plena crisis? Algunos parecen retenidos en Bolonia por razones económicas; otros están sólo de paso; todos, de cualquier manera, evitan presentarse como estudiantes después del 21 de marzo. Moralmente, incluso si no personalmente, la mayoría de los estudiantes apoyó el exilio como medio de presión para obtener concesiones que los ultramontanos ambicionaban desde tiempo atrás, y sólo una minoría siguió en el Estudio; de hecho, en la autoridad del rector de los ultramontanos residuales, Bartolomeo Lamberti de Chipre, no creyeron ni los propios «negros» boloñeses. Siena suponía mayor tranquilidad para los estudiantes en la negociación que Imola. Todos sabían que, frente a un exilio que supiese resistir y permanecer unido, el municipio boloñés siempre había cedido. Los dos años (1321-1323) de emigración son por otra parte el único momento de verdadero esplendor del Estudio de Siena durante la Edad Media ${ }^{190}$ : esta debilidad es la mejor demostración de lo instrumental de la opción toscana para los escolares boloñeses. Cansado de esperar, el Consejo del Pueblo, consciente de que, salvo excepciones, la emigración era general, y la supervivencia del Estudio estaba en peligro, accedió a negociar, aunque siempre con la suficiente lentitud como para permitir que el tiempo evitase concesiones de fondo.

También había en Bolonia una parte del partido «negro» que seguía siendo intransigente frente a los emigrados y que obtuvo una absolución formal para Michele Zagnoni por la muerte de Jaime y por los incidentes anteriores a la misma; esta sentencia tuvo lugar el 8 de mayo, precisamente en lo más delicado de las negociaciones y coincidiendo con la ruptura de las mismas y la marcha a Siena. Se ha dicho ya de las razones académicas, personales y económicas que llevaron a los escolares a este paso, pero también hubo en él algo de respuesta a sus enemigos de la

189 A.S.B., Memoriali, 143, 1321; f. 333v., 5 (1. 29-46) [29-38 doble columna]. A. García Y García, Escolares, pág. 32, n. 8; Berengarius de Perpiniano catalanus, Berengarius Raymundi de Argionellis, Bernardus Arardi, Bernardus Bartolomei de Salmo, Gualtrianus Raymondi de Vilanova, Guillelmus Raynaldi, Jacobus Galgeranni, Petrus Beltranis Petri, y Petrus Martinis Petriçoli.

190 F. FILIPPIN1, L'esodo, pág. 131. L. BanCHI, Alcuni, pág. 246. 


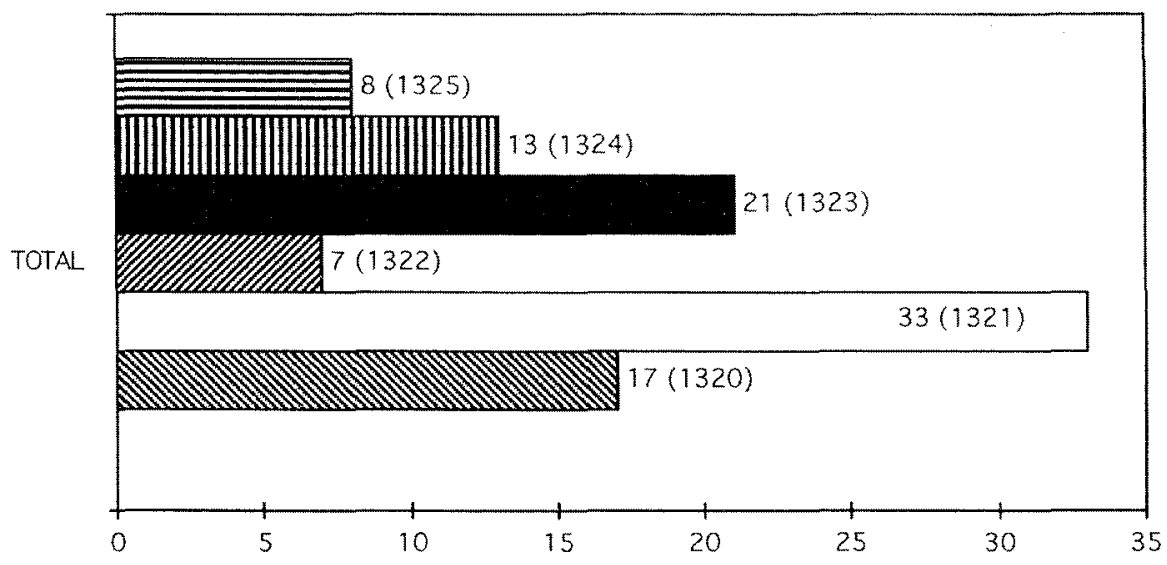

Evolución de la presencia española en Bolonia, 1320-1325.

ciudad. Los españoles Esteban de Rota, alumno de Butrigariis del que ya hemos hablado, Antonio Guillermo, Bernardo Guillermo y Guillermo Cauletti, con el húngaro Gregorio y el francés Petrus Petribanne, de Narbona, son mencionados en la absolución como heridos o maltratados por Zagnoni y sus cómplices. Lógicamente ellos, junto a los demás españoles y los ultramontanos más allegados, constituyeron el núcleo duro de la emigración. La sentencia acrecentó su intransigencia, y entre sus exigencias pasó a figurar la renuncia por la ciudad de la condena de los emigrados y de la absolución de los boloñeses implicados. La decisión de mayo de ir a Siena no fue, pues sólo para conseguir plena satisfacción de sus peticiones, sino porque dentro de Bolonia las opiniones estaban divididas y, aunque muchos querían aceptar las peticiones de los escolares, había una minoría opuesta a hacerlo.

En este sentido ha de entenderse la multa y la expulsión de la ciudad sufridas por el maestro Paolo de' Liazari, que había acompañado a los rebeldes a Siena, el 26 de junio ${ }^{191}$. El Consejo del Pueblo autorizó paralelamente, en estos meses, la contratación a expensas del municipio de nuevos y prestigiosos profesores, sobre todo en Padua, y también nuevos incentivos para atraer estudiantes de las ciudades güelfas. Con una política similar a la de los Pepoli, la parte «negra» intentaba combatirles y combatir a sus aliados los ultramontanos. Como culminación de esta lucha, el 17 de julio el Consejo expulsó de la ciudad a los Pepoli y a sus partidarios,

191 F. FILIPPINI, L'esodo, págs. 131 y 134-135. 
asumiendo el control total de la ciudad, bajo la presidencia de Bernardino Bambagliuoli. La guerra siguió sin embargo, pues los Pepoli eran fuertes en el territorio de la ciudad, y de hecho consiguieron tal clima de inestabilidad que se hizo imposible la llegada de nuevos estudiantes en aquel segundo semestre de 1321, de tal manera que, a pesar del creciente gasto, no se consiguió el regreso de los escolares y maestros exiliados. De esta manera, la emigración estudiantil, empezada para durar unas pocas semanas, como las anteriores, pasó a formar parte de una situación política más compleja y más amplia que la simple realidad boloñesa; pero la clave para solucionar el conflicto seguía siendo principalmente boloñesa y pasando por maestros como d'Andrea y Butrigariis que, aunque todavía en la ciudad, eran abiertamente partidarios de los Pepoli y de los estudiantes ${ }^{192}$.

Las condiciones para el retorno, planteadas por los estudiantes en mayo desde Imola, siguieron siendo substancialmente la mismas a lo largo de estos meses ${ }^{193}$. Parecieron en principio excesivas a sus enemigos boloñeses; ante todo, como satisfacción moral, pedían que el municipio, el Podestà y su juez se disculpasen por la muerte de Jaime de Valencia, que la ciudad observase luto durante un tiempo y que se construyese una capilla expiatoria conrnemorativa. En lo inmediato, pedían la expulsión de los Zagnoni de la ciudad, bajo el control de los rectores, y la libertad para algunos escolares encarcelados. Judicialmente, exigían para todos los estudiantes la posibilidad de elegir en cada caso criminal la jurisdicción competente (el Podestà o Capitano del Popolo, es decir los Pepoli, o, en el caso de los clérigos, la episcopal), límites al uso de la tortura y un límite máximo de 30 días en la duración de los procesos. En conjunto, de ser aceptadas, estas medidas habrían puesto a los estudiantes bajo la tutela conjunta de sus propios rectores y de los Pepoli (verdadera dinastía de Capitanes del Pueblo). Políticamente, el mayor obstáculo a la aceptación de este programa por Bolonia eran no tanto las consecuencias para el funcionamiento del Estudio (ya que los ultramontanos renunciaban a su viejísima aspiración de ser juzgados en exclusiva por sus rectores). Con el tiempo, la ciudad habría de aceptar, y precisamente tiempo es lo que los estudiantes buscaban yendo a Siena; porque Siena, al menos para los españoles, nunca fue otra cosa que un paso hacia Bolonia, un alto en las negociaciones ${ }^{194}$.

192 F. FILIPPINI, L'esodo, pág. 140

193. G. Rossı, «Universitas scholarium», págs. 257-258.

194 R. GReCl, L'associazionismo, págs. 35 y ss, y, aunque superado, G. Cencerti, Il foro deg/i studenti negli Studi medievali italiani, "Atti e Memorie della Deputazione di Storia Patria per l'Emilia e la Romagna”, 5, Bologna, 1939-1940, págs. 163-188. 
Bolonia buscó mientras tanto apoyo pontificio contra el Estudio, presentando la migración como una maniobre gibelina ${ }^{195}$. Así, las negociaciones se hicieron con cuatro partes implicadas (Bolonia, Siena, el Papa y los escolares), y no sólo sobre el problema concreto de la migración. De hecho, desde finales de 1321, hubo dos tipos de negociaciones: por una parte las conversaciones directas entre la ciudad y los estudiantes; por otra, los contactos políticos entre las dos ciudades, con intervención de la Curia. Para Bolonia, los estudiantes no representaban en sí mismos un problema político, sino económico, como económica era la naturaleza de sus peticiones. Eran las diferencias políticas internas las que hacían difícil el acuerdo, y más con intervención de Siena. Dividiendo ambos problemas, en un momento de 1322 que no se puede precisar (carecemos de base documental fechada), las negociaciones con los estudiantes concluyeron con satisfacción por ambas partes. Entre finales de febrero y principios de marzo, los rectores de lo que quedaba en Bolonia de las Universidades iniciaron las obras de la capilla conmemorativa de Jaime de Valencia, mientras pedían a la ciudad y al Papa garantías frente a sus colegas que probablemente regresarían pronto del exilio. Todas las condiciones de los estudiantes fueron aceptadas, excepto las que ya no tenían sentido: el nuevo Podestà no podía pedir disculpas por los errores de su predecesor, y los Zagnoni, marido, mujer e hija, habían abandonado la ciudad ${ }^{196}$.

El 20 de abril, el Consejo confirmó la validez de los acuerdos, en los términos antedichos, a los que el maestro Butrigariis había llegado, en Imola y en Siena, en los meses anteriores, y así, finalmente, la crisis se resolvió a plena satisfacción de los escolares. Una garantía adicional para el regreso fue el nombramiento como rector de los juristas ultramontanos para 1323 del portugués Martín de Llerena ${ }^{197}$, canónigo de Coimbra, para el que la ciudad pidió a la vez una canonjía en Braga. La plena ejecución de las condiciones de retorno fue así ratificada con la elevación de un his-

195 F. FILIPPINI, L'esodo, pág. 142.

196 R. GreCl, L'associazionismo, pág. 36. F. FILIPPINI, L'esodo, págs. 144-145.

197 G. Rossi, «Universitas scholarium», pág. 259. A. GaRcía y GARcía, Escolares, pág. 40, n. 69 y 70. A.S.B., Memoriali, 150, 1324; f. 194v., 1 (I. 16-33), para 1324, A.S.B., Memoriali, 154 , 1325; f. 48r., 2 (I. 7-16), y A.S.B., Memoriali, 154, 1325; f. 48r., 3 (I. 17-24), para 1325. F. FILIPPINI, L'esodo, págs. 145-146, sobre la elección de rector en 1322-1323. Se le conoce como «Martinus Martini de Lerena de Ispania, scolar Bononiae in iure canonico rector ultramontanus, canonicus Colubriensis et Portuensis exspectans, ac rector Sanctae Columbae de Hoo Columbriensis diocessis» en la petición del Comune al Papa; en C. PIANA, Nuovi II, pág. 28. En el segundo semestre de 1323 cedió el cargo al alemán Heinrich Dapifer (ibídem, pág. 29). A. PÉrEz MARTín, La precedencia, pág. 704, C. MaLAGOLA, I Rettori, págs. 1-128, y C. MaLAGOLA, Serie dei Rettori, págs. 129-220. 
España en la Universidad de Bolonia: vida académica y comunidad nacional...

pánico a esa responsabilidad tan delicada. Este nombramiento fue de alguna manera una fianza, pues no en vano los ibéricos habían sido la causa del éxodo, los dirigentes del mismo y, en fin, los únicos capacitados en todo momento para negociar con firmeza garantizando el regreso a la normalidad. No es seguro que todos los escolares volviesen a Bolonia inmediatamente después del acuerdo: por ejemplo, sabemos que Antonio Ansaldi de Galiana, el catalán que hemos encontrado en 1320-21, y después en Imola como uno de los partidarios de la marcha a Siena, fue precisamente maestro en la ciudad toscana incluso después de 1322, con una alta remuneración (495 libras anuales, según cálculos de L. Banchi) y la cátedra de Volumen ${ }^{198}$. De Bolonia había salido como estudiante, y, aunque no se conservan los documentos, probablemente se doctoró en Siena inmediatamente después de su llegada; tal vez ese título y ese contrato eran parte del precio para favorecer la marcha de muchos ultramontanos hacia el nuevo Estudio. Con seguridad, nunca volvió a Bolonia como escolar.

En efecto, los estudiantes, que habían emigrado en bloque y habian negociado unidos, volvieron divididos, o no volvieron (pues las ciudades rivales mantuvieron ofertas muy interesantes). La capilla llamada «de la paz", impuesta por los exiliados, fue inaugurada a finales de abril por el nuevo Capitano del Popolo, Taddeo Pepoli, que con esto consagraba su retorno a Bolonia y su victoria frete al Consejo ${ }^{199}$, como símbolo de reconciliación de los ultramontanos con Bolonia y de victoria de los Pepoli dentro de la ciudad. Ambas causas habían terminado por identificarse pero, a diferencia de ocasiones anteriores, el poder estudiantil, aunque determinante, no había sido suficiente para forzar el triunfo. Los españoles, no por casualidad, dirigieron esta lucha, ejerciendo así un rol directivo entre los ultramontanos que era el suyo en aquellos años; pero su fuerza fue apenas suficiente, $y$, en un Estudio ya decadente, se vislumbraba ya la necesidad de cambios organizativos para adaptarse a un poder civil más cercano y más invasivo, incluso en el campo antes vedado de los maestros.

La crisis de 1321 demostró cumplidamente que sólo la unidad de acción y una adecuada presencia institucional permitiría a los estudiantes extranjeros defenderse de las aspiraciones municipales. La ciudad podía contar con una presión constante de la que los escolares, que pasaban unos breves años en Bolonia, eran incapaces. La victoria de 1322 fue po-

198 L. BANCHI, Alcuni, págs. 321-322 y 327-328, documentos XI y XII.

199 Guido da Polenta, enemigo de los "negros»; F. FILIPPINI, L'esodo, págs. 149-150. 
sible gracias a una tradición de enfrentamientos recibida a través de las nationes y, sobre todo, gracias a la presencia de un grupo numeroso, compacto y activo de españoles directamente afectados por lo sucedido en 1321. Los Colegios, nacidos en las décadas sucesivas, significaron una solución pragmática para obtener los mismos resultados con comunidades de estudiantes mucho más limitadas y con rivales mucho más fuertes. Para los españoles, desde 1322 y hasta prácticamente el último tercio del siglo, se abrió una fase de decadencia cuantitativa y de menguante influencia en el Estudio, en el que las Universitates estaban ya «cristalizadas corporativamente» 200 .

\section{EL REGRESO DE LOS EXILIADOS: 1321-1330}

A partir de 1321 Bolonia no conoció la paz, entre guerras externas y conflictos internos, con las breves excepciones del régimen pontificio de Bertrando del Poggetto y del gobierno de Taddeo Pepoli. Las condiciones de paz necesarias para una afluencia numerosa y constante de ultramontanos no se volvieron a dar establemente hasta la llegada cardenal Albornoz. Entre tanto, el Estudio fue poco más que un elemento en las luchas políticas internas, al albur de las peores consecuencias de las mismas; 1321 representa, pues, la última ocasión en la que los estudiantes consiguieron imponer con autoridad a la ciudad el que conocemos como «modelo boloñés» 201.

En 1322 y hasta 1325 se asiste al retorno de los mismos españoles que lo habían dejado en 1321. Por un tiempo se pudo tener la impresión de un regreso a la normalidad, aunque sin volver a las cifras de 1320-21, cuando se había alcanzado un máximo. En los Memoriali de 1322 (volúmenes 144,145 y 146) los hispanos ya aparecen en tres documentos, incluso antes de la formalización definitiva del acuerdo con la ciudad ${ }^{202}$. El 9 de febrero el aragonés Guillermo Gómez Alfasi de Perula recibió en préstamo de Laurentius de Manaellis 19 libras boloñesas ${ }^{203}$. Después, tras un paréntesis muy largo, el 1 de octubre Domingo Fernández Verdejo, tam-

200 G. RossI, «Universitas scholarium», pág. 264. R. GRECl, L'associazionismo, pág. 36.

201 G. FAsol, Bologna, págs. 176-177. N. Rodolıco, Dal Comune alla Signoria. Saggio sul governo di Taddeo Pepoli in Bologna, Bologna, 1898. A. SoRBELLI, Storia, págs. 222-224, y C. CALCATERRA, Alma Mater, 1948, pág. 122.

202 L. CONTINELLI, L'archivio, págs. 137-142.

203 A.S.B., Memoriali, 145, 1322; f. 13v., 2 (1. 17-28). A. García y García, Escolares, págs. 36 , ก. 40 . 
bién aragonés, y Miguel lbáñez Pérez de Tarazona, cambiaron 9 libras de groses venecianos en 58 libras boloñesas a Thoma Rainerii Girardi: el clásico préstamo disimulado ${ }^{204}$. Al día siguiente, Fernando, canónigo de Cartagena, sustituto de Guillermo de Garnoia (¿García?), procurador del estudiante Alfonso Rodríguez (el canónigo de Cartagena ya presente en 1316), recibió de Acarixio Nobis de Caruis, representante del judío Lapius de Baçantis de Foraboschis, 10 libras boloñesas a cuenta de un préstamo de $90^{205}$.

La situación en 1323 cambió como resultado del regreso de más exiliados ${ }^{206}$. Hay seis documentos, y un número de españoles casi igual al relativamente enorme de dos y tres años antes. $Y$ aún así es seguro que el número real fue mucho mayor que el registrado documentalmente, porque, por ejemplo, el rector de los ultramontanos en 1323 Martín Martínez de Llerena, canónigo de Coimbra, no aparece en los documentos notariales hasta $1324{ }^{207}$. Conviene subrayar que casi todos estos hispanos parecen estar en Bolonia desde años atrás, antes de la migración de 1321; tras la crisis, vuelven a la ciudad para completar sus estudios, pero, a diferencia de ocasiones anteriores, no hay evidencias de una nueva generación que renueve la tradición. De esta forma, la victoria estudiantil sobre las oligarquías municipales fue negativa a medio y largo plaz para el Estudio y sobre todo para las naciones de juristas hispanos ${ }^{208}$. El 29 de julio los catalanes Domingo Serule y Bernardo de Coreliano, canónigo de Mallorca, se reconcilian con el librero (estacionario) Bernardus Johannis, y el primero de ellos recibe una indemnización ${ }^{209}$. El 12 de septiembre siguiente Bernardo Guillérmez de Montegato, su hermano Ugenus ( $¿ E$ Eugenio?), Berenguer Pérez Discolo, Berenguer Raimúndez de Frunys, Juan Ibáñez García, Arnaldo Arnáldez Parage, Florio Florii, Raimundo Tomás de Gerona, Bernardo Guillérmez de Lorone, el catalán Nicolás Pérez de Villa Torta, Guillermo Beltrán de Barasio —llamado «nobilis miles»- y Pedro Pérez Parzelli, españoles, con Jacobus Millani, milanés, cambiaron 300

204 A.S.B., Memoriali, 145, 1322; f. 324v., 1 (I. 11-24). A. García Y García, Escolares, pág. 34 , n. 25 , y pág. 41, n. 77.

205 A.S.B., Memoriali, 146, 1322; f. 272r., 2 (I. 10-18). A. Garcia Y GARCiA, Escolares, pág. 35 , n. $30 ;$ pág. 37 , n. 43 ; pág. 31 , n.2.

206 L. CONTINELLI, L'archivio, págs. 143-148 (volúmenes 147,148 y 149), y A. SoRBELLI, Storia, pág. 223.

207 A. Garcia y Garcia, Escolares, pág. 40, n. 69 y 70. A. Pérez Martín, La precedencia, pág. 704, C. MALAGOLA, I Rettori, págs. 1-128, y C. MaLAGolA, Serie, págs. 129-220. Más interesante C. PIANA, Nuovi, pág. 28.

208 G. FASOLI, Bologna, pág. 176.

209 A.S.B., Memoriali, 149, 1323; f. 7v., 3 (1. 21-17). Documento parcialmente publicado por G. Orlandelli, II libro, pág. 107, doc. 304. A. García y Garcia, Escolares, pág. 33, n. 16. 
florines de oro por 600 libras boloñesas por 15 dias a Bartholomeus y $\mathrm{Pe}$ trus Ambolii, dejando como prenda 9 caballos: probablemente uno de los préstamos de mayor evergadura de todo el período en lo tocante a los españoles ${ }^{210}$. Por desgracia, no es seguro que sean estudiantes, al menos todos ellos, pudiendo tratarse de una partida de soldados. Escolares eran, en cambio, el inglés Symonis Guillielmi y el aragonés Guardo Berenguer, representado por el catalán Raimundo Berenguer, que el 10 de octubre pagaron a Albertus Thomaxini 21132 libras de groses venecianos a cambio de 80 libras boloñesas, y el canonista Fernando Jacobi de Mora de Perpiñán, que el 4 de noviembre, junto a Raimundo Berenguer Montado, canónigo de Mallorca, llamado «de Tolosa» y presente en el documento anterior, recibió 75 florines a través del mercader mallorquín Guillermo y los cambiaron por 100 libras boloñesas a Petrus Ugolini. Este Raimundo Berenguer ya estaba en Bolonia antes de 1321, en que aparece por vez primera; la mención «de Tolosia» puede deberse a una estancia, en un momento anterior de la "peregrinatio academica", en aquel Estudio ${ }^{212}$.

En 1323 vuelven los españoles, por primera vez desde 132i, a los documentos judiciales de la Curia del Podestà, con una acta del 19 de noviembre, por la que algunos vecinos de la capilla de S. Cristoforo «de Saragotia" denunciaron a los escolares Luis de Valencia y Dominichus Andree de Poregia [ $i$ ?] por haber herido al italiano Gabriele de Piacenza.; sólo nos consta que fuese español el estudiante valenciano ${ }^{213}$. El 16 de diciembre, finalmente, el doctor en medicina Lippus Uxeppi recibió como prenda del civilista catalán Arnaldo Nendoni de Perpiñán una Summa Ostiense contra un pago de 50 libras boloñesas, con unas condiciones muy rígidas que revelan lo preciado del bien. Fueron testigos del acto los estudiantes catalanes Barbero Gerardi y Berenguer Alemán ${ }^{214}$.

Otros seis documentos nos informan sobre la presencia española en $1324{ }^{215}$. El 23 de febrero ${ }^{216}$, Bartholomeus Guillielmi, boloñés, recibió de

210 A.S.B., Memoriali, 149, 1323; f. 278v.[279v.], 3 (1. 29-42).

211 A.S.B., Memoriali, 149, 1323; f. 88r., 4 (I. 36-45). A. GARCía Y GARCía, Escolares, pág. 43, ก. 95.

212 A.S.B., Memoriali, 149, 1323; f. 363r., 2 (I. 11-32). A. GaRcia Y García, Escolares, pág. 35 n. 31.

213 A.S.B., Curia del Podestà, Giudici ad Maleficia, Carte di Corredo, Scolari e Maestri, III, Documenti estratti, Busta 65,1318 ( $1^{\circ}$ Semestre), doc. n. 4. Documento en papel, $200 \times 250,18$ líneas.

214 A.S.B., Memoriali, 148, 1323; f. $347 \mathrm{v}$., 4 (1. 27-38). Documento parcialmente publicado por G. Orlandelli, II libro, pág. 108, doc. 307, y en A. Garcia y García, Escolares, pág. 26; pág. 32, n. 5 ; pág. 32 , n. 9.

215 L. CONTINELLI, L'archivio, págs. 148-153 (volúmenes 150,151 y 152).

216 A.S.B., Memoriali, 150, 1324; f. 54r., 4 (I. 51-60). 
Juan Parzello, catalán, 270 libras boloñesas como pago parcial de un préstamo de 540; el 27 del mismo mes ${ }^{217}$ nueve boloñeses (Johannes de Remenghis, Jacobus Juliani, Nicholaus Petri, Johannes Benirendi, Johannes de Manzolino, Petrus Symonis y otros tres) fueron acusados ante el juez podestaril de haber golpeado y robado a Raimundo Raimúndez Rubey y a Arnaldo Bernárdez Mendoni, civilistas catalanes, y a sus criados Juan y Berenguer. El estudiante catalán Pedro, también civilista, que en estuvo en Bolonia al menos hasta 1329, fue testigo de que en la noche del 27 de febrero «circha a mezzanotte dum iret ad vivendum tripudium per civitatem Bononie" vio a algunos hombres, seis o siete, con cuchillos, espadas y palos, que después amenazaron robaron a los ya citados Arnaldo, Raimundo, Juan y Berenguer, robándoles el candelabro que uno de ellos llevaba; otros dos testigos italianos, Nicolaus Zani de Imola, criado de Berenguer de Cataluña, y una cierta Belda, confirman esta versión.

El 12 de mayo los estudiantes catalanes Berenguer Pérez Alemán, presente en 1323 y cuyo criado había declarado en la denuncia anterior, Raimundo Raimúndez Rubey y Arnaldo Bernárdez Mendoni, se reconciliaron con Johannes Beriennensis, probablemente uno de los asaltantes boloñeses ${ }^{218}$. En otro documento del mismo día, Nicolás, criado de Berenguer, hizo la paz con Zachinellus. Rolandi Zachinelli y, al día siguiente, Juan, criado de Raimundo, catalán como su patrón, hizo lo mismo. El episodio se concluyó el 29 de junio cuando Berenguer Pérez Alemán, Raimundo Raimúndez Rubey, Arnaldo Bernárdez Mendoni y Berenguer de Berenguer Pérez, todos estudiantes catalanes, se reconciliaron formalmente con Petrus Andreotis, Johannes Benintendi, Petrus Girdeni y Dandus Zacharellii, los restantes agresoresde febrero. El 15 de mayo, los portugueses Martín Martínez de Llerena, canónigo de Coimbra, rector el año anterior, y Gregorio Ibáñez, canonista también y rector de la iglesia de S. Pedro de Portavalla, en la diócesis de Lisboa, cambiaron a Albertus Thomaxini 5 libras de groses venecianos por 100 boloñesas; Antolín Tomás fue el testigo ${ }^{219}$.

217 A.S.B., Curia del Podestà, Giudici ad Maleficia, Carte di Corredo, Scolari e Maestri, III, Documenti estratti, Busta 65, 1324 ( $1^{\circ}$ Semestre), doc. n. 5, ultra. Documento en papel c. $200 \times 350$, en dos folios, difícilmente legible, en mal estado de conservación. A. García y García, Escolares, pág. 43, n. 97 .

218 A.S.B., Memoriali, 151, 1324; f. 183r., 3 (I. 27-38). A. García Y Garcia, Escolares, pág. 33, n. 12. Los tres documentos que siguen: A.S.B., Memoriali, 151, 1324; f. 183r., 5 (I. 39-47); A.S.B., Memoriali, 151, 1324; f. 267r., 3 (l. 44-52); A.S.B., Memoriali, 150, 1324; f. 211 v., 1 (I. 10-31).

219 A.S.B., Memoriali, 150, 1324; f. 194v., 1 (l. 16-33). A. GARCía y GARcía, Escolares, pág. 40, ก. 69 y 70 ; pág. 38, n. 58 . 
1325 representa otros tres volúmenes de Memoriali ${ }^{220}$. El 20 de enero, el escolar español Martín Martínez -que no es sino el portugés del año anterior-, Petrus Simonis y Thoma Bramae recibieron en cambio (es decir, préstamo) de Nicholaus Anscharii de Blanchiis 80 libras boloñesas por 40 florines de oro ${ }^{221}$. El mismo día, en otro documento, el mismoo Martín Martínez, con Vinciano lbáñez, español, Blanchenes Blanchene, marsellés, y Gonglanus Johannis, italiano, reconocen y saldan una deuda solidaria de 80 libras boloñesas con el doctor Petrus Dimonis, heredero de su común maestro Nicholaus ${ }^{222}$. El 1 de marzo ${ }^{223}$, Simonitus de Poggio cedió a Lipo Bonaguidi, florentino, un credito de 50 florines sobre Guillermo de Rodolfo, rosellonés (del reino de Mallorca), en pago parcial de una deuda de 60 florines. El 11 del mismo mes ${ }^{224}$, Arnaldo Bernárdez y el mismo Guillermo Raimúndez de Rodolfo, catalanes, recibieron en cambio de Bliçardus Maregnoni, florentino, 400 libras boloñesas a cambio de 20 libras de groses venecianos a dos meses. Este Arnaldo Bernárdez, mallorquín de la parte continental del reino, no se puede identificar con Arnaldus Bernardi Nendoni (o Mendoni), porque no aparece en este caso el patronímico identificativo. El 12 de agosto ${ }^{225}$, Michelinus Petri Zoha Marascho pagó a Dimas, sacerdote, y a Ubertus de Stephanis, procuradores de Milano de Medio de Valencia, canónigo de Bolonia, una deuda de 25 libras boloñesas. El 5 de octubre ${ }^{226}$, por último, el maestro Jaime Estébanez de Valencia pagó a los mismos Dimas y Ubertus, en función de la misma procura, una deuda idéntica a la anterior.

Sólo hay cuatro documentos de interés en los Memoriali de $1326{ }^{227}$. El 28 de enero ${ }^{228}$, los españoles Rodolfo Beltrán, Pedro Ragaldo de Lilete, catalán, Reinaldo Jacobini, Emansias Pérez da Randiga, aragonés, y Juan Ibáñez cambiaron 340 florines por 700 libras a Dino Gerardini de Gastaldi. El 12 de marzo, Juan Pérez de Becia y Felipe Ranignani de Balduinis, canónigos de Mallorca, con Nicolás de Jaime Bordinus, Sancho Gudiz Domixi y Guillermo, hijo del maestro Pedro, cambiaron 60 sueldos venecianos

220 L. ContinelLi, L'archivio, págs. 153-160 (153, 154 y 155).

221 A.S.B., Memoriali, 154, 1325; f. 48r., 2 (I. 7-16). A. GARCíA y GARCíA, Escolares, pág. 40, n. 69 y 70 .

222 A.S.B., Memoriali, 154, 1325; f. 48r., 3 (I. 17-24). A. García y GaAcia, Escolares, pág. 45, ก. 114.

223 A.S.B., Memoriali, 153, 1325; f. 299r., 3 (l. 30-40).

224 A.S.B., Memoriali, 153, 1325; f. 33r.-33v., 6 (l. $48-63$ y 1-5).

225 A.S.B., Memoriali, 155, 1325; f. 20r., 1 (I. 1-11).

226 A.S.B., Memoriali, 155, 1325; f. 32v., 3 (I. 31-40).

227 L. CONTINELLI, L'archivio, págs. $160-167(156,157$ y 158).

${ }_{228}$ A.S.B., Memoriali, 157, 1326; f. 99v., 2 (I. 16-31). 
por 60 libras boloñesas a Paulus Baxillii Egidii ${ }^{229}$. El 1 de diciembre, Juan Ibáñez, que ya ha aparecido en otro documento, y Juan Hurici cambiaron 10 libras de groses venecianos por 200 boloñesas ${ }^{230}$.

Un solo documento menciona a los españoles en 1327: el 13 de mayo, Arnaldo Bernárdez Mendoni, civilista catalán con bastantes años de presencia en Bolonia, al menos desde 1323, y tal vez desde antes de 1321, con la garantía de Marino Alfonso, civilista portugués, y Bernardo Pérez de Saysy, canonista, recibieron en cambio de Jacoba Anfuxii de Loglano, mujer y representante de Fulchius Villani de Pacibus, 70 libras por 40 florines de oro. Los testigos fueron dos italianos, el maestro Giovanni de Módena y Jacobino Condelini, y el civilista español Bernardo de Arnaldo Guillérmez ${ }^{231}$. Idéntica la situación de 1328 , con otro documento aislado de utilidad para esta investigación. El 31 de enero, Arnaldo Bernárdez Mendoni hace su última aparición conocida en esta serie documental, junto a Thomax Rolandini de Formaglinis, para recibir en cambio (préstamo) de Jacobus Dominici Ysolani 200 libras teóricamente por 120 florines de oro ${ }^{232}$. En este momento de escasez comparativa de la documentación notarial, un documento judicial ayuda a conocer la situación de la comunidad española; el 2.2 de agosto de $1328{ }^{233}$ se notificó al juez del Podestà que Máximo y Sinibaldo de Valencia, estudiantes de medicina residentes en la capilla del Arcangelo, alumnos y residentes junto a los maestros Giuliano y Matteo de Gubbio, ehabían entrado de noche en el huerto de Petronio, rector precisamente de la iglesia del Arcángel, y allí, aparentemente embriagados, habían cortado con las espadas árboles y vides, en particular un melocotonero, un moral, una gran parra, y habían descortezado varios frutales, causando daños graves pero sin robar nada.

En 1329 se asiste a un modesto crecimiento de las presencias registradas documentalmente, a través de tres inserciones en los Memoriali ${ }^{234}$.

229 A.S.B., Memoriali, 157, 1326; f. 154v., 1 (I. 1-10).

230 A.S.B., Memoriali, 158, 1326; f. 289r., 4 (I. 51-62).

231 L. ContinelLi, L'archivio, págs. 168-172 (Volúmenes 159, 160 y 161). A.S.B., Memoriali, 159 , 1327; f. 233r., 1 (I. 10-23). A. García y García, Escolares, pág. 33, n. 13, sobre Arnaldo Guillérmez.

232 L. CONTINELLI, L'archivio, págs. †72-180: Volúmenes 162 (primer semestre), 163 (primer y segundo semestre) y 164 (segundo semestre). A.S.B., Memoriali, 162, 1328; f. 78r., 5 (l. 44-53).

233 A.S.B., Curia del Podestà, Giudici ad Maleficia, Carte di Corredo, Studio. Maestri e scolari $1318-1348$ (fascicoli estratti), busta 65 , documento 1328-21. Documento en papel, c. $200 \times 300$, 30 líneas.

234 L. CONTINELLI, L'archivio, págs. 180-186: Volúmenes 165 (primer semestre), 166 (segundo semestre) y 167 (primer y segundo semestre). Un documento, que ha sido adecuadamente comentado en otro lugar, se refiere al nombramiento de Juan Sánchez de Airaga como comendador del hospital de la Mascarella: P. TamburRi, Presencia institucional (Apéndice). (A.S.B., Memoriali, 167, 1329; 1329, noviembre, 17. Bologna). 
El 24 de octubre, Bernardo Jordán, catalán, recibió de Sabadinus Petri de Sabadini un préstamo de 20 florines de oro, y se comprometió a devolverle 23; Nicolás Guillérmez de Cartagena fue testigo del acto, entre otros ${ }^{235}$. El 4 de noviembre, en fin, el caballero catalán Berenguer de Racha Salva se comprometió a pagar a los también catalanes Pedro, civilista, y Arnaldo 40 libras por los salarios de sus criados Rabrus, Brandus, Vigerhbr (nombre ilegible) y Guillermo «Grossus» (catalán este último). Tal vez este Arnaldo sea el Arnaldus Bernardi que nos hemos encontrado antes, pero esta no pasa de ser una hipótesis. No se le puede identificar, en cambio, con Arnaldus Nendoni o Mendoni, con seguridad. Otro Pedro «de Catelonia» está presente como testigo ${ }^{236}$.

Con dos solos documentos de 1330 termina la serie que ha servido de base a nuestro análisis ${ }^{237}$. El 23 de enero el catalán Guillermo Raimúndez de Villa Setha recibió un préstamo de Parius [?] Egidii por 82 libras, de lo que Bernardo Arnáldez, Julián Ortiz y Rodomeo de Aragón fueron testigos ${ }^{238}$. Finalmente, el 16 de agosto, Pedro Bernárdez de Açure - lugar no identificado en el obispado de Urgel-, catalán, recibía de su mujer Franceschina Bruni Braybatis "pro matrinaria» 100 florines de oro, con cinco italianos y el español Bernardo Miguélez como testigos; se trata, por consiguiente, de un español que, como una parte pequeña pero significativa de los que hemos visto a lo largo de estas páginas, se asentó profundamente en la ciudad y no la abandonó al concluir sus estudios ${ }^{239}$.

La evolución cuantitativa de la presencia española en estos últimos años del primer tercio del siglo puede resumirse en una breve recuperación en 1322-23, con el regreso de los exiliados de 1321, seguida de una decadencia clara y veloz hasta 1328. El período termina con una leve recuperación en 1329-1330, aunque muy lejana de los máximos alcanzados en la década anterior. Después de la crisis, una generación de ultramon-

235 A.S.B., Memoriali, 167, 1329; í. 75v., 1 (l. 1-13). A. García y García, Escolares, págs. 3334, n. 17. Conviene recordar la diferencia entre «Bernardus Coradi», presente hacia 1321, y «Bernardus Gordanus», presente hacia 1329. Sobre el estudiante de Cartagena, ibidem, pág. 41, n. 79.

236 A.S.B., Memoriali, 166, 1329; f. 292v.-293r., 5 (।. 62-72 y 1-2). A. García Y Garcia, Escolares, pág. 32, n. 6; pág. 42, n. 85.

${ }_{237}$ L. CONTINELLI, L'archivio, págs. 186-192. Volúmenes 168 (primer semestre), 169 (primer y segundo semestre) y 170 (segundo semestre).

238 A.S.B., Memoriali, 168, 1330; f. 244v., 4 (l. 31-57). A. García y García, Escolares, pág. 37, n. 48; pág. 33, n. 13; pág. 44, n. 104; págs. 43-44, n. 98 . Uno de estos estudiantes puede identificarse con Guillelmus de Vilerico "de Catelonia», Rector de los Ultramontanos en 1337, que el 13 de septiembre de aquel año contrató a Paolo de' Liazari; C. PIANA, Nuovi documenti pág. 30.

239 A.S.B., Memoriali, 170, 1330; f. 267v., 2 (I. 28-35). A. García Y GARcía, Escolares, pág. 42 , ก. 84 ; pág. 45, n. 109. 


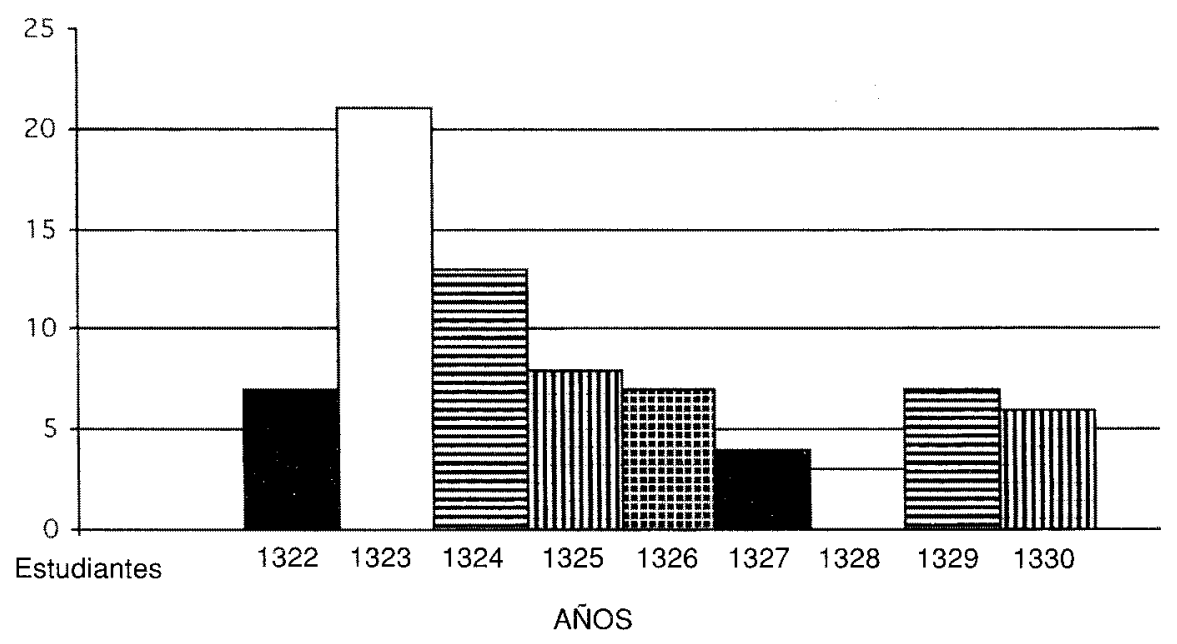

Los españoles en Bolonia de 1322 a 1330.

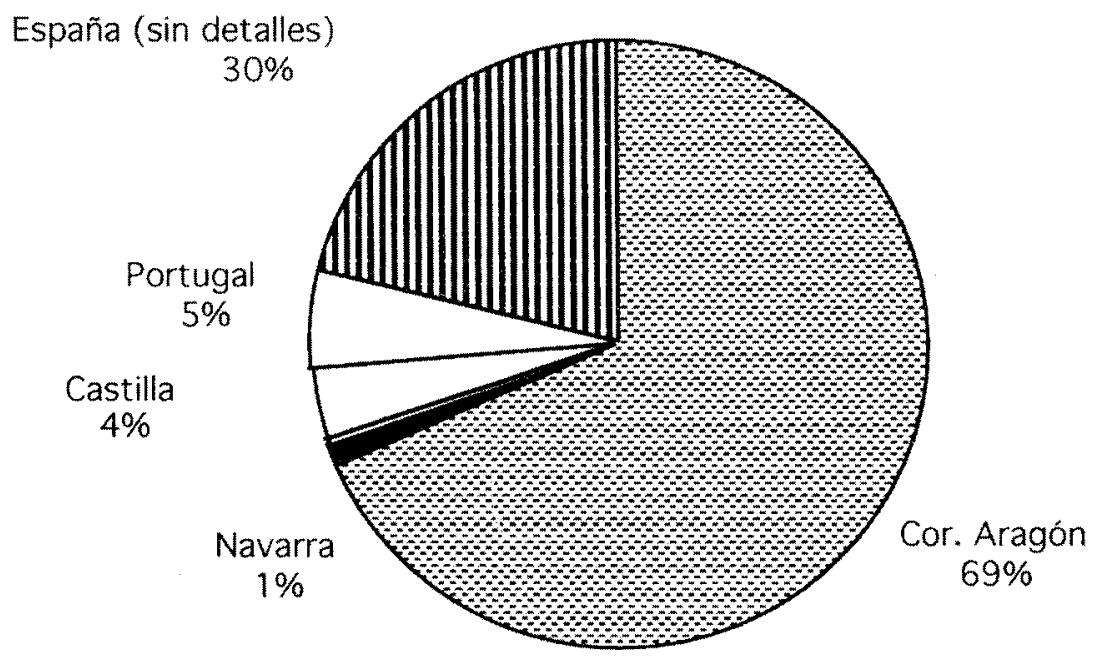

Origen de los estudiantes en Bolonia (1321-1330).

tanos decidió no acudir a Bolonia, o hacerlo en cifras mucho más reducidas. Pocos cambios hubo, por otra parte, en la distribución regional de los escolares por su origen; una mayoría de aragoneses todavía más amplia que la de los años anteriores, con una estabilidad substancial de portugueses y castellanos y una disminución de la proporción de aquellos hispanos que no declaran su prominencia en este sentido. 
Desde 1321, y con seguridad a partir de 1330, el papel del Estudio boloñés en España padeció un cambio muy importante. Perdida una parte importante de su tradicional capacidad de atracción sobre los españoles, y sin poder contar ya con una enorme ventaja de nivel científico sobre otras Universidades con estudios jurídicos, la presencia peninsular disminuyó con rapidez, y al mismo tiempo la influencia de Bolonia en la cultura española. Dos generaciones de españoles, las que comenzaron sus estudios superiores entre 1325 y 1365, no estuvieron presentes en Bolonia en cantidades apreciables. Pero en España, aunque menguada, la participación del Estudio italiano en la vida cultural, especialmente jurídica, no podía desaparecer. Muchos habían recibido, de un modo u otro, la cultura humanística de Bolonia, y para volver a hacer de aquella Universidad un centro de formación de las minorías rectoras de los distintos reinos faltaba sólo una modernización y una reorganización que evitasen las crisis cíclicas de la comunidad española. Esencial para comprender la cultura jurídica española, el vínculo con Bolonia no se podría haber roto sin consecuencias muy graves ${ }^{240}$.

Martín de Zalba de Pamplona (1337-1403) fue uno de los pocos españoles de formación boloñesa en el segundo tercio del siglo XIV. Formado como canonista a partir de 1350, enseñó en varias Universidades francesas antes de ser canciller de Navarra, obispo de Pamplona y, como consejero de Benedicto XIII, cardenal ${ }^{241}$. Su presencia en el Estudio italiano enlaza dos grandes momentos de la comunidad universitaria medieval española: antes de 1330, como comunidad estudiantil, y a partir de 1364, en torno al Colegio de España. Con seguridad, los españoles no dejaron abruptamente de acudir, y sabemos por el testamento mismo del cardenal Albornoz que existía un cierto número de escolares hispanos que permanecieron ajenos a la institución que allí se funda. A la luz de las atormentadas vicisitudes de los españoles en la organización tradicional de las Universitates, descrita en las páginas anteriores, la creación de un Colegio que, sin reunir a todos los españoles, concentrase un cierto número y diese a todos un peso institucional permanente con mayor coherencia que la decadente Mascarella, era una solución a largo plazo. Esta decisión probablemente salvó un vínculo intelectual entre los juristas españoles e Italia que, establecido al más alto nivel en los si-

\footnotetext{
240 F. Calasso, Medio Evo págs. 616-617.

24. J. GoÑ GAZTAMBIDE, La formación intelectual de los navarros en la Edad Media (11221500), «Estudios de Edad Media de la Corona de Aragón», 10, Zaragoza, 1975, n. 111, págs. 202203, y n. 170, pág. 218: también su sobrino Miguel de Zalba estudió en Bolonia, licenciándose en ambos Derechos en 1403.
} 
glos anteriores, se consagró como comunidad de vida entre el xIII y el XIV ${ }^{242}$.

\section{CONCLUSIONES}

Desde un punto di vista metodológico, parece haber un acuerdo general en considerar, por un lado, que la documentación notarial boloñesa ofrece un gran potencial para la historia universitaria, y por otro, que su enorme volumen es el principal obstáculo para extraer todo su contenido. Los dos grandes proyectos para emplearla sistemáticamente (el Chartularium Universitatis Bononiensis, para la historia del Estudio, y el Corpus Scholarium Bononiensium, para la historia interna de la comunidad estudiantil) han tropezado con idéntica dificultad. En este sentido, en las páginas que anteceden se han identificado los problemas de los Memoriali como fuente al tiempo que se han experimentado algunas soluciones, a falta de coordinación y criterios internacionales adecuados.

La documentación iusprivatística plantea, en primer lugar, el problema de su propio volumen, que, al no incluir datos de interés el resumen mínimo de los Provvisori, ha de afrontarse a través de los Memoriali, relativamente extensos. En este sentido, y sin negar la importancia del Chartularium, el Corpus concebido por Stelling-Michaud es realizable sin grandes medios ni esfuerzos. El modelo del profesor suizo aplicado a sus compatriotas juristas medievales, con la aportación de la prosopografía medieval, de la que ha sido pionero en el caso boloñés Antonio Pérez Martín, puede arrojar nueva luz sobre un período y un aspecto cruciales de nuestra historia jurídica. Otra gran cuestión es el índice de representatividad de la documentación registrada. Se ha dicho que los Memoriali recogen los nombres de entre un treinta y un cincuenta por ciento de los escolares, pero este porcentaje tal vez sea, a la luz de este estudio, algo mayor en el caso de los españoles, al menos en algunos años. Nuevas investigaciones, sobre otros momentos de la presencia española y sobre otros grupos nacionales, deberían tender a comprobar la fiabilidad de esta conclusión que consideramos esencial. En particular, un empleo detenido de la docu-

242 J. Beneyto Pérez, Albornoz, fundador. Perduración de la obra del Cardenal en la Política y especialmente en el Colegio, "Studia Albornotiana», XI, "El cardenal Albornoz y el Colegio de España", I, Bolonia, 1973, págs. 199-211, y E. DUPRÉ THESEIDER, Egidio de Albornoz e la riconquista dello Stato della Chiesa, «Studia Albornotiana», XI, «El cardenal Albornoz y el Colegio de España», I, Bolonia, 1973, págs. 458-459. G.P. BRIzzI, I collegi per borsisti e lo studio bolognese. Caratteri ed evoluzione di un'istituzione educativo-assistenziale fra XIII e XvIII secolo, "Studi e memorie per la storia dell'Università di Bologna», 4, n.s., Bologna, 1984, págs. 9-31. 
mentación emanada por los órganos jurisdiccionales competentes en las causas criminales relativas a estudiantes ultramontanos podría matizar estas conclusiones.

Antes de finales del siglo XII había, según investigaciones clásicas, bastantes maestros juristas españoles en Bolonia, que marcan la presencia española en Italia desde la aparición de la Universidad hasta algo antes de 1300. Hubo ciertamente entonces estudiantes, pero no definían ni el prestigio ni las actividades de la comunidad jurídica española, especialmente en la propia España. El primer tercio del XIV está caracterizado, en cambio, como resulta de este trabajo, por una presencia numerosa y organizada de estudiantes; los Memoriali de los treinta y dos que hemos estudiado, tomados como fase de transición entre ambos tipos de presencia española (1299-1330), son muy explícitos en corregir algunas de las conclusiones provisionales de A. García y García al asomarse a la misma documentación, especialmente sobre la importancia numérica de la presencia española y su evolución. Otros aspectos, por contra, deben ser confirmados: la distribución por regiones de origen, por ejemplo, sigue viendo a la cabeza a los súbditos (peninsulares o insulares) del Rey de Mallorca, seguidos por otros venidos de la Corona de Aragón, los castellanos y finalmente los portugueses y los navarros. Es interesante subrayar que alrededor de un treinta por ciento de los españoles con menciones documentales aparecen $\sin$ referencias regionales, simplemente llamados hispani.

La distribución cronológica de los españoles no es uniforme: las crisis internas del Estudio, las tensiones con las autoridades y los partidos municipales y las fluctuaciones económicas hacen que, de un máximo a caballo entre los dos siglos, se sufran diversas crisis, en 1306 y 1321 especialmente. La mayor crisis sobrevino en 1321 Las aspiraciones universitarias a la autonomía y el intervencionismo político dramáticamente plasmado en un caso criminal produjo una explosión, en la que los españoles fueron el detonante, $y$, a través de su control de los juristas ultramontanos, verdadera razón de ser del Estudio, guiaron un abandono en masa del Estudio y la ciudad como medio de presión. Un hecho fundamental es que, en aquella ocasión, los españoles negociaron el regreso en nombre de todos los estudiantes, señal de su peso relativo incluso en una época en que ningún maestro importante era español. Habiendo vencido, aquella generación de juristas regresó a Bolonia, pero 1321 fue un punto de inflexión definitivo, por cuanto no se produjo el siguiente relevo generacional. Desde entonces, y más a partir de la peste, los españoles no sólo fueron muchos menos, sino que su importancia en España fue menor y carecieron de organización e institucionalización estable en Bolonia hasta el último tercio del siglo. 
Otras hipótesis de Stelling-Michaud para los suizos pueden reproponerse para los españoles de la misma época. Fueron, en efecto, canonistas en su mayoría, aunque entre los españoles se entrevé un virtual empate con los civilistas. Prevalecen estudiantes mayores en edad que los citramontanos italianos, aunque siempre con casos de menores de edad. En cuanto a la estancia en Bolonia, como media era de seis $u$ ocho años. Una peculiaridad del grupo de españoles constantemente presente en la ciudad italiana a lo largo de estos años es la proporción comparativamente reducida de clérigos: raramente más de un veinte por ciento. También las diversiones y la vida social de los ibéricos parece haber sido muy diferente de la de los europeos del Norte: abundan los delitos contra las personas en la documentación judicial, y escasean relativamente los delitos contra la propiedad.

En un siglo XIV que comienza sin grandes maestros españoles pero con numerosos estudiantes, es la fama de las escuelas y el prestigio de los juristas formados en Bolonia en todos los campos el que atrae un flujo constante desde Occidente. Una comunidad estudiantil ya entonces secular, organizada y con una cuota de poder en la gestión universitaria, garantizaba a los españoles una cierta calidad de vida a los españoles. Bolonia, que hasta el siglo anterior había ofrecido sólo el saber, en aquel momento ofrecía también el poder. Esta evolución, por una parte, reforzó el prestigio del Estudio, pero lo hizo por otra más dependiente de los poderes públicos, especialmente de los radicados en la ciudad. Las fundaciones universitarias en toda Europa, especialmente en España, debilitaron la capacidad de los ultramontanos para mantener su control del Alma Mater, llevando a una italianización de las escuelas boloñesas que es paralela, por ejemplo, al afianzamiento de Salamanca.

Hasta entonces, la impronta española estuvo fuertemente presente en Bolonia: hasta el siglo XIII, porque a los estudiantes se unían los maestros, como queda dicho; a partir del XIV, porque la comunidad española supo dotarse de instrumentos de institucionalización: organizada en dos nationes, vio cómo en su seno surgía el fenómeno nuevo de la vida en comunidad. Así, el grupo de estudiantes alojados en el hospital de Santa María de la Mascarella, dependiente de Roncesvalles, constituye, a lo largo de estas décadas, un germen de la renovación que la Universidad emprenderá cincuenta años después con el nacimiento de los Colegios. La Mascarella nació para cubrir las necesidades formativas de una gran institución eclesiástica hispana, y surgió como modelo cuando los resortes comunitarios y la relación privilegiada con los mendicantes empezaron de ser insuficientes para defender los intereses de los escolares ibéricos; esto, a pesar de indudables problemas de funcionamiento y de una evolu- 
ción decadente. Así terminó, desde el punto de vista español, el «modelo boloñés», y comenzó la Universidad moderna.

Cuantitativamente, Bolonia contribuyó substancialmente a la preparación de muchos maestros, juristas y clérigos, y su aportación no puede limitarse a unos pocos licenciados. No menos de diez estudiantes conocidos cada año hasta 1330 equivalen, según las proporciones comúnmente aceptadas, a unos seiscientos juristas españoles formados en Bolonia en el primer tercio del siglo XIV. No se trata en general de figuras de primera fila (si bien futuros trabajos de síntesis habrán de matizar esta apreciación), sino de una parte importante de los cuadros ejecutores de la profunda transformación que los reinos hispánicos, y especialmente Castilla, experimentaron a partir de 1350. En aquel proceso, dos fueron las aportaciones fundamentales de la Universidad boloñesa: ante todo, los esquemas jurídicos y de mentalidad propios del alto Derecho romano; además, la experiencia de convivencia entre hispanos de todas las procedencias, unidos en instituciones comunes durante unos años esenciales en las vidas de todos ellos.

La Casa de Trastámara, después, elaboró con estos y otros elementos un programa de autoridad monárquica y unidad política, sirviéndose de instrumentos legados por sus antecesores, como las Partidas y el Ordenamiento de Alcalá, que introdujeron el romanismo jurídico culto. De esta manera, don Gil de Albornoz no se nos presenta, ni en su obra de gobierno española ni en su fundación universitaria, como un innovador, sino como un continuador de tradiciones anteriores, que, en todo caso, depura de defectos de funcionamiento. Aquella comunidad de estudiantes que, según José Antonio Maravall, había hecho nacer un sentimiento de comunidad nacional no sólo entre príncipes y guerreros, sino también entre los intelectuales, había entrado en crisis desde 1321 y parecía abocada a una desaparición cierta en torno a la gran Peste. El antiguo canciller salvó esa tradición renovando sus formas y dando nueva vida a una expresión característicamente hispánica del movimiento universitario, para cuyo estudio se ha intentado sugerir un esquema de análisis en las páginas que preceden.

\section{$X$. INDICE DE ESTUDIANTES}

En 97 documentos notariales fechados de 1299 a 1330 y registrados en los Memoriali se han hallado los nombres de 183 estudiantes españoles. En la variada documentación procesal de los jueces ad maleficia de la Curia del Podestà en las mismas fechas se encuentran 19 personajes, 
entre el 10 de mayo de 1316 (el primer documento de interés que se conserva en este período) y el 22 de agosto de 1328 . 7 estudiantes (equivalentes al $36,8 \%$ de los escolares encontrados en la documentación judicial y al $3,8 \%$ de los presentes en los registros notariales) aparecen en ambos tipos de fuentes. En total, en el presente trabajo se han manejado los nombres y biografías de 195 españoles, con 212 menciones documentales en total.

Como aportación para futuros estudios, se transcriben a continuación, en orden cronológico, los nombre de todos los estudiantes localizados entre 1298 y 1330 . Se ha preferido mantener las formas latinas o latinizadas originales de los mismos, para evitar posibles errores de interpretación.

1. Guillelmus Bruni de Gironda de Cathalogna.

2. Guillielmus Guillielmi de Unde de Cathalogna.

3. Thibaldus Soliti de Cathalogna.

1300

1. N. N. de Barga [Lucensis diocessis].

2. Berengarius Guillelmi Fuxerii de Magloricis (Maiolicis) Scholar Bononiae (1302).

3. Guidus Deodati de Barga Lucensis diocesis Scolaris Bon. in legibus.

4. Guillelmus Bernardi Ferre de Magloricis, catelanus Scholar Bononiae.

5. Guillelmus Raymondi, militis de Villa Marino de natione cathelanorum Canonicus, scolar Bononiae.

6. Johannes de Gerardi de Malgorio de Narbona Scholar Bononiae.

7. Martinus Eximini Yspanus, doctor decretorum, magister, Scholar bon., iurisperitus (1281, 1282, 1301, 1302).

8. Petrus Baioli de civitate Barciane, provincia Cathelogne Scholaris in utroque iure.

9. Petrus Eximinis, commendatore di S. Maria Mascarella, sacrista canonicus burdegalensis $(1269,1270,1275)$.

10. Petrus Petri de Villaraxa de Magloricis, catelanus Scholar Bononiae.

11. Petrus Villani.

12. Rodulfus Dominici..? Jacobi de Barga. 
1. Gualterius Semidi de Morama.

2. Jacobus de Tardaro.

3. Lanfranchus? domini Michelinis.

4. Martinus Eximini Yspanus: doctor decretorum, magister, Scholar bon., iurisperitus $(1281,1282,1300,1302)$.

5. Petrus Sancii de Aragonia Legum doctor.

6. Sancius de Savenis Decretorum doctor.

7. Sebonus Bitigotis de Spania Scholar Bononiae.

8. Ugonis de Hermo utriusque iuris doctor.

1302

1. Berengarius Guillelmi Fuxerii de Magloricis (Maiolicis) Scholar Bononiae (1300).

2. Gerardus Bernardi de Palatiolo (Palarolo), de Barcelona de natione cathelanorum Scolar Bononiae.

3. Martinus Eximini Yspanus: doctor decretorum, magister, Scholar bon., iurisperitus (1281: 1282, 1300, 1301).

4. Michael de Spagna.

5. Michael Michaelis Boterii de Therracona vicarius Castilionis, Scholar Bononiae.

6. P?anelonis? Fusii?

7. Raymondus Bonaccursii de Toleto.

8. Stephanus Suerii Canonico Siliensis.

1305

Michael Johannis de Yspania Scolar in decretalibus.

1306

1. Bonetus Dominici de Ripol Scolar.

2. Johannes de Ludrino.

3. Johannes Mini Didaci Ispanus Canonicus Care Rubenxis, Burgensis diocesis, scolaris Bon. in iure canonico.

4. Michael Ispanus canonico Legitinensi (Sigüenza), scolaris Bon. 
1307

Berlingerius de Chillano de Catellogna.

1308

Eximinus Petri Commendator hospitalis (pro hospitali) Sancte Marie Rosci de Vallis (in Ytalia) Pampilonensis diocesis, syndicus yconomus $(1310,1318)$.

1309

1. Benedacius de Bonaroda.

2. Bornius Dominici de Repoli de Yspania Scolaris Bon.

3. Gombaldus Garsie de Vergua Archipresbiter Cexaraugustanus, scolar Bononiae.

4. Nicholaus Blanchi.

5. Petrus Esiminis de Nabal de Aragonia.

6. Ugolinus Donati.

1310

1. Eximinus Petri Commendator hospitalis (pro hospitali) Sancte Marie Rosci de Vallis (in Ytalia) Pampilonensis diocesis, syndicus yconomus (1308, 1318).

2. Francischus Dominici de capella Sancte Marie de Mascharella.

1311

Bernardus Arnaldi di Castignone de Chatalogna.

1312

1. Fortugnius Petri Amorabilis de Spagna.

2. Garsias Asinarii de Aragonia.

3. Petrus Amorabilis de Spagna.

1313

1. Guillelmus Petri Brastichani de Catalugna.

2. Raymondus Raymondi Gota de Catalugna. 
1314

1. (Amanda) Alegii de Girona.

2. Anthonius de Aruria Scolar Bononiae.

3. Berlengerius Coregonis de Cathelogna.

4. Laurentio Peris de regno valenciano.

5. Petrus Baralis de Tolosa Scolar Bononiae.

6. Petrus Petri Façe de comitatu Urgelii Cathelogne diocesis.

1316

1. Alfonsus Roderici Canonicus Cartaginensis olim scolar (1322).

2. Anthonius de Rota de Murcia.

3. Branabuetis? Guillelmi de Oselitis.

4. Gerardus Guillelmi de Sancto Lerio castro diocesis Catelogne.

5. Martinus de Vanello de Aragonia, Scolaris in legibus (1320).

6. Monducius? de Pacis.

7. Petrus Gomecii Canonico toletano.

8. Ponço Ponçi de Castellario diocesis Catelogne.

1. Chimirus Alamanii: 1317.

2. Gerardinus Jacobi.

3. Jacobus Bernardi de Villa provincie Aragonie.

4. Jacobus Guillemi Calberi de Catelogna Scolaris in Studio bononiense in iure civili.

5. Johannes Bernardi qui fuit de Concasona.

6. Martinus Juliani Conheneii? de Chatelogna Scolar bon.

1. Accendo? Martini de Aiesta?

2. Alphonsus Egidii de Baesa.

3. Bernardus Raimondi de Tore de Chatalonea.

4. Bonetus Raimondi de Tore de Chatalonea. 
5. Eximinus Petri Commendator hospitalis (pro hospitali) Sancte Marie Rosci de Vallis (in Ytalia) Pampilonensis diocesis, syndicus yconomus $(1308,1310)$.

6. Garsia Petri de Olcoz.

7. Johannes de Aragonia.

8. Matheus Gundisalvi.

9. Petrus Johannis de Chinelghi?

10. Raimundus Raimondi de Tore de Chatalonea.

11. Sanctius Petri de Caperoxa.

1. Bartholomeus Martini de Nissella de comitatu Rosilionis.

2. Beringherius Sarre de Monbiancho Scolaris in Studio bononiense in iure civili.

3. Bernardus (Lunardi) Martini de Perpiniano (Perpignano) de Chatelonia Scolar in Studio in iure canonico.

4. Fondrighius?

5. Guillelmus Lunardi Martini de Perpignano Scolar in Studio in iure civili.

6. Remengardus Hominisdei de Perpiniano Scolar in Studio Bononiae

1. Anthonius Ansaldi de Gallionis (de Galiana) Canonicus Maioriçensis (Maglioricensis) ecclesie de Chatelogna (1321).

2. Bartolatius Derli de Malorichis Magister.

3. Bernardus Berengarii Taragonensis Scolar Bononiae in iure civili.

4. Garsia Friandi de Vanello de Aragonia.

5. Guillelmus de Teracia de Catelonia.

6. Guillielmus Golberti de Cathelonia Scolar Bononiae in scolis domini Jacobi de Butrigariis legum doctoris.

7. Jacobus de Miragliis mercatore tarraconense.

8. Johannes Petri de Taraçona (1320). 
9. Johannes Rodulfi.

10. Laurentius Borzali.

11. Martinus de Vanello de Aragonia, Scolaris in legibus (1316).

12. Martinus Romei de Catelogna Rector Ecclesie de Stuba? in Catelogna, diocessis Darasonenssis.

13. Matheus Guercius Alexandri Guercii de Maxana Scolar Bononiae.

14. Rodricus Friandi de Vanello de Aragonia.

15. Sancius Friandi de Vanello de Aragonia.

16. Sancius Siminis Çordani de Unducastello.

17. Semenius Michelis.

18. Stephanus (Guillelmi) de Rota de Cathelonia Scolaris Bononiae, scolaris forensis, in scolis domini Jacobi de Butrigariis legum doctoris (1321).

1321

1. Anthonius Ansaldi de Gallionis (de Galiana) Canonicus Maioriçensis (Maglioricensis) ecclesie de Chatelogna (1320).

2. Anthonius Guillelmi de Roda Scolaris forensis.

3. Berengarius de Perpiniano catalanus.

4. Berengarius Raymundi de Argionellis.

5. Bernardus Arardi.

6. Bernardus Bartolomei de Salmo.

7. Bernardus Coradi de Catellogna.

8. Bernardus Guillelmi Çafantis Scolaris forensis.

9. Bernardus Johannes Beli..? de Chatellogne.

10. Bernardus Tucrii de Catellogna.

11. Blaxius Bartolomei Blaxii.

12. Blaxius Tucrii de Catellogna.

13. Coradus Bernardi de Catelogna.

14. Franciscus Johannis de Castesib.?

15. Gualtrianus Raymondi de Vilanova.

16. Guillelmus Guillelmi Cauletti de civitate Ylerde Scolaris forensis. 
17. Guillelmus Raynaldi

18. Guillelmus Toracii diocesis Vallentie Rector ecclesie de Spiocha.

19. Jacobus Galgeranni

20. Jacobus Jacobi de Tolloxia (Oliexia) Vallentie, in Studio commorans in legibus, Scolaris forensis.

21. Johannes de Urgellis.

22. Johannes Guidi de Yspania Tanssorerius ecclesie Cermllonii?, clericus scolaris Bononiae.

23. Johannes Sadur..?

24. Martinus Guidonis.

25. Petrus Bayle de Catelogna.

26. Petrus Beltranis Petri

27. Petrus de Tornente (Torrente) diocesis Vallentie, in Studio commorans in legibus, rector ecclesie de Montechatono, commissarius relictus? d. Jacobo Jacobi.

28. Petrus Martinis Petriçoli

29. Raymondus Berengerii (Berlegherii, Berlengherii) de Montadi de Tolloxa de Catelonia Canonicus de Maiorica, scolar Bononiae in iure canonico (1323).

30. Stephanus (Guillelmi) de Rota de Cathelonia Scolaris Bononiae, scolaris forensis, in scolis domini Jacobi de Butrigariis legum doctoris (1320).

31. Symone Aullinerii de Barcellone comitatu Chatellogne.

32. Vincencius Anforis de Yspania Scolaris Bononiae in Studio in decretalibus in scolis domini Johannis Andree doctor.

\section{2}

1. Alfonsus Roderici Canonicus Cartaginensis olim scolar (1316).

2. Dominicus Ferandi Verdeço de [A]ragona.

3. Ferrandus, portionarius in ecclesia Cartagenensi.

4. Guillelmus de Garnoia Procurator domini Alfonsi Roderici.

5. Guillelmus Gomessi Alfasi de Perula de Aragonia.

6. Michael Johannis Peres de Teraçona. 
1. Arnaldus Arnaldi Parage de Cathelonia.

2. Arnaldus Bernardi Nendoni (Mendoni, Modoni) de Perpignano (Puponiano) de Cathelonia (Catelogna) Scolaris Bononiensis Studii in iure civile; Scolaris Bononiae in iure (in legibus) $(1324,1327,1328)$.

3. Barberus Gerardi Scolar Bon.

4. Berlengerius Raymondi de Frunis.

5. Bernardus de Coreliano de Catelonia Canonicus Mayolicarum.

6. Bernardus Guillelmi de Lorone.

7. Bernardus Guillelmi de Montegato de Cathelonia.

8. Bilengerus Alamani de Catelonia Scolar Bon.

9. Blengherius Petri Discolo de Cathelogna.

10. Dominichus Andree de Poregia Scholaris.

11. Dominicus Serule (cap. S.M. Magdalene de strata S.Donati).

12. Ferrandus Jacobi de Mora de Perpignano de Catellonia Scolaris studens Bononiae in iure canonico.

13. Florius Florii.

14. Guardus Berlegherii [A]ragonensis Scolaris Bononiae in iure civili.

15. Guillelmus Beltrani de Barasio, nobilis miles.

16. Johannes Johannis Garsia de [A]ragonia.

17. Luysius de Valentia Scolaris.

18. Nicholaus Petri de Villa Torta de Cathelogna.

19. Parcellus Petri Parzelli de Catellonia.

20. Raymondus Berengerii (Berlegherii, Berlengherii) de Montadi de Tolloxa de Catelonia Canonicus de Maiorica, scolar Bononiae in iure canonico (1321).

21. Raymondus Thomassi de Cathelogna.

22. Ugenus Guillelmi de Montegato de Cathelonia.

1. Albertus Thomae gerundensis.

2. Antholinus Thomatis. 
España en la Universidad de Bolonia: vida académica y comunidad nacional...

3. Arnaldus Bernardi Nendoni (Mendoni, Modoni) de Perpignano (Puponiano) de Cathelonia (Catelogna) Scolaris Bononiensis Studii in iure civile; Scolaris Bononiae in iure (in legibus) $(1323,1327,1328)$.

4. Berlengerius Berlengerii Petri Scolar in legibus.

5. Berlengerius famulus Arnaldi Bernardi Mendoni.

6. Berlengerius Petri Alegnani de Catelogna Scolaris Bononiae in legibus.

7. Gregorius Johannis de civitate Portavallensi Rector ecclesie Sancti Petri de Portavalla Ulisbonensis diocesis, scolar Bononiae in iure canonico

8. Johannes famulus Raymundi Rubey.

9. Johannes Petri Porgelli (Parzelli) de Catelogna.

10. Martinus Maŕini de Lerena de Ispania Canonicus Colubriensis, scolar Bononiae in iure canonico (1325).

11. Petrus de Catalogna Scolaris in iure (1329).

12. Raymundus Raymundi Rubey de Catalogna, Scolaris in legibus (in iure).

13. Thoma Garsie.

\section{5}

1. Arnaldus Bernardi comitati de Castro Toregli regni Maiolice de Chatelogna.

2. Dimis Capellanus in Sciolla.

3. Guillielmus (Raymundi) Rodulfi de comitatu Rusiglum Regni Maiolice de Chatelogna.

4. Jacobus Stebanis de Vallentia Magister.

5. Martinus Martini de Lerena de Ispania Canonicus Colubriensis, scolar Bononiae in iure canonico (1324).

6. Milanus de Medio de Valentia Canonicus Bononiensis ecclesie.

7. Ubertus de Stephanis de Valentia.

8. Vincianus Johannis de Yspania.

1. Emansias? Petri de Randiga de Aragonia.

2. Guillielmus magistri Petri. 
3. Johannes Petri de Becia Canon. Maior. ecclesie.

4. Nicolaus Jacobi Bordinus.

5. Petrus Ragaldi de Lilete de Catelonia.

6. Phillipus Ranignani de Balduinis Canon. Maior. ecclesie.

7. Sancius Domixi Gudiz.

1. Arnaldus Bernardi Nendoni (Mendoni, Modoni) de Perpignano (Puponiano) de Cathelonia (Catelogna) Scolaris Bononiensis Studii in iure civile; Scolaris Bononiae in iure (in legibus) $(1323,1324,1328)$.

2. Bernardus Arnaldi Guillelmi de Yspania Scolaris in iure civile.

3. Bernardus Petri Saysy Scolaris Bon. Studii in iure canonico.

4. Marinus Aufensi de Portugallia Scolaris Bon. St. in iure civile. 1328

1. Arnaldus Bernardi Nendoni (Mendoni, Modoni) de Perpignano (Puponiano) de Cathelonia (Catelogna) Scolaris Bononiensis Studii in iure civile; Scolaris Bononiae in iure (in legibus) $(1323,1324,1327)$.

2. Maximus de Valencia Scholaris in medicina in scholis magistri Juliani sive magistri Mathei de Egubio.

3. Sinibaldus de Valencia Scholaris in medicina in scholis magistri Juliani sive magistri Mathei de Egubio.

1. Arnaldus de Catellogna.

2. Berlingherius de Racha Salva de Catelonea.

3. Bernardus Çordanus de Catelogna.

4. Johannes Sancii de Airaga (1331).

5. Nicholaus Guillelmi Cartaginensi.

6. Petrus de Catalogna Scolaris in iure (1324).

7. Petrus de Catellogna. 
1330

1. Bernaldus Arnaldi de Catelogna

2. Bernardus Michaellis de Chatellogna.

3. Guillielmus Raymondi de Villa Setha de Chatelogna.

4. Julianus Ortixii de [A]ragonia.

5. Petrus Bernardi de Açure, de episcopatu Urgielsis de comitatu Barçelonie.

6. Rodomeus de $[A]$ ragonia. 